\title{
Advancing Reactive Tracer Methods for Measurement of Thermal Evolution in Geothermal Reservoirs: Final Report
}

Mitchell Plummer

Earl Mattson

Carl Palmer George Redden

Gracy Elias

Laurence Hull

July 2011

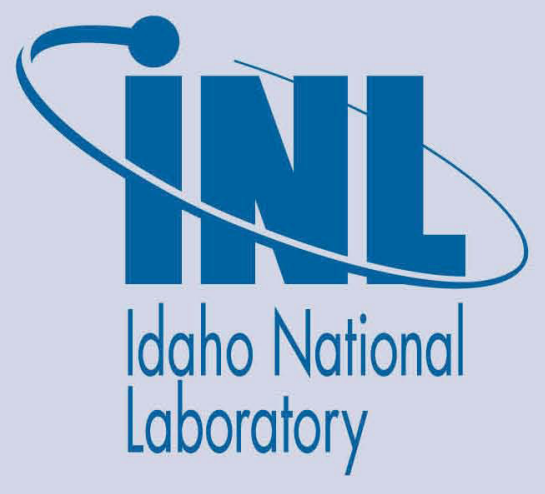

The INL is a U.S. Department of Energy National Laboratory operated by Battelle Energy Alliance 
INL/EXT-11-22632

\title{
Advancing Reactive Tracer Methods for Measurement of Thermal Evolution in Geothermal Reservoirs: Final Report
}

\author{
Mitchell Plummer \\ Earl Mattson \\ Carl Palmer \\ George Redden \\ Gracy Elias \\ Laurence Hull
}

July 2011

\section{Idaho National Laboratory Geothermal Technologies Program \\ Idaho Falls, Idaho 83415}

http://www.inl.gov

Prepared for the

U.S. Department of Energy

Assistant Secretary for Energy Efficiency and Renewable Energy

Under DOE Idaho Operations Office

Contract DE-AC07-05ID14517 


\section{DISCLAIMER}

This information was prepared as an account of work sponsored by an agency of the U.S. Government. Neither the U.S. Government nor any

agency thereof, nor any of their employees, makes any warranty, expressed or implied, or assumes any legal liability or responsibility for the accuracy, completeness, or usefulness, of any information, apparatus, product, or process disclosed, or represents that its use would not infringe privately owned rights. References herein to any specific commercial product, process, or service by trade name, trade mark, manufacturer, or otherwise, does not necessarily constitute or imply its endorsement, recommendation, or favoring by the U.S. Government or any agency thereof. The views and opinions of authors expressed herein do not necessarily state or reflect those of the U.S. Government or any agency thereof. 



\section{ABSTRACT}

The potential use of reactive tracers for estimating migration of a cold front between an injection well and a production well in a geothermal reservoir is studied to investigate application of reactive tracers to monitoring the thermal evolution of a geothermal reservoir. Aspects considered in this study include (1) mathematical investigation of the sensitivity of known and hypothetical reactive tracers, (2) laboratory testing of novel tracers that would improve method sensitivity, (3) a software tool for design and interpretation of reactive tracer tests and (4) field testing of the reactive tracer temperature monitoring concept at the Raft River geothermal field.

Mathematical modeling using analytical and numerical solutions and suggests that tracers with a single thermal degradation pathway can be sensitive enough to detect thermal evolution of the reservoir. Using tracers with multiple degradation pathways (simultaneous or sequential) does not improve the sensitivity. Instantaneous quenching of the reactions at a temperature slightly below the maximum values in the reservoir can greatly improve sensitivity; however, significant work is needed to indentify applicable tracers or approaches before this method will be viable.

Several single-pathway tracers have been identified from the literature and their kinetic parameters summarized. The temperature ranges over which these tracers may be applicable are reviewed. The potential use of racemization reactions and thermoluminescense for monitoring thermal evolution in the reservoir are discussed. Encapsulations methods for these tracers were tested in the laboratory and the results clearly show the potential for manufacturing temperature-time sensitive colloid tracers.

A software tool programmed in MatLab ${ }^{\circledR}$ has been developed to aid in the design and analysis of tracer tests in geothermal reservoirs. The Tracer Analysis Toolbox includes several analytical solutions and fitting routines that are already in common use for tracer analysis in geothermal systems but extends application of those methods to temperature dependent degradation of a reactive tracer. The method provides a means of calculating temperature along hypothetical flow paths defined by user selected aperture, interfracture spacing and other variables. The evolution of temperature along those flow paths is used to estimate production well temperature as a function of time and to calculate the behavior of a reactive tracer transported through the simplified model of the reservoir.

Two tracer tests using both reactive and conservative tracers were conducted in collaboration with U.S. Geothermal, Inc., at the Raft River geothermal field in south-central Idaho. Design of the tracer tests was largely based on the 2008 tracer test conducted by U.S. Geothermal. Analysis based on this prior data and published information about various tracers resulted in the decision to use fluorescein as a conservative tracer and butyramide as a reactive tracer in the first tracer test. In the second tracer test, naphthalene 2,6-disulfonate was used as the conservative tracer and acetamide was used as the reactive tracer. Analytical methods to improve the detection limits of the reactive tracers by HPLC were developed. The conservative tracer mass recoveries from the three tests differ and suggest some differences in the flow systems between the different tests; however, the shapes of the conservative tracer breakthrough curves from all three tracer tests are similar suggesting that the characteristics of the reservoir along 
those different flow paths are similar. Plots of the breakthrough data for the reactive tracers are nearly identical to the theoretical curves based on published second-order rate coefficient data for butyramide and acetamide, the estimated $\mathrm{pH}$ of the reservoir fluids, the mean of the temperatures of the three wells involved in the tracer tests, and the assumption of isothermal conditions.

Results of this study indicate that reactive tracers can be used to determine thermal evolution in a geothermal reservoir. We have developed tools and methods to aid in the interpretation of both conservative and reactive tracers in geothermal systems and we demonstrated the applicability of such tools in the analysis of tracer tests that we have conducted at the Raft River geothermal field. 


\section{CONTENTS}

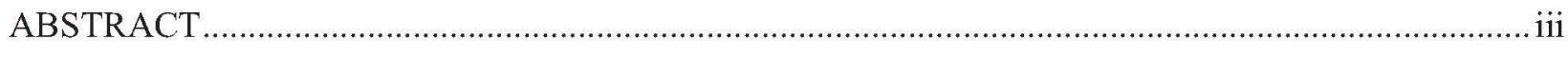

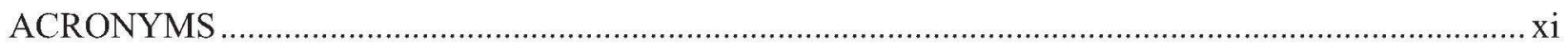

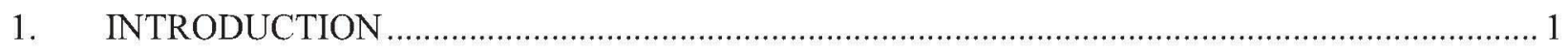

1.1 Description of Problem ................................................................................................ 1

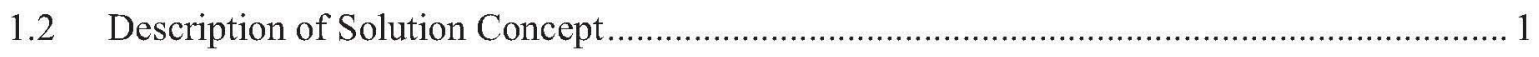

1.3 Description of Work Needed to Demonstrate Concept.................................................. 2

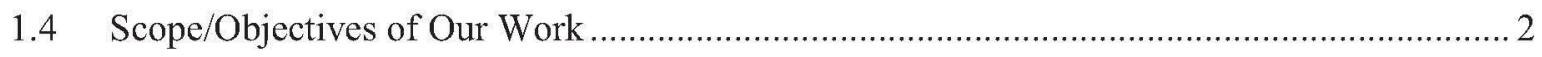

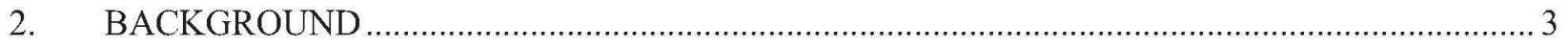

2.1 Thermal Depletion in a Reservoir with a Single Fracture ..................................................... 3

2.2 Thermal Depletion in a Reservoir with Multiple Fractures ................................................ 4

3. THEORY OF REACTIVE TRACERS AND MATHEMATICAL DEVELOPMENT.................... 6

3.1 Reactive Tracer with a Single Pathway ........................................................................... 6

3.2 Single Pathway with Instantaneous Quenching …...................................................... 10

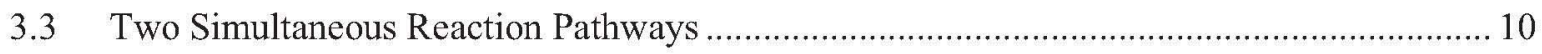

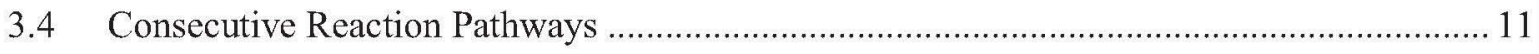

4. IDENTIFICATION AND ASSESSMENT OF REACTIVE TRACERS ...................................... 13

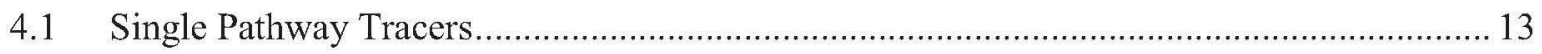

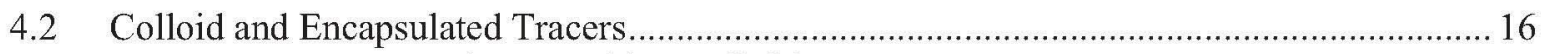

4.2.1 Temperature-Time Sensitive Colloid Tracers ........................................................ 16

4.2.2 Colloid Tracer Encapsulation: an Enabling Approach............................................ 16

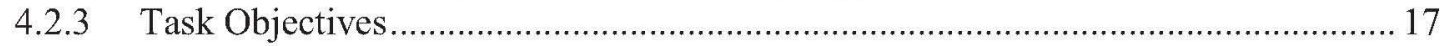

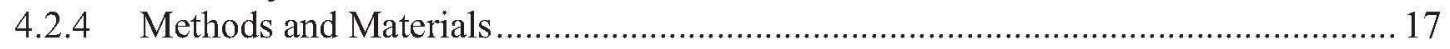

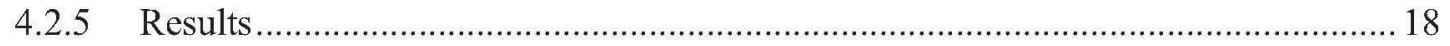

5. METHODS FOR DESIGN AND INTERPRETATION OF REACTIVE TRACER TESTS..........20

$5.1 \quad$ Tracer Analysis Functions Provided ............................................................................. 20

5.1.1 Residence Time Distribution Analysis.............................................................. 20

5.1.2 BTC Analysis via Deterministic Models of Fracture Geometry and

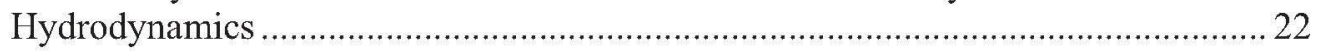

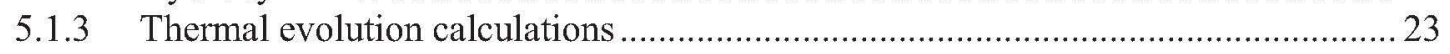

5.1.4 Extension of deterministic approach to temperature-dependent tracer

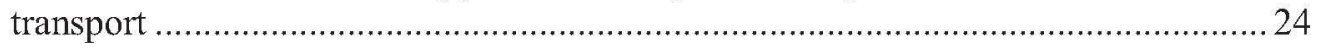

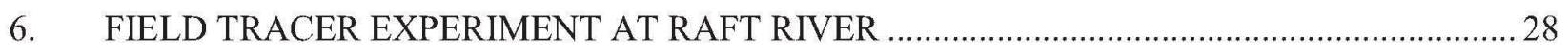

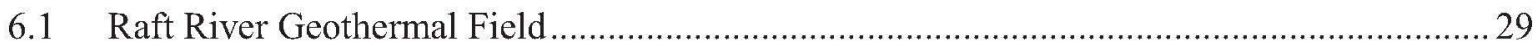

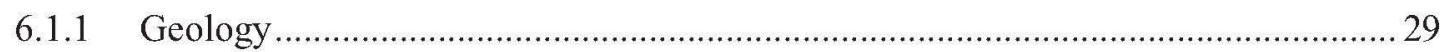

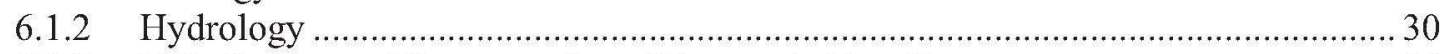

6.1.3 U.S. Geothermal Interpretation of Reservoir Heat Transport ..................................... 31

6.1.4 U.S. Geothermal, Inc. 2008 Tracer Test Results........................................................ 31

6.1.5 Estimated behavior of a reactive tracer in a replication of the 2008 test .................. 32 


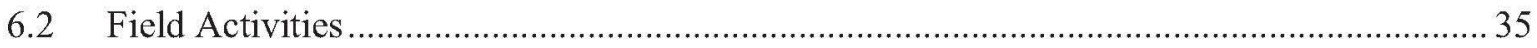

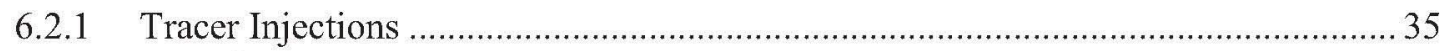

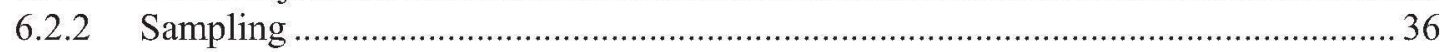

6.2.3 Reservoir conditions during field tracer test period ……....................................... 36

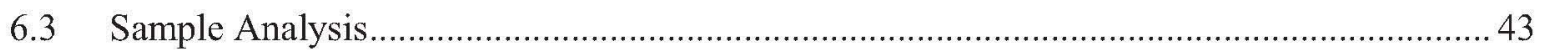

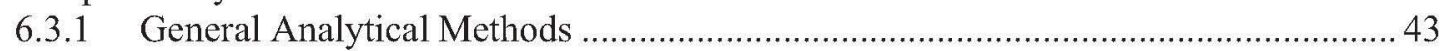

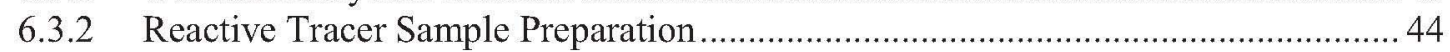

6.3.3 Fluorescein disodium salt hydrate....................................................................... 44

6.3.4 Naphthalene 2,6-disulfonic acid sodium salt ........................................................... 44

6.3.5 Thermally Reactive Tracers ………………………………………………… 45

6.3.6 Groundwater Matrix.......................................................................................... 45

6.3.7 Estimate of Analytical Uncertainty ..................................................................... 46

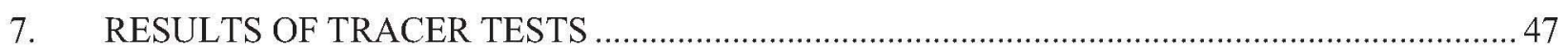

7.1 Conservative Tracer Results ................................................................................. 47

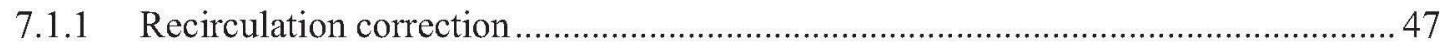

7.1.2 Interwell comparison of Tracer Test Breakthrough Curves ........................................ 48

7.1.3 Tracer Test Intercomparison .......................................................................... 51

7.1.4 Flow Capacity vs. Storage Capacity ……………………………………………. 52

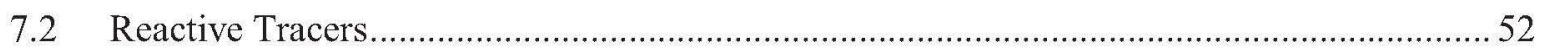

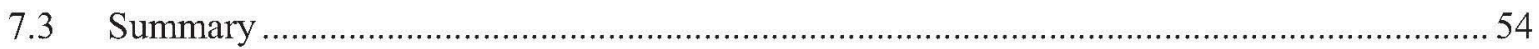

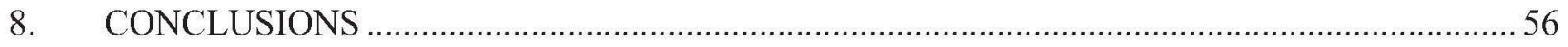

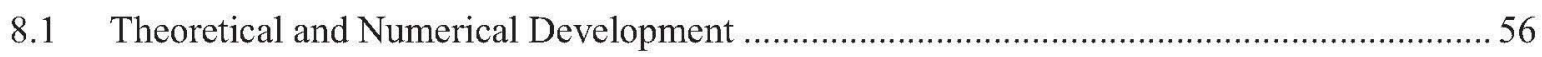

8.2 Laboratory Studies ...................................................................................................... 57

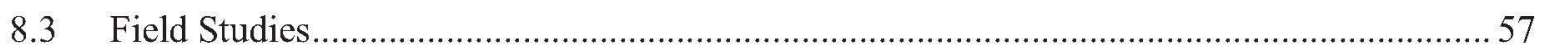

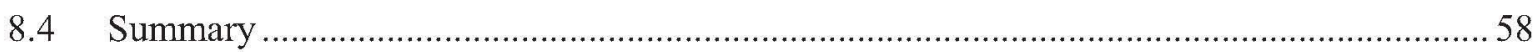

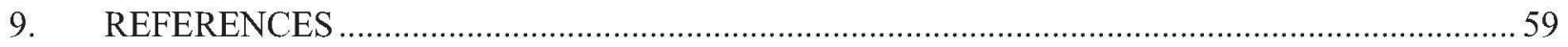

Appendix A Reservoir Cooling Time versus Tracer Transport Time.......................................................6 64

\section{FIGURES}

Figure 1. Conceptual model of temperature distribution in a fractured reservoir where colder fluid (blue) is being injected and hot fluids (red) are being produced. 1

Figure 2. Temperature as a function of dimensionless distance at four different operating times of a hypothetical single fracture in an engineered geothermal system. Curves are given at $\mathrm{tD}=0.001,0.01,0.1$ and tcrit.

Figure 3. Temperature vs distance in five hypothetical sets of fractures with varying fracture spacing. Flow velocity in each fracture is $430 \mathrm{~m}_{\text {day }}^{-1}$, fracture aperture is $2 \mathrm{~mm}$, and time since initiation of flow is 35 years.

Figure 4. Reaction rate $(A \& C)$ and thermal reaction time $(B \& D)$ plots for a fracture flowpath for operating times and temperature profiles corresponding to those in Figure 2. Graphs A and B represent piston flow of a pulse of tracer transported through the fracture. Curves $\mathrm{C}$ and $\mathrm{D}$ approximate the effect of dispersion on a slug of tracer transported through the 
system, where the concentration decreases approximately exponentially with dimensionless position, $\mathrm{f}=\mathrm{x} / \mathrm{L}$, according to the expression $\mathrm{C} / \mathrm{C}_{0}=\exp (-3 \mathrm{f})$.

Figure 5. Activation entropy-enthalpy compensation effect for the second-order hydrolysis reactions of some ester and amide tracers.

Figure 6. Temperature profiles at two different dimensionless operating times, $t_{D} \_$init and $t_{D \_ \text {init }}+\Delta t_{D}$.

Figure 7. Conservative tracer breakthrough curve and base case reactive tracer breakthrough for two tracer tests conducted at different times.

Figure 8. Breakthrough curves with activation energy doubled for reactive tracers relative to the simulation results in Figure 7.

Figure 9. Breakthrough curves for base case conditions, with reaction quenched at $T_{r e s}-10^{\circ} \mathrm{C}$, 10

Figure 10. Relative concentration of $\mathrm{A}$ and $\mathrm{B}$ in a parcel of water as it flows between the injection and production wells for two parallel reaction paths. $\mathrm{B}^{*}$ denotes the concentration of $\mathrm{B}$ in the absence of $\mathrm{A}$.

Figure 11. Relative concentration of $\mathrm{A}$ as a function of the fraction of the cooling time of the reservoir for a parallel reaction pathway for $\mathrm{B}$.

Figure 12. Relative concentrations of A, B and C for the case of consecutive reactions (chain decay).

Figure 13. Relative concentration of $\mathrm{B}$ and $\mathrm{C}$ as a function of the fraction of the cooling time of the reservoir for a chain decay......

Figure 14. Chemical structures of some tracers considered for use at Raft River. 14

Figure 15. A) photograph of the base of the Wurster coater with the sleeve (dotted line) removed.

B) A schematic of the cell showing how particles are entrained into a stream of polymer/solvent where the solvent is removed by evaporation and polymer layers are deposited on the core particles......

Figure 16. A) $\gamma$-irradiated $\mathrm{NaCl}, \mathrm{B}$ ) Polymer-coated $\mathrm{NaCl}$ suspended in water.

Figure 17. Tracer Analysis Toolbox graphical output displaying raw BTC data (points) for two production wells in a geothermal reservoir and the calculated recirculation-corrected BTC data (lines).

Figure 18. Example graphical output of illustrating aggregate curve fit (dark blue curve) to measured BTC data (symbols) for cases where (A) system is represented with a single fracture set and (B) system is represented as two sets of fractures. Light blue curves illustrate BTCs of the contributing fracture sets.

Figure 19. Dimensionless outlet temperature (ordinate axis) vs time for systems of parallel fractures with dimensionless spacing as defined in the legend. In this example, using common heat flow parameters and flow parameters described in the text, the smallest fracture spacing is $15 \mathrm{~m}$. Curve with square symbols illustrates the Carslaw and Jaeger solution for infinite fracture spacing.....

Figure 20. Flow net for a dipole well arrangement, with injection on the right and discharge on the left.

Figure 21. Breakthrough curves for a tracer injected into a dipole flow field as a function of (A) time relative to earliest arrival and (B) the exit angle of the streamtube that defines the residence time in the system. Different curves in Panel A reflect ranges of flow paths 
with specified maximum exit angles, where the exit angle is measured relative to a line connecting the two wells.

Figure 22. Simulated temperature forecasts for production well RRG-4 for (A) a case where RRG-5 is used as one of several injection wells and (B) the lowest productivity case of four scenarios in which injection at RRG-5 is discontinued. Temperature scale is removed to protect proprietary information provided by U.S. Geothermal, Inc.

Figure 23. Location of the Raft River geothermal site (from U.S. Geothermal, Inc.).

Figure 24. Raft River Valley and major structural features (modified from Dolenc et al., 1981).

Figure 25. Conceptual model of the hydrology of the Raft River geothermal system (from Dolenc et al., 1981).

Figure 26. Aerial view of the central portion of the Raft River geothermal site indicating the location of the tracer injection well and the two closest production wells.

Figure 27. Tracer concentration vs. time following U.S. Geothermal's 2008 tracer test injection.

Figure 28. Fitted fluorescein breakthrough curve for RRG-4 from 2008 tracer test (data from Holt 2008)

Figure 29. Calculated OH- concentrations for wells used in tracer tests.

Figure 30. Estimated breakthrough curves for amide reactive tracers based on the 2008 tracer test. ........ 35

Figure 31. Injection of napthalene 2,6-disulfonic acid sodium salt and acetamide at well RRG-5 on July $21,2010$.

Figure 32. Production rates from Raft River wells over the span of the tracer test. Time (days) axis begins at time of injection of the first (June 21,2010). Dashed line indicates time of second injection. 36

Figure 33. Temperature in production wells RRG1, RRG2, RRG4, and RRG7 over time.

Figure 34. $\mathrm{pH}$ versus temperature for $0.00005 \mathrm{~m} \mathrm{H}_{2} \mathrm{SO}_{4}$. Solid curve is fitted sigmoid function with $\mathrm{r}^{2}=0.9995$ and stand error of the fit $=0.00273$.

Figure 35. $\mathrm{pH}$ versus temperature for $0.001 \mathrm{NaOH}$. Solid curve is a fitted fourth-order polynomial with $r^{2}=0.999987$ and standard error of the fit $=0.00345$.

Figure 36. Electrode potential for $0.00005 \mathrm{~m} \mathrm{H}_{2} \mathrm{SO}_{4}$ obtained in the laboratory by Earl Mattson. Solid line is the regression line for the first cooling cycle. Black dots are data from the first cooling cycle used in the regression, gray dots are measurements from the 2 nd cooling cycle that were not used in the regression. Statistics for the regression line are summarized in Table 8 .

Figure 37. Electrode potential for $0.001 \mathrm{~m} \mathrm{NaOH}$ obtained in the laboratory. Solid line is the regression line for the first cooling cycle. Black dots are data from the first cooling cycle used in the regression. Statistics for the regression line are summarized in Table 8 .

Figure 38. Electrode potential versus $\mathrm{pH}$ for $0.00005 \mathrm{~mol} / \mathrm{kg} \mathrm{H}_{2} \mathrm{SO}_{4}$ and $0.001 \mathrm{~mol} / \mathrm{kg} \mathrm{NaOH}$ at three temperatures based on the regression equations in Tables 1 and 2 ......

Figure 39. Comparison of measured and theoretical slopes (volts $/ \mathrm{pH}$ ).

Figure 40. INL staff conducting field measurements of $\mathrm{pH}$ at production well RRG-1. 
Figure 41. Calibration curves for butryamide and acetamide in the groundwater matrix which were used to determine the reactive tracer concentrations in groundwater samples.

Figure 42. Measured concentration vs. time for first conservative tracer test (Panel A; fluorescein) and for second conservative tracer test (Panel B, naphthalene 2,6-disulfonate) for wells RRG-1 (blue) and RRG-4 (red). The plus (+) symbols are raw data; open symbols show correction for recirculation.

Figure 43. Recirculation corrected data from the two tracer tests conducted by INL and from U.S. Geothermal's 2008 test. Data are shown for both well RRG-1 (circles) and RRG-4 (squares). Green curves show results of fluorescein injection (Test 1). Red lines show results of naphthalene-disulfonate injection (Test 2)

Figure 44. Fraction of injected tracer recovered at each well during INL's 2010 tests and the 2008 U.S. Geothermal test.

Figure 45. Comparison of conservative tracer breakthrough curve at well RRG-1 with that at RRG-4, for the first (fluorescein) test (A) and second (naphthalene 2,6-disulfonate) test (B).

Figure 46. Results of fitting equations to data from well RRG-4 using INL's Tracer Analysis Toolbox. Panels A and B illustrate fit assuming that the system can be represented as a single channel that connects the injection well to the production well. Panels C and D illustrate fit assuming that the system is best represented by two separate channels connecting injection well with each production well. Derived parameters are shown in Table 9.

Figure 47. Comparison of results of first test with those of second test for well RRG-1 (A) and well RRG-4 (B).

Figure 48. Flow capacity, F, vs. storage capacity, $\Phi$, curves for three conservative tracer tests conducted at Raft River. Note that the 2008 curve is based on extrapolation of the breakthrough curve.

Figure 49. Reactive tracer concentrations measured at wells RRG-1 and RRG-4 coincident with the conservative tracer tests described in the preceding sections. Panel A displays the butyramide concentrations of Test 1 . Panel B displays the acetamide data of Test 2 . 53

Figure 50. Relative concentrations of conservative and reactive tracers measured at well RRG-4 .54

Figure A-1. Factor times the tracer travel time from the injection point to the production well to cool the reservoir at $\mathrm{X}$ from 0.50 to 0.49 relative temperature.

\section{TABLES}

Table 1. Reactive tracer parameters used in simulations for Figure 7 and Figure 8 ............................... 9

Table 2. Summary of data on candidate reactive tracers. ............................................................... 15

Table 3. Fitted parameters calculated from fitting equations to BTC data as illustrated in

Figure 18

Table 4. Fitted parameters for fluorescein versus time curve for RRG-4.

Table 5. Pre-exponential factors $(A)$ and activation energies $\left(E_{a}\right)$ for amides (Robinson and Tester, 1990). 34

Table 6. Water chemistry used to calculate $\left[\mathrm{OH}^{-}\right]$at the Raft River site (Dolenc, et al. 1981). 34 
Table 7. Summary statistics for regression lines used in Figure 34 and Figure 35................................40

Table 8. Summary statistics for regression of electrode potential versus temperature for $\mathrm{H}_{2} \mathrm{SO}_{4}$ and $\mathrm{NaOH}$ buffers...

Table 9. Parameters derived from fitting 1D solute transport equation to breakthrough curves from well RRG-4 for Tests 1 and 2. 


\section{ACRONYMS}

EGS engineered geothermal system

RTD residence time distribution 


\section{Advancing Reactive Tracer Methods for Measurement of Thermal Evolution in Geothermal Reservoirs: Final Report}

\section{INTRODUCTION \\ 1.1 Description of Problem}

The injection of cold fluids into engineered geothermal systems (EGSs) and conventional geothermal reservoirs may be done to help extract heat from the subsurface or to maintain pressures within the reservoir (Rose et al. 2001). As these injected fluids move along fractures, they acquire heat from the rock matrix and remove it from the reservoir as they are extracted to the surface. A consequence of such injection is the migration of a cold-fluid front through the reservoir (see Figure 1) that could eventually reach the production well and result in the lowering of the temperature of the produced fluids (thermal breakthrough). Efficient operation of an EGS as well as conventional geothermal systems involving coldfluid injection requires accurate and timely information about thermal depletion of the reservoir in response to operation. In particular, accurate predictions of the time to thermal breakthrough and subsequent rate of thermal drawdown are necessary for reservoir management, design of fracture stimulation and well drilling programs, and forecasting of economic return. If the time to thermal breakthrough occurs earlier than expected, revenues may be lost as anticipated energy delivery is not met. Alternatively, if thermal breakthrough occurs on a much longer time scale than anticipated, opportunities for increased power generation and revenues may be missed.

In principle, cold-fluid fronts could be tracked by measuring temperature in monitoring wells between the injection well and the production well; however, the installation of such a monitoring system would involve large capital costs and is unlikely to occur at most EGS/conventional geothermal facilities. What is needed is a cost-effective method for measuring and extrapolating the migration of cold-fluid fronts through the reservoir using the existing facility infrastructure of wells. This information can then be used to more accurately determine the timing and rate of thermal breakthrough at the production well.

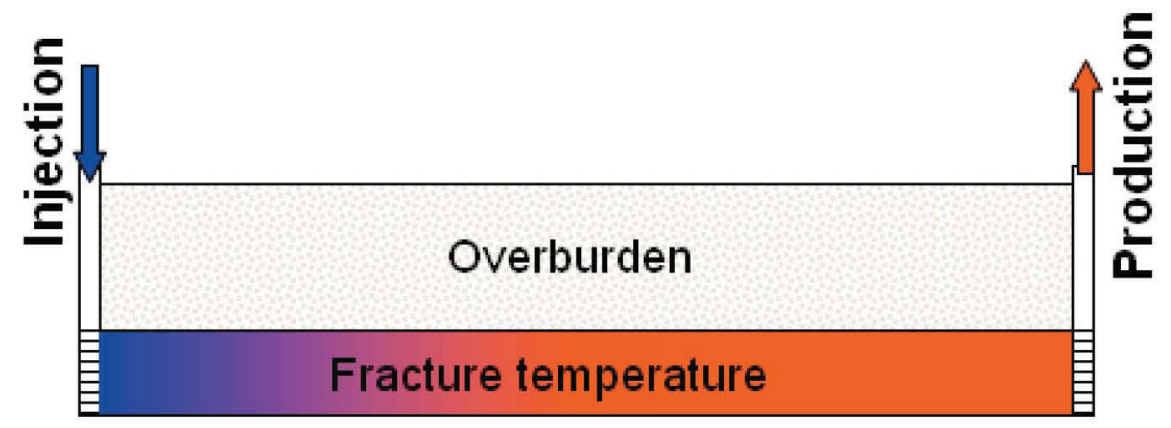

Figure 1. Conceptual model of temperature distribution in a fractured reservoir where colder fluid (blue) is being injected and hot fluids (red) are being produced.

\subsection{Description of Solution Concept}

A potential method for estimating the how far a cold front moves between the injection well and the production well is by measuring the concentrations of injected reactive tracers whose rate of degradation is dependent on the reservoir temperature between the two wells (e.g., Robinson 1985). With repeated tests, the rate of migration of the thermal front can be determined, and the time to thermal breakthrough calculated. While the basic theory behind the concept of thermal tracers has been understood for some time, effective application of the method has yet to be demonstrated. 


\subsection{Description of Work Needed to Demonstrate Concept}

For the reactive tracer method to be viable, the concentrations in the production well must be sensitive to changes in the temperature distribution in the reservoir. Several researchers have questioned whether single reactive tracers are sufficiently sensitive to detect changes in temperature for other than very large differences in operating times between tracer tests (e.g., Plummer, et al. 2010a, Behrens et al. 2009). To determine the viability of using reactive tracers for estimating thermal depletion and thermal drawdown, several factors need to be considered. The theoretical basis for thermal depletion in a fractured reservoir needs to be understood. Such theoretical models provide an expectation of temperature distributions in the reservoir over time and space that can be used in calculating the concentrations of the reactive tracers in the working fluid. Once a temperature distribution is assumed, one can estimate the tracer response for different types of degradation pathways. Knowledge of the sensitivity of the results to different types of degradation pathways can help us identify tracers that are likely to provide us with the best indication of thermal conditions in the reservoir. If the viability of reactive tracers for measuring thermal breakthrough is to be demonstrated, then some field test data needs to be acquired. Before such a test can be conducted, appropriate tracers need to be selected, the experiment must be properly designed, and there must be appropriate tools to interpret the results.

\subsection{Scope/Objectives of Our Work}

The goal of the proposed work is to provide a cost-effective means of monitoring the thermal evolution of EGS reservoirs via periodic testing with suites of reactive and conservative tracers. To attain this goal, three primary objectives must be met: (1) development of a set of tracer-test planning and analysis tools to define the necessary kinetic parameters, injection concentrations, and other parameters necessary for successful testing, (2) identification of tracers suitable to a wide range of potential reservoir volumes and permeabilities, and (3) demonstration of the utility of the identified tracers and methods in a system representative of EGS. 


\section{BACKGROUND}

The injection of cold fluids into EGS and conventional geothermal reservoirs may be done to help extract heat from the subsurface or to maintain pressures within the reservoir (e.g., Rose et al. 2001). As these injected fluids move along the fractures, they acquire heat from the rock matrix and remove it from the reservoir as they are extracted to the surface. At some point in time, a sufficient amount of heat has been removed from the reservoir such that the injected fluid can no longer attain the initial reservoir temperature and thermal breakthrough begins. This thermal breakthrough can be investigated using analytical solutions.

\subsection{Thermal Depletion in a Reservoir with a Single Fracture}

For a single fracture with constant fluid velocity, the temperature at the extraction well can be estimated from an equation developed for heat exchangers (Carslaw and Jaeger 1959, Section 15.3, Case III):

$$
\frac{T(\infty, 0)-T(x, t)}{T(\infty, 0)-T_{i n j}}=\operatorname{erf}\left(\frac{\lambda_{r} x}{\rho_{f} c_{p_{-} f} b v \sqrt{\alpha_{r}(t-x / v)}}\right)
$$

where:

$$
\begin{array}{ll}
\lambda_{r} & \text { rock thermal conductivity } \\
x & \text { distance traveled along the flow path } \\
b & \text { fracture aperture } \\
\rho_{f} & \text { carrier fluid density } \\
c_{p f} & \text { fluid specific heat } \\
v & \text { velocity in the fracture } \\
\alpha_{r} & \text { rock thermal diffusivity } \\
t & \text { time since the initiation of fluid injection } \\
T_{i n j} & \text { injection temperature. }
\end{array}
$$

Taking $1 \%$ of the difference between the injection and initial reservoir temperature (i.e., $\left.[T(\infty, 0)-T(x, t)] /\left[T(\infty, 0)-T_{i n j}\right]=0.99\right)$ as an arbitrary indication of measurable cooling at the production well, Equation (1) indicates that for injection and extraction wells separated by a distance $\mathrm{x}=$ $\mathrm{L}$, the operating time of interest is $\mathrm{t}_{\mathrm{op}}<\mathrm{t}_{\text {crit, }}$, where

$$
t_{c r i t}=\frac{L}{v}+\frac{1}{\alpha_{r}}\left(\frac{L \lambda_{r} X}{b \rho_{f} c_{p_{-} f} v \cdot e r f^{-1}(0.99)}\right)^{2}
$$

where $X$ is the fraction of the distance between the injection well and the production well $(X=x / L)$ the inverse error function $\left(\mathrm{erf}^{-1}\right)$ of 0.99 is 1.821 . Using $t_{\text {crit }}$ as the reference time for the system, we define dimensionless operating time, $t_{D}$, as $t_{o p} / t_{c r i t}$.

Figure 2 illustrates temperature profiles along a hypothetical fracture flow path after dimensionless operating times of $0.001,0.01,0.1$, and 1 . These are the temperature profiles that a reactive tracer encounters along its flow path between the injection point and the production well. In the following section, we discuss the ability of reactive tracers to provide information about these types of temperature profiles. 


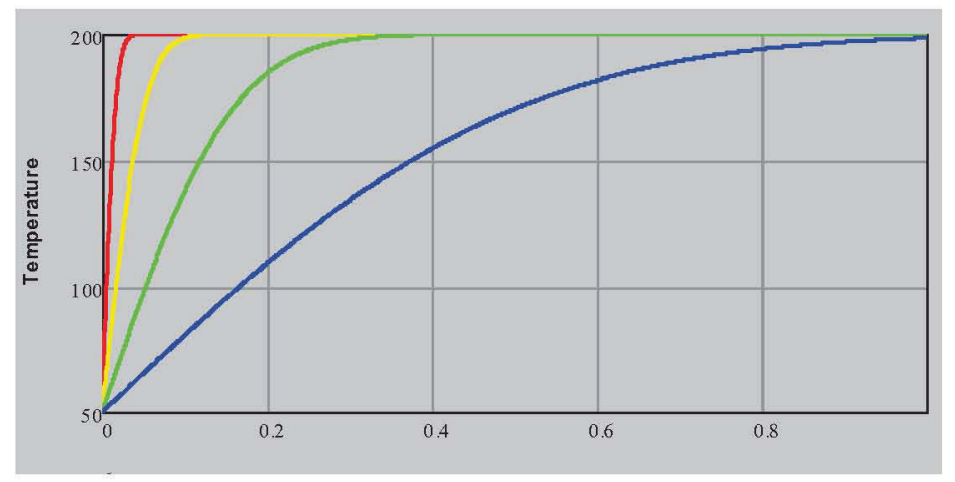

Figure 2. Temperature as a function of dimensionless distance at four different operating times of a hypothetical single fracture in an engineered geothermal system. Curves are given at $\mathrm{tD}=0.001,0.01,0.1$ and tcrit.

\subsection{Thermal Depletion in a Reservoir with Multiple Fractures}

The solution in the preceding section is based on the assumption that a single fracture controls the flow through the reservoir. In many reservoirs, it is likely that the flow is controlled by multiple fractures through the system. Gringarten et al. (1975) provide an analytical solution based on an infinite series of parallel vertical fractures that have uniform thickness and spacing. Applying the Laplace transform, the solution in Laplace space, $\tilde{T}_{W D}$, is given as

$$
\tilde{T}_{W D}(X, s)=\frac{1}{s} \exp \left(-X s^{1 / 2} \tanh \left[\frac{\rho_{f} c_{p_{f} f} Q x_{E}}{2 K_{R} L} s^{1 / 2}\right]\right)
$$

for dimensionless time, $t_{\mathrm{D}}$,

$t_{D}=\frac{\left(\rho_{f} c_{p_{-} f}\right)^{2}}{4 \lambda_{r} \rho_{r} c_{p_{-} r}}\left(\frac{Q}{L}\right)^{2}(t-x / v)$

where

$\mathrm{X}_{\mathrm{E}} \quad$ half fracture spacing

Q volumetric flow rate per fracture per unit thickness of the system perpendicular to the fracture plane

An analytical inversion of Equation (3) back to the original space is not provided and, therefore, a numerical inversion must be applied. We accomplished this inversion using the INVLAP Matlab program (Hollenbeck 1998) which is described by Nellis and Klein (2008) and based on the method of de Hoog et al. (1982).

In the case of flow through a system of parallel fractures, the cooling front perpendicular to flow eventually intersects that from an adjacent fracture, leading to more rapid cooling. As an example of the difference in cooling behavior, Figure 3 displays the behavior of five hypothetical sets of fractures with interfracture spacings of $100 \mathrm{~m}, 50 \mathrm{~m}, 25 \mathrm{~m}, 12.5 \mathrm{~m}$ and $6.25 \mathrm{~m}$. In each fracture the fluid-flow velocity is $430 \mathrm{~m} \mathrm{day}^{-1}$, the fracture aperture is $2 \mathrm{~mm}$, and the profiles are calculated for a time 35 years after initiation of flow. For the widest spaced fractures $(200 \mathrm{~m}$ and $100 \mathrm{~m})$, the cooling front into the rock, perpendicular to the plane of the fracture has not yet extended to the half interfracture spacing that would produce interference, and the temperature - distance plots are essentially identical. For the more closely spaced fracture sets, however, substantial overlap in the cooling of the fractures' walls produces 
dramatically different profiles. Cooling behavior after interference progresses very differently than prior to that condition. For a single fracture in an infinite system, interference never occurs, and cooling to the injection temperature never extends significantly beyond the injection end of the fracture. After interference occurs, further cooling propagates as a steep front, and an increasingly larger fraction of the fracture reaches the injection temperature.

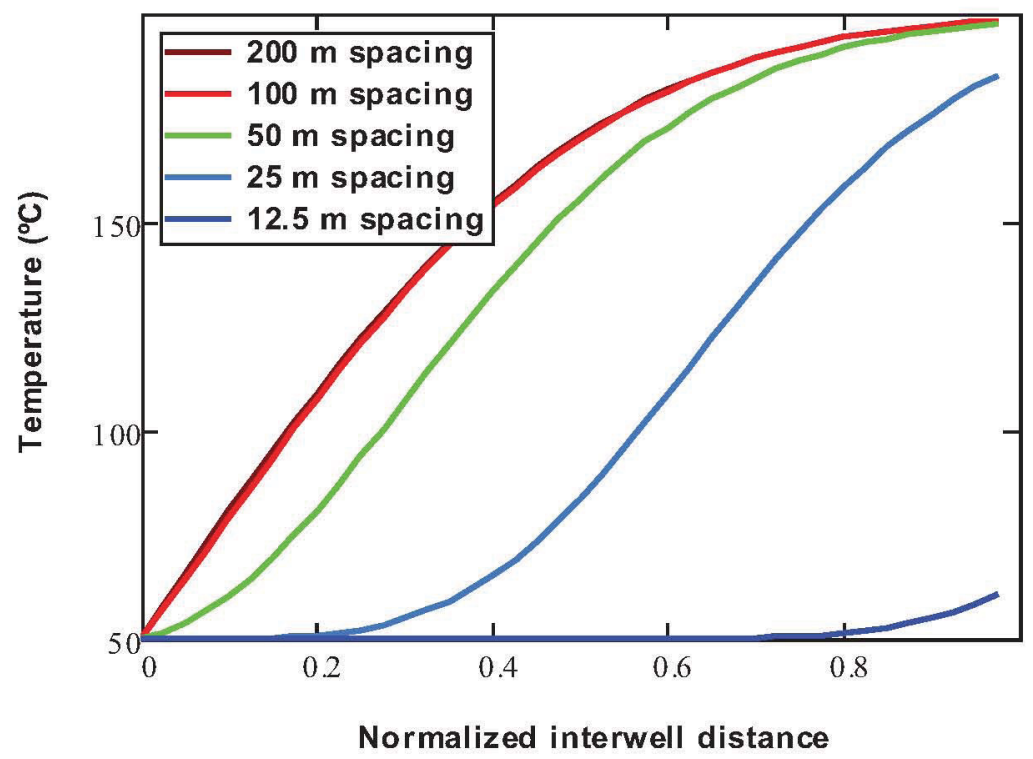

Figure 3. Temperature vs distance in five hypothetical sets of fractures with varying fracture spacing. Flow velocity in each fracture is $430 \mathrm{~m}_{\text {day }}{ }^{-1}$, fracture aperture is $2 \mathrm{~mm}$, and time since initiation of flow is 35 years. 


\section{THEORY OF REACTIVE TRACERS AND MATHEMATICAL DEVELOPMENT}

Characterizations of the hydraulic properties of reservoirs use breakthrough data from injected conservative tracers, which are often soluble compounds (Rose, et al. 2001a,b; Shook 2003; Shan and Pruess 2005). Conservative, artificial tracers can provide valuable information about reservoir residence times and flow paths that can used to determine locations and operation of injection wells and heat transfer in the reservoir (Behrens et al., 2009). Geochemical modeling of the composition of produced fluids can provide evidence of temperature histories (Moller et al., 2006). Reactive tracers have been proposed and used where temperature-dependent reaction rates should provide a record of the temperature history along the flow paths (Robinson, et al. 1984; Tester, et al. 1987; Nottebohm, Licha et al. 2009).

The application of reactive tracer testing to monitoring the thermal evolution of a reservoir is based on the temperature dependence of reaction rates for a tracer moving with the injected fluid through a fracture. A reactive tracer following a path in which temperature varies with distance undergoes reaction at a rate dependent on that temperature. The amount of tracer that reaches the point where the tracer is detected will thus reflect a path-integrated temperature. Repeated testing, over intervals for which significant cooling occurs in the reservoir (see Figure 2), would thus display different path-integrated temperatures and thereby provide information about the rate of cooling of that part of the reservoir.

The kinetics of the reaction, or reactions, involved in this approach depend on the number of reactions and their interdependencies. In this study, we considered single pathway reactions, parallel reaction pathways, and sequential reaction pathways, and these are described in the following subsections. An implicit assumption in these tracer tests is that the temperature profile remains constant over the time interval of a single tracer test. Based on the equation for a single fracture, Equation (1), and reported values of thermal conductivity of granite (Heuze 1983, Horai and Susaki 1989), this assumption is demonstrated to be true under most circumstances (see calculations in Appendix 1) except for very close to the injection well $(X<0.01)$.

\subsection{Reactive Tracer with a Single Pathway}

For many solutes with properties suitable for use as reactive tracers in geothermal systems, the relative reaction rate along a flow path can be described by a first-order or pseudo first-order equation of the form

$\frac{d C(t)}{d t}=-k(T) C(t)$

where $k(T)$ is the temperature-dependent rate coefficient given by the Arrhenius equation,

$$
k(T)=A \exp \left(\frac{-E_{a}}{R T}\right)
$$

where $T$ is the temperature in Kelvin, $R$ is the gas constant, and $E_{a}$ is the activation energy. The relative reaction rates along a flow path between the injection point and the extraction well are illustrated in Figure 4. The integrated reaction rate gives the amount of initial reactant remaining. The amount of conversion observed during transport between the wells decreases as the reservoir cools. A tracer test conducted at some $\Delta t_{D}$ after an initial test at time $t_{D_{-} \text {init }}$ should thus have measurably higher breakthrough curve concentrations than during the first test. 


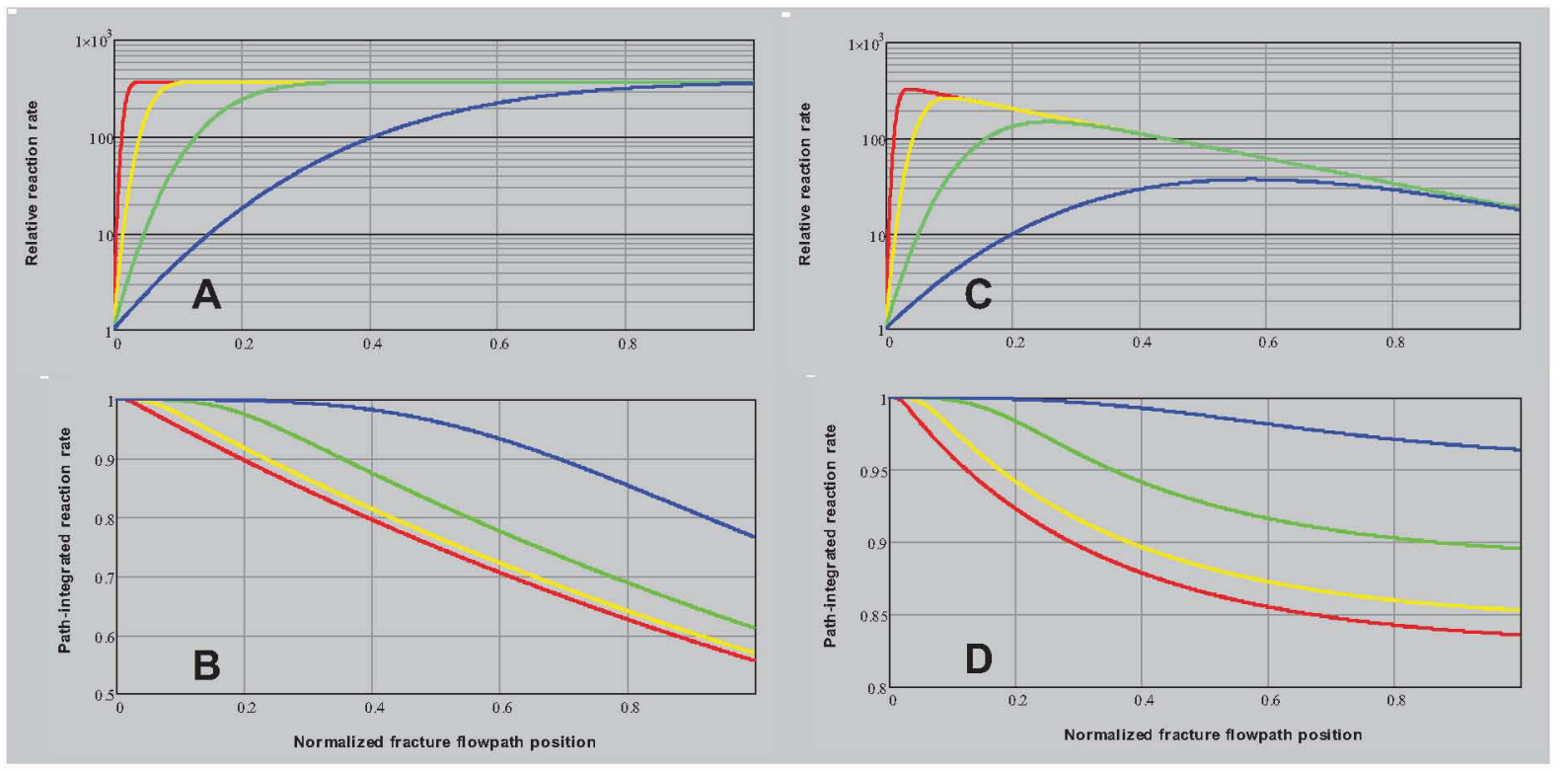

Figure 4. Reaction rate $(A \& C)$ and thermal reaction time $(B \& D)$ plots for a fracture flowpath for operating times and temperature profiles corresponding to those in Figure 2. Graphs A and B represent piston flow of a pulse of tracer transported through the fracture. Curves $\mathrm{C}$ and $\mathrm{D}$ approximate the effect of dispersion on a slug of tracer transported through the system, where the concentration decreases approximately exponentially with dimensionless position, $\mathrm{f}=\mathrm{x} / \mathrm{L}$, according to the expression $\mathrm{C} / \mathrm{C}_{0}=\exp (-3 \mathrm{f})$.

For piston-flow transport of a reactive tracer undergoing first-order decay, the relative tracer concentration, $\mathrm{C}_{\mathrm{rel}}=\mathrm{C} / \mathrm{C}_{0}$ with time, or equivalently, distance, can be obtained by substituting Equation (6) into Equation (5) and integrating to yield

$$
C_{r e l}(t)=\exp (-A \theta)
$$

where $\theta$, the thermal reaction time, is defined

$$
\theta(f)=\int_{0}^{f} \exp \left(-\frac{E_{a}}{R T}\right) \frac{L}{v} d f
$$

and $f$ is the fraction of the flow path traveled and $L$ is the flowpath length (Tester et al. 1987).

Examination of the relative concentration curves along the flowpath (Figure 4B) illustrates a problem with the proposed method. Only for very large differences in the operating time are the final thermal times significantly different, suggesting that the method is a relatively insensitive measure of thermal drawdown. As Behrens et al. (2009) point out; this appears to be the case for both large and small values of the activation energy, $E_{a}$. The primary difficulty is that the highest reaction rates occur in the downstream portion of the flow path, where temperatures converge on the initial reservoir temperature, and this is true for $\mathrm{k}(\mathrm{T})$ with either strong or weak temperature dependence. While sensitivity increases slightly with $E_{a}$, the net conversion with large $E_{a}$ also decreases toward immeasurably small values.

While available tracers may provide some choice in $\mathrm{E}_{\mathrm{A}}$, the choices are effectively very limited, and each choice is explicitly tied to a corresponding pre-exponential factor, A, that is the primary control on the absolute amount of conversion that will occur between the injection and production wells. In addition, for a class of tracers with different substituents, $E_{a}$ and A are correlated. This effect (activation enthalpyentropy compensation effect) is well known (Lasaga 1998, Liu and Guo 2001) and is illustrated in Figure 5with the ester and amide hydrolysis data of Robinson and Tester (1990). 


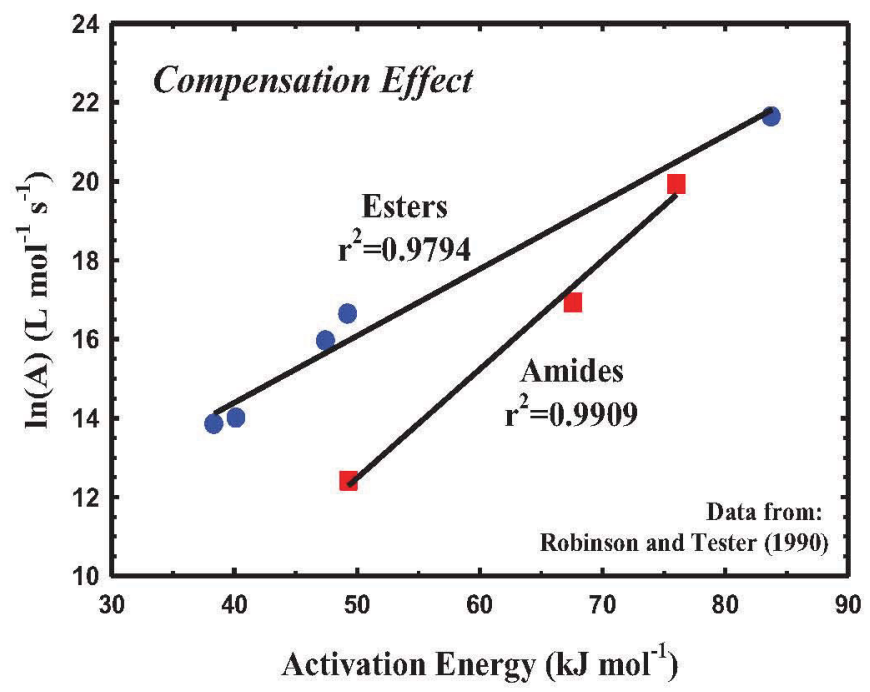

Figure 5. Activation entropy-enthalpy compensation effect for the second-order hydrolysis reactions of some ester and amide tracers.

The simple analysis described thus far overlooks a factor that could significantly increase the sensitivity of the method. The reaction term in the solute transport equation of interest is $k C$, not just $k$, and $C$ is affected by dispersion as well as chemical reaction. Concentration of a pulse of conservative tracer will typically decrease several orders of magnitude during flow through the system, and highest concentrations should generally occur in the regions of lowest temperature near the injection well. Along the flow path, $\mathrm{k}(\mathrm{T})$ will increase, but $\mathrm{C}$ will decrease. The result will be a reduction in the reaction term $(\mathrm{kC})$ with distance along the flow path partially counteracting the increase with temperature that otherwise dominates the resultant concentration at the production well. To illustrate the potential effect, we use a simple exponential term to describe the decrease with distance that a conservative tracer might undergo during transport and recalculate the reaction rate (Figure 4C) and thermal time (Figure 4D) curves of Figure $4 \mathrm{~A}$ and B. Separation between the thermal time curves is significantly increased, and net conversion is slightly reduced relative to the base case of Figure 4B. We conclude that a more accurate solution to the heat flow and solute transport problem is needed to accurately assess the potential sensitivity of the reactive tracer approach to measuring thermal drawdown.

To illustrate how the tracer test might work in an actual system, we simulated heat flow and solute transport using finite element methods, with the solute transport solution coupled to the output of the heat flow solution. The model represents water flow through a hypothetical fracture with a length of $1 \mathrm{~km}$ and flow velocity of $2 \mathrm{E}-3 \mathrm{~m} / \mathrm{s}$. The fracture aperture is $2 \mathrm{~mm}$, and the spacing between fractures is $20 \mathrm{~m}$. Based on the analyses previously discussed, which assume infinite spacing between fractures, $t_{c r i t}$ for this system would be approximately 27 years. 
Two tracer tests were simulated, one after a dimensionless operating time of 0.019 and a second at $t_{D}=0.387$. Temperature profiles corresponding to these times are very different (Figure 6). Thermal

drawdown extends to approximately 0.1 of the total flow distance $(\mathrm{L})$ for the first profile and to approximately 0.6 for the second profile. The conservative and reactive tracers were introduced into the well over an 8-hour period. Because solute transport is coupled to heat transport, the reaction rates are based on the simulated temperature history. Reactive tracer parameters are summarized in

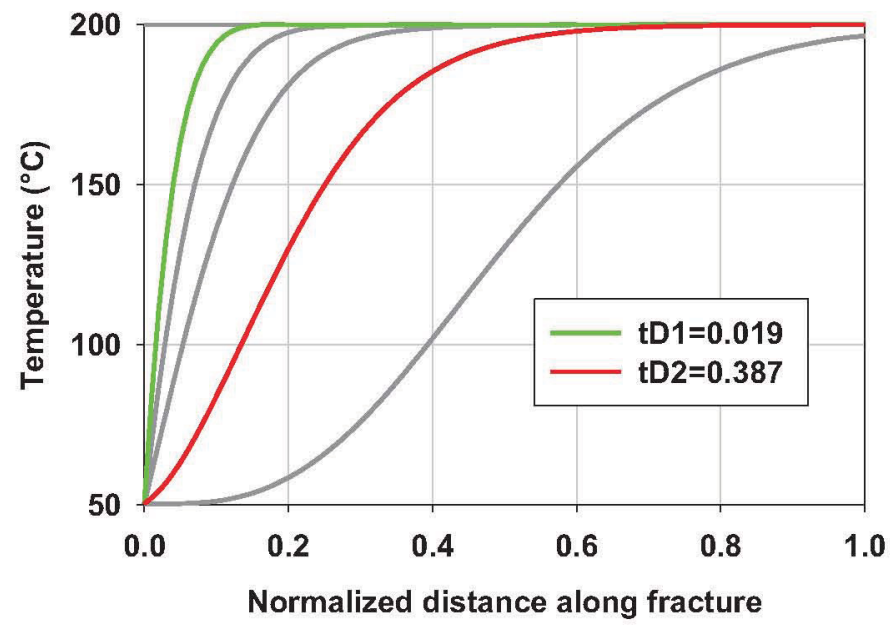

Figure 6. Temperature profiles at two different dimensionless operating times, $t_{D_{-} \text {init }}$ and $t_{D_{-} \text {init }}+\Delta t_{D}$.

Table 1.

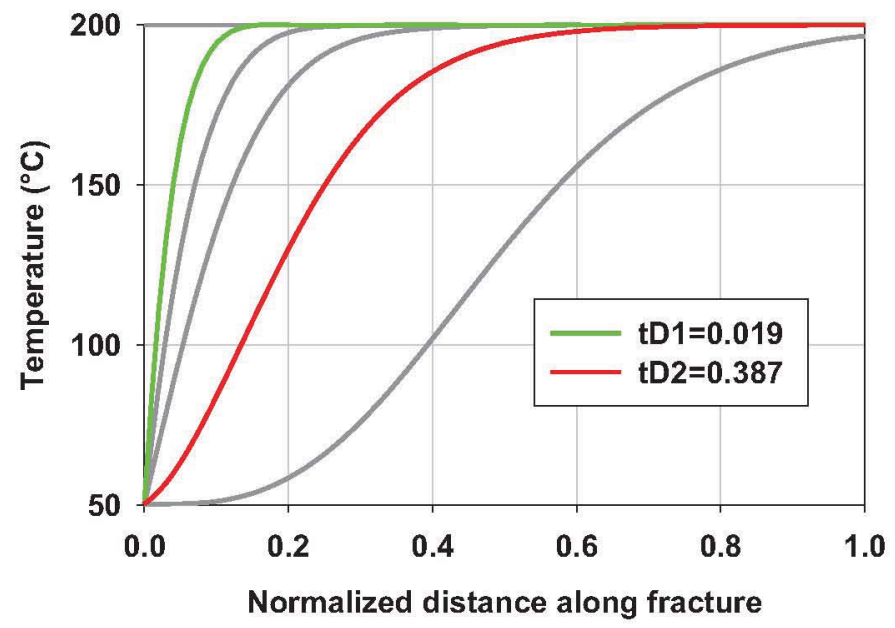

Figure 6. Temperature profiles at two different dimensionless operating times, $t_{D_{-} i n i t}$ and $t_{D_{-} \text {init }}+\Delta t_{D}$.

Table 1. Reactive tracer parameters used in simulations for Figure 7and Figure 8.

\begin{tabular}{|l|l|}
\hline Activation Energy, $E_{a}$ & $1,433[\mathrm{~kJ} / \mathrm{mole}]$ \\
\hline Pre-exponential factor, $A$ & $5.0 \mathrm{E}+10\left[\mathrm{~s}^{-1}\right]$ \\
\hline Injection period & 8 hours \\
\hline
\end{tabular}




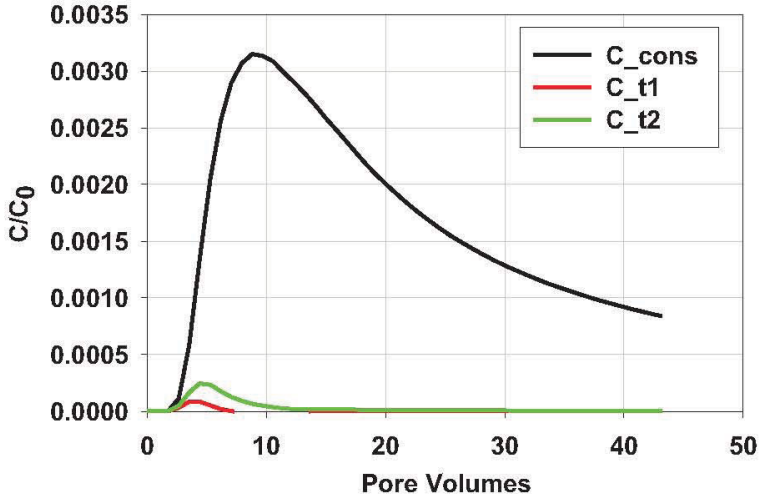

Figure 7. Conservative tracer breakthrough curve and base case reactive tracer breakthrough for two tracer tests conducted at different times.

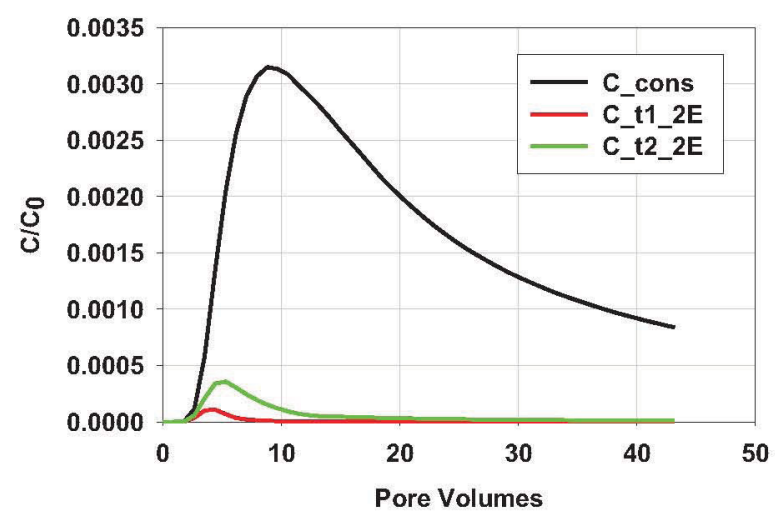

Figure 8 . Breakthrough curves with activation energy doubled for reactive tracers relative to the simulation results in Figure 7.

Simulated conservative and reactive tracer breakthrough curves are plotted in Figure 7 . The reactive tracer breakthrough curve from the later injection test shows slightly higher concentrations because the net conversion is lower for the slightly cooler system, but the magnitude of the difference is small. The relative sensitivity of the method is expected to increase with the magnitude of the $E_{a}$. To examine how an increase in $E_{\alpha}$ would affect results, we repeated the same simulation after doubling $E_{a}$ and increasing $A$ by a factor of $6.7 \mathrm{E}+15$ to maintain the same maximum rate coefficient. While the resultant breakthrough curves (Figure 8) demonstrate greater sensitivity to the difference in thermal profiles, the increase is small.

\subsection{Single Pathway with Instantaneous Quenching}

To improve the sensitivity of the reactive tracer method, Plummer et al. $(2010 \mathrm{a}, \mathrm{b})$ suggested that a reactive tracer may be more sensitive to changes in temperature distribution in the reservoir if the reaction could be quenched at some appropriate temperature. Quenching the reaction near the initial reservoir temperature should effectively reduce that influence, so that the resultant breakthrough curves are a more sensitive measure of the zone of thermal drawdown. Such quenching reactions may be feasible using the encapsulation techniques described by Redden et al., (2010). To illustrate the potential of such a tracer, we altered the base case simulation by including a term that shuts down the reaction when the temperature reached $10^{\circ} \mathrm{C}$ below the background reservoir temperature $\left(T_{\text {res }}\right)$. In this scenario, the breakthrough curve concentrations shown in Figure 9 for the later tracer test are distinctly lower than for the initial test and the concentrations are larger than for the case of unquenched reactive tracers (Figure 7). This reflects the fact that the conversion is now dominated by the lower temperatures near the injection well rather than the maximum temperatures. The concentration difference in this case is large, both with relatively small and relatively large $E_{a}$ values, demonstrating that the sensitivity of this method is influenced more by $A$ than by $E_{a}$. 


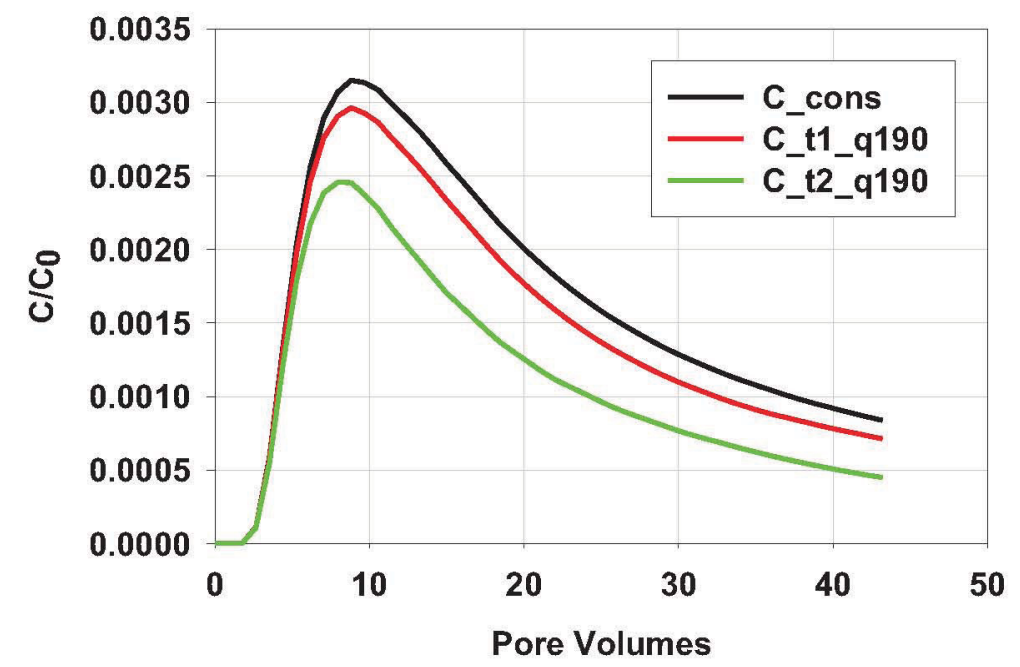

Figure 9. Breakthrough curves for base case conditions, with reaction quenched at $T_{r e s}-10^{\circ} \mathrm{C}$,

A quenched reaction mathematically shows good promise as a means of increasing the sensitivity of reactive tracers for measuring thermal drawdown. Significant work is needed to indentify applicable tracers or approaches that demonstrate this property.

\subsection{Two Simultaneous Reaction Pathways}

One approach to quenching a reaction is to have two reaction pathways for one reactant. When that reactant is consumed, the concentration of the second reactant will be fixed. To further investigate this possibility, we considered two parallel reactions involving tracers $\mathrm{A}$ and $\mathrm{B}$ :

$A+B \stackrel{k_{1}}{\longrightarrow} C$

$B \stackrel{k_{2}}{\longrightarrow} D$

We assume that the rates for these reactions are respectively given by

$\frac{d A}{d t}=-k_{1} A B$

$\frac{d B}{d t}=-k_{1} A B-k_{2} B$

where the rate coefficients $\mathrm{k}_{1}$ and $\mathrm{k}_{2}$ are given by the Arrhenius equation, Equation (6). Conceptually, we expect that $A$ and $B$ will react to form $C$ while $B$ is also consumed via a second pathway to $D$. A and $B$ will continue to react to form $\mathrm{C}$ until all of the $\mathrm{B}$ is consumed. At this point, the concentrations of $\mathrm{A}, \mathrm{C}$, and $\mathrm{D}$ become fixed. In this sense, the $\mathrm{A}+\mathrm{B}$ reaction is quenched when all of the $\mathrm{B}$ has been consumed. An example of the potential distribution of tracer concentrations in a parcel of water as it travels along a flow path between the injection well and the extraction well shows the concentration of A deceasing to a constant value (Figure 10). 


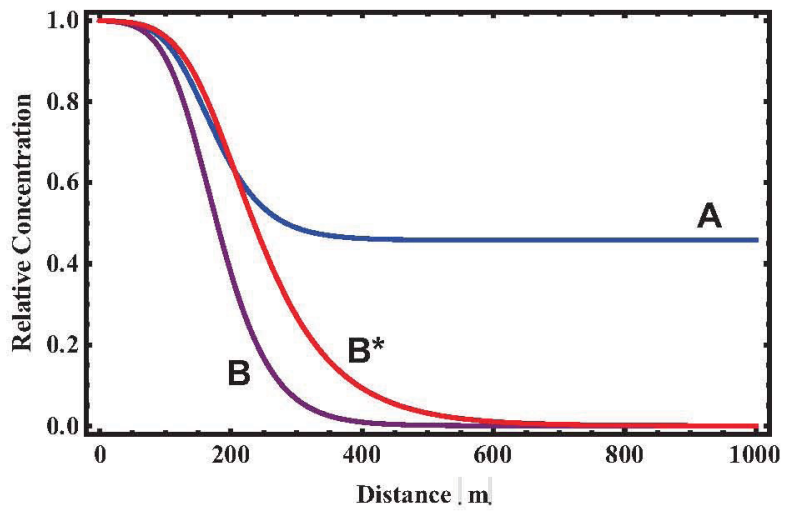

Figure 10. Relative concentration of $\mathrm{A}$ and $\mathrm{B}$ in a parcel of water as it flows between the injection and production wells for two parallel reaction paths. $\mathrm{B}^{*}$ denotes the concentration of $\mathrm{B}$ in the absence of $\mathrm{A}$.

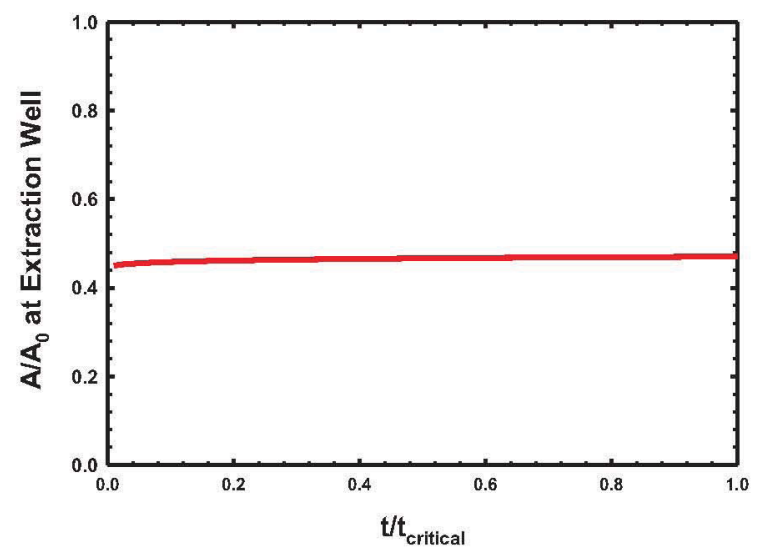

Figure 11. Relative concentration of $\mathrm{A}$ as a function of the fraction of the cooling time of the reservoir for a parallel reaction pathway for $\mathrm{B}$.

We have tested several sets of parameters and for a particular set, we presented the values of $\mathrm{A}$ as a function of the fraction of the reservoir that has been cooled (Figure 11). The results indicate that the concentration of $\mathrm{A}$ is not sensitive to the amount of cooling in the reservoir (generally $<1 \%$ ) and, therefore, this approach is unlikely to be useful.

\subsection{Consecutive Reaction Pathways}

An alternative approach is to use a tracer that degrades in several consecutive steps as chain decay. Consider the decay of A through the intermediate $\mathrm{B}$ and then to $\mathrm{C}$ :

$$
\begin{aligned}
& A \stackrel{k_{1}}{\longrightarrow} B \\
& B \stackrel{k_{2}}{\longrightarrow} C
\end{aligned}
$$

If these are first order reactions, the rate equations can be written as

$$
\frac{d A}{d t}=-k_{1} A
$$

$$
\frac{d B}{d t}=k_{1} A-k_{2} B
$$

$$
\frac{d C}{d t}=k_{2} B
$$




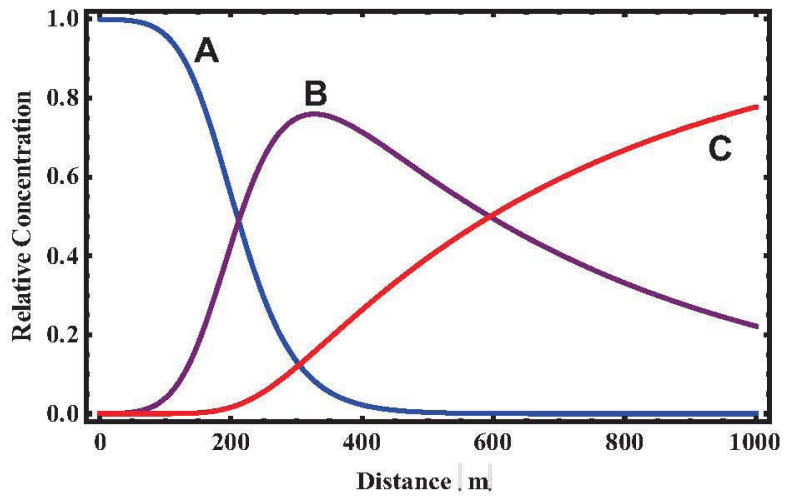

Figure 12. Relative concentrations of A, B and C for the case of consecutive reactions (chain decay).

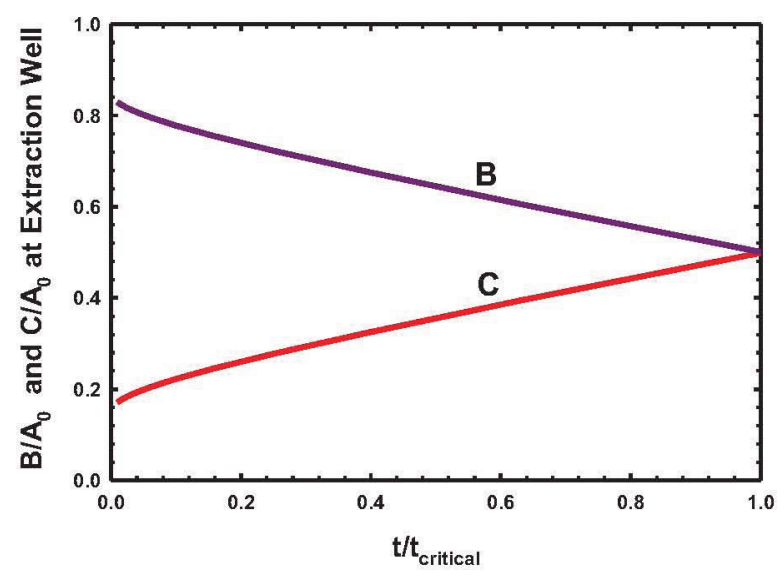

Figure 13. Relative concentration of $\mathrm{B}$ and $\mathrm{C}$ as a function of the fraction of the cooling time of the reservoir for a chain decay.

where the rate coefficients are given by the Arrhenius equation, Equation (6). We numerically solved this system of differential equations with the initial conditions $\mathrm{A}(0)=1, \mathrm{~B}(0)=0$ and $\mathrm{C}(0)=0$. A typical set of response curves (Figure 12) show A decreasing with residence time with B simultaneously increasing to a maxima. $B$ does not attain unit relative concentration because of the mass loss due to transformation of $B$ to $\mathrm{C}$, which increases as $\mathrm{B}$ decreases. The concentrations of $\mathrm{B}$ and $\mathrm{C}$ as a function of the fraction of the reservoir that has been cooled (Figure 13) indicate that these concentrations are much more sensitive to the amount of cooling in the reservoir than for the parallel reaction pathway case; therefore, the use of consecutive reaction pathway may prove useful in delineating the migration of thermal fronts in reservoirs. 


\section{IDENTIFICATION AND ASSESSMENT OF REACTIVE TRACERS 4.1 Single Pathway Tracers}

Tracers can be either reactive or conservative and they may be soluble in the aqueous phase or exist as colloids. Regardless, the use of a soluble conservative tracer is generally desired to aid in the interpretation of other types of tracers. Fluorescein was used as a conservative tracer at Raft River in 2008 (Holt 2008) and could be used again. However, there is some concern that the background levels may be elevated as a consequence of its previous employment. Rose et al. (2001a) have demonstrated that several polyaromatic sulfonates can act as conservative tracers in geothermal reservoirs. P.E. Rose (personal comm., 03/05/2010) has suggested the use of naphthalene-2,6-disulfonate (disodium salt) as a conservative tracer for Raft River.

A tracer may be conservative or reactive, depending on the temperature it experiences along its flow path through the reservoir. The working temperature range at Raft River is approximately $100-170^{\circ} \mathrm{C}$, with the temperatures likely to be encountered during the tracer test being around $140^{\circ} \mathrm{C}$. Many of the tracers characterized by Adams et al (1992) will not react at these temperatures and can be used as conservative tracers (e.g. naphthalene sulfonates, fluorescein or other dyes). Amides (e.g. acetamide, butyramide) and esters (e.g., hexylacetate) characterized by Robinson and Tester (1990) are candidates for reactive tracers, although most of the esters characterized in this study may be too reactive for use at temperatures greater than $100^{\circ} \mathrm{C}$. Colloids (particles $<10 \mathrm{um}$ in diameter) under consideration include iron and polystyrene. Others may be identified in the future and will be presented to USG for deployment as tracers.

Any tracer under consideration must be sufficiently soluble (or in the case of particles, abundant) to withstand approximately $10^{5}$ to $10^{6}$ dilution and still be detectable by the analytical technique employed. The 2008 Raft River tracer test conducted by US Geothermal and modeled by Richard Holt suggests that injection of a conservative tracer into RRGP-5 was accompanied by a dilution factor of approximately 2 $\mathrm{X} 10^{5}$.

A review of the existing literature has indicated several tracers that could potentially be used at Raft River. These tracers and their properties are summarized in Table 2. Many of the tracers are still stable at temperatures close to $200^{\circ} \mathrm{C}$. Temperatures at Raft River are expected to be $\leq 145^{\circ} \mathrm{C}$. The esters studied by Robinson and Tester (1990) appear to be unstable, even at temperatures $<100^{\circ} \mathrm{C}$. As a preliminary selection, we believe that the amides described by Robinson and Tester (1990) provide the best possibility for success in the temperature ranges expected at Raft River. The structures and chemical formulas of a set of plausible conservative and reactive tracers is provided in Figure 14. 


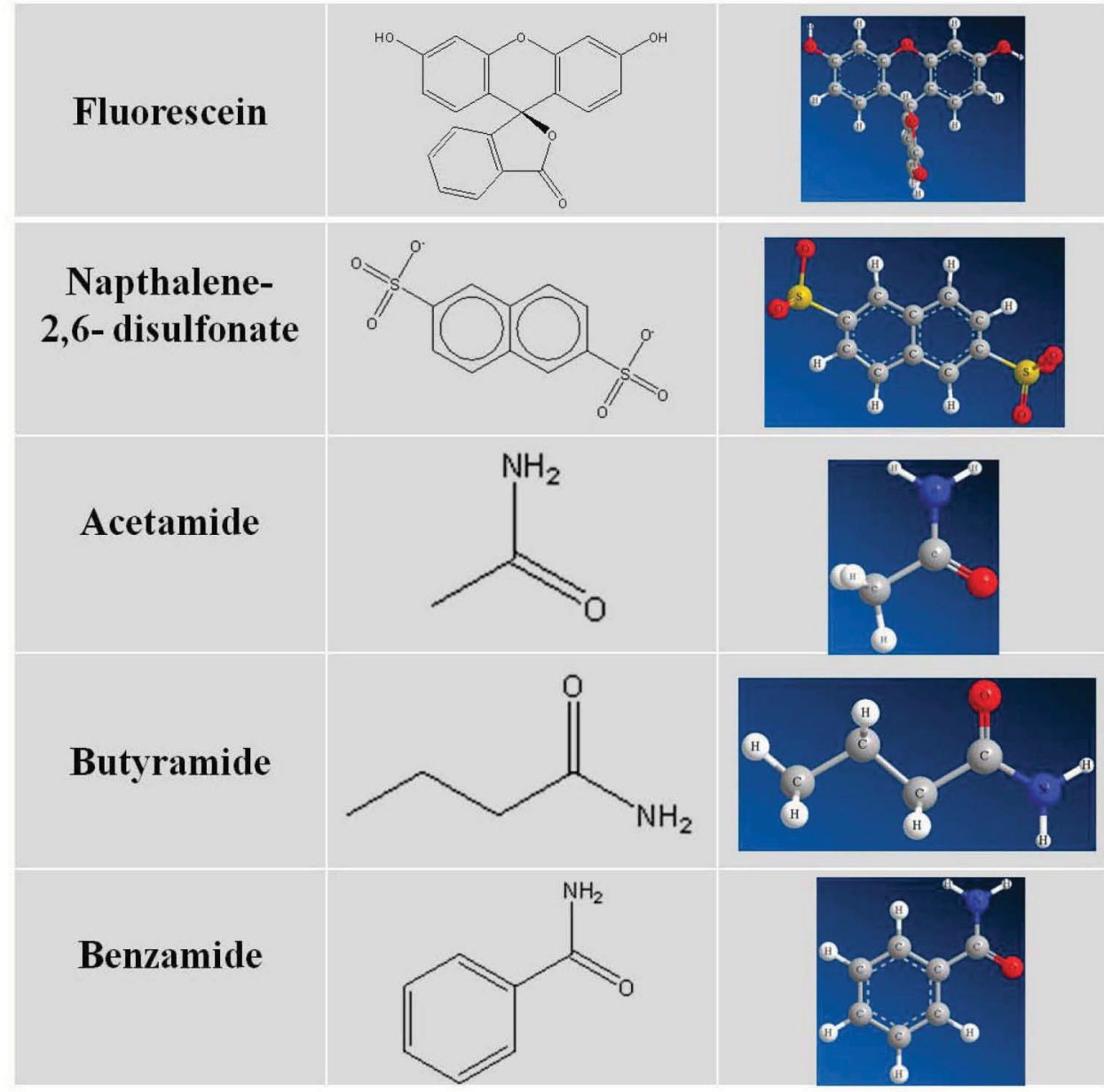

Figure 14. Chemical structures of some tracers considered for use at Raft River. 
Table 2. Summary of data on candidate reactive tracers.

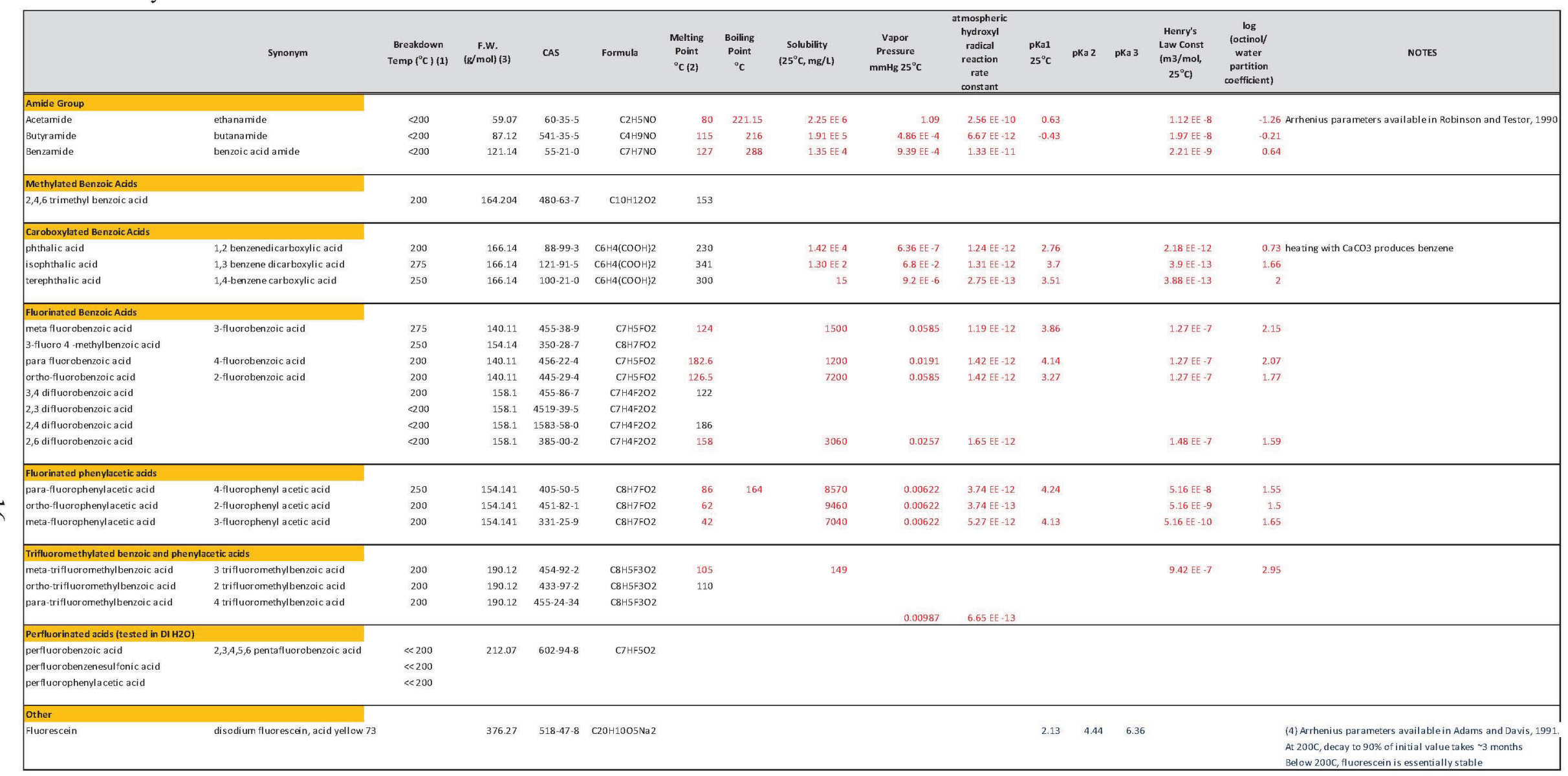

(1) Reactive Temperatures ${ }^{\circ}$ C, from Adams et al. 1992, except for amides, which come from Robinson and Tester, 1990 (2) Data in RED come from Handbook of Physical Properties of Organic Chemicals Ed. PhilipH. Howard and William M. Meylan, Lewis Publ ishers, Boca Raton, 1997

(4) Data in BLUE are from Adams and Davis, 1991 . 


\subsection{Colloid and Encapsulated Tracers}

In some cases, particle-based tracers have been used for the characterization of subsurface flow (Harvey et al. 1989, Grindrod et al. 1996, Vilks and Bachinski 1996, StrongGunderson and Palumbo 1997, Vilks, Frost 1997, Niehren and Kinzelbach 1998, Becker, Reimus, and Vilks 1999, Becker and Shapiro 2000, Knapp, Chiarappa, and Durham 2000, Vilks and Baik 2001, Becker 2003, Zvikelsky and Weisbrod 2006, Vilks, Miller, and Vorauer 2008). Most of these studies of colloid transport have involved low temperature systems and targeted issues related to contaminant or biological transport. Interpretation of colloid transport is difficult because of limitations in our understanding of filtration processes and because particle transport in physically heterogeneous and fractured systems deviates significantly from the transport of soluble species; breakthrough of colloids is often found to occur ahead of the breakthrough of soluble tracers.

For geothermal systems, colloids should have several useful properties compared to soluble tracers. Geothermal systems are generally characterized by flow paths with larger apertures than typical groundwater systems (fractures and voids), and flow rates can be high enough to reduce particle loss by classical filtration, straining and settling. Colloids have been used in low temperature systems to study the nature of fluid and solute transport in fractured systems (Toran and Palumbo 1992, McKay, Gillham, and Cherry 1993, Vilks and Bachinski 1996, Chrysikopoulos and AbdelSalam 1997, Grindrod and Lee 1997, Vilks, Frost, and Bachinsky 1997, Becker, Reimus, and Vilks 1999, James and Chrysikopoulos 1999, Becker and Shapiro 2000, James and Chrysikopoulos 2000, Alonso et al. 2002, Missana et al. 2002, Becker 2003, Reno, James, and Altman 2006, Zvikelsky and Weisbrod 2006, Vilks, Miller, and Vorauer 2008, Zvikelsky, Weisbrod, and Dody 2008). Colloidal tracer loss during transport can present interpretation challenges when the colloids are used specifically to characterize flow in geologic media. Comparisons between the time and shape of breakthrough curves for colloids and conservative tracers provide useful interpretations.

In this project we investigated colloids that have temperature-recording properties. Such colloids could be applied to determine how the temperature profile of a geothermal system changes over time as heat is extracted. We evaluated colloidal tracers where the reference point for the temperature history is contained in the particle itself.

\subsubsection{Temperature-Time Sensitive Colloid Tracers}

To temperature sensitive colloid tracers that show promise are colloids that exploit the properties of thermoluminescence (Mahesh, Weng, and Furetta 1989, Mercier 2008) and polymer racemization (Bada, Maynard, and Luyendyk 1970, Clarke and Murray-Wallace 2006, Kaufman 2006, Tsukegi et al. 2007). Both processes have kinetic properties that are temperature sensitive and allow the reaction precursors and products to be contained within a particulate package. The advantage, then, is that tracer loss by dilution and filtration is acceptable as long as measurable quantities of the tracers can be recovered.

In the thermoluminescence model, a radiation-activated mineral phase is used where attenuation of the thermoluminescence glow curve is a function of temperature and residence time. In the racemization model, the $\mathrm{L}$ form of a polymerized racemic compound (poly-L-lactic acid or polymerized amino acid) is used. Changes in the $\mathrm{D}$ to $\mathrm{L}$ ratio will serve as the temperature-time indicator.

\subsubsection{Colloid Tracer Encapsulation: an Enabling Approach}

In many cases it may be advantageous or necessary to protect tracers (particulate or solutions) from unwanted reactions with components of a reservoir fluid or mineral surfaces. For example, dissolution of a thermoluminescent tracer, even if only partial, would obliterate the record of exposure to heat. Hydrolysis, oxidation, or other unwanted reactions would compromise a racemic polymer tracer. Encapsulation of a tracer using heat- and chemical-resistant polymers offers several advantages. These include: 
- Isolation from the chemical environment of a reservoir

- The possibility of modifying surface charge in order to optimize colloid stability and minimize attachment (filtration)

- The possibility of modifying the density of a particle-based tracer for improved transport (reduced settling of large or dense particles)

- By keeping tracer reaction products with unreacted initial states, the potential for tracers to have internal reference points (via reactant/product ratios) and be less dependent on establishing mass balances.

In addition, the ability to package multiple components in a capsule opens up additional possibilities for the design of other "smart" or novel tracers that can record temperature-time histories. For example, a core-shell structure could carry two solid components that fuse at selected temperatures. Further, the mixing of reactants could be used to quench a temperature-dependent reaction, which can then amplify the temperature history along the flow path of a geothermal reservoir Plummer et al. (2009). For this project, we tested methods for forming core-shell structures with materials that can survive under reservoir conditions and that record temperature-time history.

\subsubsection{Task Objectives}

We tested methods for encapsulation of colloids using organic polymers with two objectives in mind. The first was to test methods for coating small particles with organic polymers. The second was to determine whether the polymer coatings protect the colloid core from the outside environment. For the development and evaluation of polymer coating methods and materials, surrogate minerals rather than the actual thermoluminescent minerals were used in order to facilitate evaluation of the polymer coatings. These surrogates have the advantage of providing simple visual indication if the coating fails to protect them from exposure to the suspending fluid (water). Sodium chloride (soluble, colored in the $\gamma$-irradiated form) and copper salts (blue in solution) were the surrogate minerals chosen for this task.

For use in the field we expect tracers will have to be relatively inexpensive since large quantities may be needed to compensate for loss and dilution factors. Using thermoluminescent minerals as temperaturesensitive tracers might not require polymer encapsulation in some cases. However, there are several potential advantages. One is that some minerals that are soluble in geothermal extraction fluids could be used. This can make it easier to identify the actual tracer colloids against background colloids in the production waters through filtering and fractionation procedures. We have observed that even sodium chloride can be recovered from polymer-coated forms when the polymers are dissolved in dry organic solvents. A second advantage to polymer coatings is that the density of the core-shell particle can be made lower than, for example, the core mineral particle. As a result, larger particles can exist in stable suspensions without settling, and the larger sizes would be excluded from entry into small pore, lower permeability media. A third advantage is that the surface charge of the mineral can be masked. This can be important in cases where differences in electrostatic charge signs can result in filtration by electrostatic interactions

\subsubsection{Methods and Materials}

The mineral phases used as the particle cores were sodium chloride (Aldrich), copper sulfate (Fisher) and copper acetate (Aldrich). The minerals were used without further purification prior to grinding. Polymers used in test coatings were polystyrene (PS), polymetheylmethacrylate (PMMA) and a polyimide (PI). Sodium chloride, a thermoluminescent material, was $\gamma$-irradiated. The irradiation results in a brown color, which can be used as a visual indicator in addition to being used to evaluate our ability to record a thermoluminescent signature. 
The particles were ground in a SPEX ball mill running at 1080 cycles per minute $(18 \mathrm{~Hz})$ for 2 twenty minute cycles using an agate ball and sample holder. The resulting powder was separated in an ATM ultrasonic sifter for two 15 minutes cycles. Two fractions were retained, the first being 38-83 micron size and the second being the fines that were $<38$ microns.
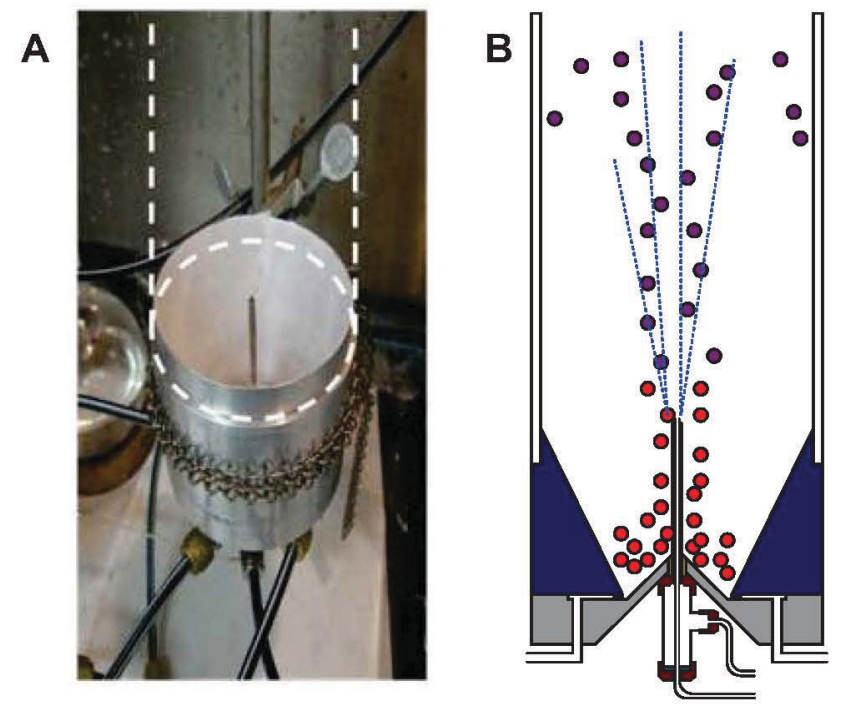

Figure 15. A) photograph of the base of the Wurster coater with the sleeve (dotted line) removed. B) A schematic of the cell showing how particles are entrained into a stream of polymer/solvent where the solvent is removed by evaporation and polymer layers are deposited on the core particles.

Two polymer coating methods were used. One is the Wurster method Arimoto, Ichikawa, and Fukumori 2004) shown in Figure 15. In this method, a gas stream forces the particles upwards in the center where they are spray coated via an aspirated polymer solution (dissolved in organic solvent). The coated particles quickly dry and fall back down and the process is repeated several times, which determines the thickness of the coating.

The second coating method involves a solvent-safe blender where the particles, polymer and solvent are homogenized and aerosolized into a non-solvent where the polymer solvent is rapidly removed resulting in a dense polymer coating on the particles. The success of this method is dependent upon the proper choices of the two solvents involved. First, a polymer such as polystyrene or a polyimide is dissolved in a solvent. Then the tracer particles, which must be insoluble in the solvent, are added to form a suspension. Once this mixture is made, it is added drop wise to a second solvent that is being rapidly stirred in a blender. The second solvent is chosen to be miscible with the first solvent while at the same time does not dissolve the polymer. As the drops fall into the blender, the first solvent disperses into the second solvent and the polymer precipitates and encapsulates the tracer particles. This process has been used to coat two different copper salts and sodium chloride particles. Samples prepared were

- $\quad \gamma$-irradiated $\mathrm{NaCl}$ in PS and PS/PMMA co-polymer

- $\mathrm{CuSO}_{4}$ in PMMA

- $\mathrm{Cu}\left(\mathrm{COOCH}_{3}\right)$ in PMMA and PI.

\subsubsection{Results}

The primary objective for the initial experiments was to obtain evidence that the coated particles would not dissolve in water. In the case of $\mathrm{NaCl}$, the colloids remained intact (Figure 16). Subsequent removal of the polymer coating using a dry organic solvent released $\mathrm{NaCl}$ to the solvent, which settled to the bottom of the flask. 
Water-soluble copper-salt particles appeared to be resistant to degradation in the presence of water. In some samples, there was seen a faint blue color, which indicated that at least some of the particles were not completely coated. (An equivalent mass of copper salt dissolved in water has a much more intense color that is easily distinguished from leachate in the presence of the coated particles.) However, after decanting the liquid and re-suspending the particles in water, the blue color was not visible to the eye, indicative that the percentage of particles that were completely coated was very high $(>90 \%)$.
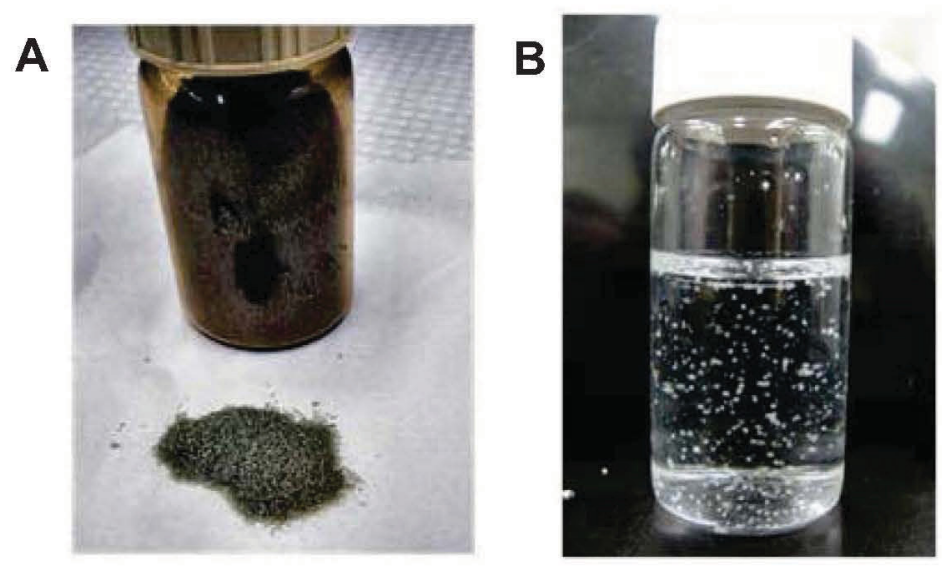

Figure 16. A) $\gamma$-irradiated $\mathrm{NaCl}$, B) Polymer-coated $\mathrm{NaCl}$ suspended in water. 


\section{METHODS FOR DESIGN AND INTERPRETATION OF REACTIVE TRACER TESTS}

Reactive tracer tests aimed at monitoring thermal changes in a reservoir can be analyzed in a number of ways, each depending on a simplified model of the reservoir. At the simplest level, for example, it can

be assumed that reservoir temperature is constant and that changes in the amount of tracer returned reflect a change in that uniform reservoir temperature. This is a useful means of assessing the general magnitude of thermal change implied by reactive tracer tests, but it does little to promote understanding of how thermal changes in the reservoir would actually occur. At the other extreme, if sufficient data are available, it is possible to use results of reactive tracer tests to help calibrate a three-dimensional model of the reservoir that predicts long-term cooling behavior based on complicated flow patterns that are not adequately described with models of lower dimensionality. Commonly, however, such data are not available, and a simpler method of analysis is desired. To provide a method of intermediate complexity, we adopted a simplified model of the reservoir that assumes that flow occurs in sets of fractures which each cool in a manner predicted by solutions of heat transfer equations describing flow in parallel fractures. The effect of cooling, in the hypothetical reservoir, is determined by solving transport equations that include the position-dependent temperature in the calculation of reaction progress. Because this analysis requires application of semi-analytical solutions that can be difficult to use, we developed a set of MATLAB (Mathworks) programs to perform the necessary calculations as well as some related tracer analysis functions that are commonly applied to geothermal systems. To facilitate use of these programs, we developed a user-interface to access those programs that automates many of the routine processes involved and which can be readily extended to incorporate other tracer analysis methods if desired. The program has been compiled for use without MATLAB. The package of forward and reverse algorithms for planning and analyzing reactive tracer tests is called the Tracer Analysis Toolbox.

\subsection{Tracer Analysis Functions Provided}

The Tracer Analysis Toolbox provides several conveniences for analysis of tracer data. These include semi-automated importing of different data file formats, including Excel files, conversion from several common unit options, and automated application to a user-selectable number of wells. The primary analysis operations are described in the following subsections.

\subsubsection{Residence Time Distribution Analysis}

The amount of heat that can be extracted from a specific volume of rock, and the efficiency of that extraction, is largely defined by the number, flow capacity, and distribution of paths through that volume that can carry a working fluid to the production well. As Robinson and Tester (1984) note, "productivity will be maximized if the fluid is forced to sweep through a large number of well-distributed fractures rather than channel through one or two major joints." Residence-time distribution analysis focuses on describing, in effect, how well distributed are the paths reflected in a tracer breakthrough curve. For an EGS system, where an injection-well/production-well pair may represent a closed system, that path distribution is essentially the sweep efficiency of the entire system. For a multiple well EGS or hydrothermal system, the path distribution reflects the sweep efficiency of paths connecting the tracer injection location to the production well at which tracer was recovered.

Residence time distribution (RTD) analysis differs from more commonly applied tracer interpretation methods (e.g., TRINV; Axellsson 1993) in that it does not attempt to depend on a particular deterministic model of the geometry or hydrodynamics of the reservoir and, therefore, does not incorporate curve fitting methods as a means of parameterizing such a model. The RTD analysis included in INL's ThermalTracer1D analysis program uses the mathematical summary described in Shook and Forsmann (2005), which emphasizes the use of the RTD as a probability distribution function.

The analysis calculates exit times, $\mathrm{E}(\mathrm{t})$, from flow and concentration data via the equations: 


$$
\begin{array}{ll}
E(t)=\frac{C(t) q_{i n j}}{M_{i n j}} & \text { for } C \text { in volume fraction } \\
E(t)=\frac{C(t) \rho q_{i n j}}{M_{i n j}} & \text { for mass fraction }
\end{array}
$$

where $C(t)$ is time-dependent tracer concentration, $\mathrm{q}_{\mathrm{inj}}$ is flow rate at the tracer injection well, $\mathrm{M}_{\mathrm{inj}}$ is the tracer mass injected, and $\rho$ is solution density.

In a typical geothermal reservoir, injection fluid is recirculated production-well fluid, which complicates analysis of tracer test data because the measured breakthrough curve reflects not just the initial tracer-mass injected, but also any tracer that is recirculated through the system. The recirculation effect is removed via deconvolution (Levenspiel 1972, Robinson and Tester 1984, Shook and Forsmann, 2005), using the equation:

$$
E(t)=E_{\text {app }}(t)-\frac{1}{1-f_{\text {loss }}} \int_{0}^{t} E_{i n j}(t-\tau) E(\tau) d \tau
$$

where $E_{\text {app }}$ is the apparent exit time distribution, $E$ the actual exit time distribution, $\mathrm{f}_{\text {loss }}$ is the fraction of water lost during recirculation (e.g., by evaporation) and $\tau$ is a dummy variable for time-dependent integration.

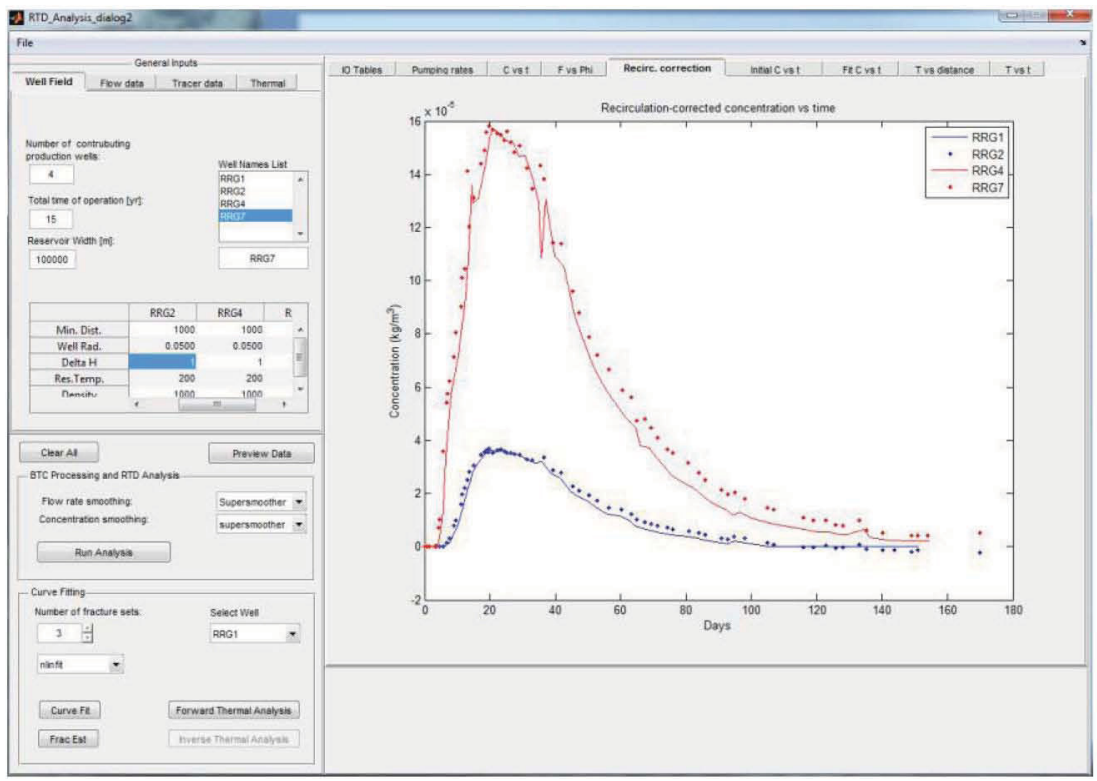

Figure 17. Tracer Analysis Toolbox graphical output displaying raw BTC data (points) for two production wells in a geothermal reservoir and the calculated recirculation-corrected BTC data (lines).

Tracer mass return for each BTC is calculated using the recirculation-corrected data, according to the equation,

$m_{i}(t)=\int_{0}^{t} C_{i}(s) Q_{i}(s) d s$

where $\mathrm{s}$ is a dummy variable for time-dependent integration up to time, $\mathrm{t}$. 


\subsubsection{BTC Analysis via Deterministic Models of Fracture Geometry and Hydrodynamics}

In contrast to the RTD approach, the deterministic approach to tracer test analysis assumes that the reservoir flow paths can be reasonably represented by a particular fracture geometry and hydrodynamic system. Parameters describing the geometry and hydrodynamics can then be obtained by fitting a solution to an equation that describes the flow through the system to the data obtained from the tracer test. The Tracer Analysis Toolbox currently provides two alternatives for definition of the hydrodynamics of the system. Each case assumes that the fracture geometry comprises one or more sets of fractures of common aperture and length and that solute transport through the system is adequately described by solutions to the advection dispersion equation for an instantaneous injection of tracer. In one case, flow is assumed to be unidimensional (after Bear 1972); while the alternative treatment assumes radially convergent flow (after Moench 1989). Solutions describing solute diffusion into the surrounding matrix or sorption in the matrix (e.g., Maloszewski and Zuber 1984, 1985, Becker and Charbeneau, 2000) are not currently included.

Several researchers have noted that a 1D uniform flow model commonly provides an accurate description of breakthrough curves in fractured media even where the flow field is believed to be radially convergent on the production well. The commonly used geothermal-reservoir tracer-analysis program TRINV (United Nations University Geothermal Training Programme, 1994) also assumes onedimensional flow and transport and generally provides a good fit to observed breakthrough curves, although that may, in part, reflect the fact that that TRINV assumes that the BTC may represent an assembly of component curves derived from flow from distinct channels. As the Research Council (U.S.). Committee on Fracture Characterization and Fluid Flow notes ${ }^{\mathrm{a}}$, a weakness of the multiple-channel model is that "a certain degree of arbitrariness can be required in its application and interpretation. This is especially evident when analyzing breakthrough curves with long tails, which can be broken down into nonunique combinations of component curves."

For uniform flow, the $1 \mathrm{D}$ transport solution is

$c(t)=\frac{M}{\phi} \frac{1}{\sqrt{4 \pi D t}} \exp \left\{\frac{-(x-v t)^{2}}{4 t}\right\}$

where $\mathrm{M}$ is injected mass, $\phi$ is porosity, $v$ is the average pore velocity, and $\mathrm{D}$ is the hydrodynamic dispersion coefficient. Assuming that molecular diffusion is negligible compared to longitudinal dispersion, $D=\alpha V$, and by substituting $\phi=Q / v$ the equation can be written

$c(t)=\frac{v M}{Q} \frac{1}{2 \sqrt{\pi \alpha \nu t}} \exp \left\{\frac{-(x-v t)^{2}}{4 \alpha v t}\right\}$

where $\mathrm{Q}$ is volumetric flow rate, $\mathrm{M}$ is injected mass, $v$ is velocity and $\alpha$ is dispersivity [L].

In forced gradient tests, it can often be assumed that the flow field at the production well is radially convergent. Sauty (1978) demonstrated an approximate solution to an equation describing transport of a slug injection to a radially convergent flow field as

$c(t)=\frac{M r}{Q} \frac{1}{2 t^{3 / 2} \sqrt{\pi \alpha \nu}} \exp \left\{\frac{-(r-v t)^{2}}{4 \alpha v t}\right\}$

where $\mathrm{r}$ is the radial distance between the injection well and the production well.

a. http://books.google.com/books?hl=en\&lr=\&id=geBhsU2k6rQC\&oi=fnd\&pg=PA1\&dq=Rock+fractures+ and +fluid+flow: + contemporary + understanding + and + applications\&ots -wdASI740GZ\&sig-Aykphh 3twgK_SeFj1V sNaeIZw\#v=0nepage\&q=component $\% 20$ curves $\& f=$ false 
Based on the governing equation (1D flow equation or radially convergent flow equation) selected by the user, the Tracer Analysis Toolbox fits a user-specified number of solutions to that equation to best fit the observed breakthrough curve data. The program provides information about goodness of fit for each fit as well as best estimates of user-selectable fitting parameters, which may include for each fracture set, $i$, inferred to exist: $v_{i}$, velocity, $\alpha_{i}$, dispersivity, $L_{i}$, flow path length and $f_{i}$, fraction of flow contributed by given fracture set. Figure 18 illustrates results of this curve fitting approach as used to obtain the estimated parameters shown in Table 3.
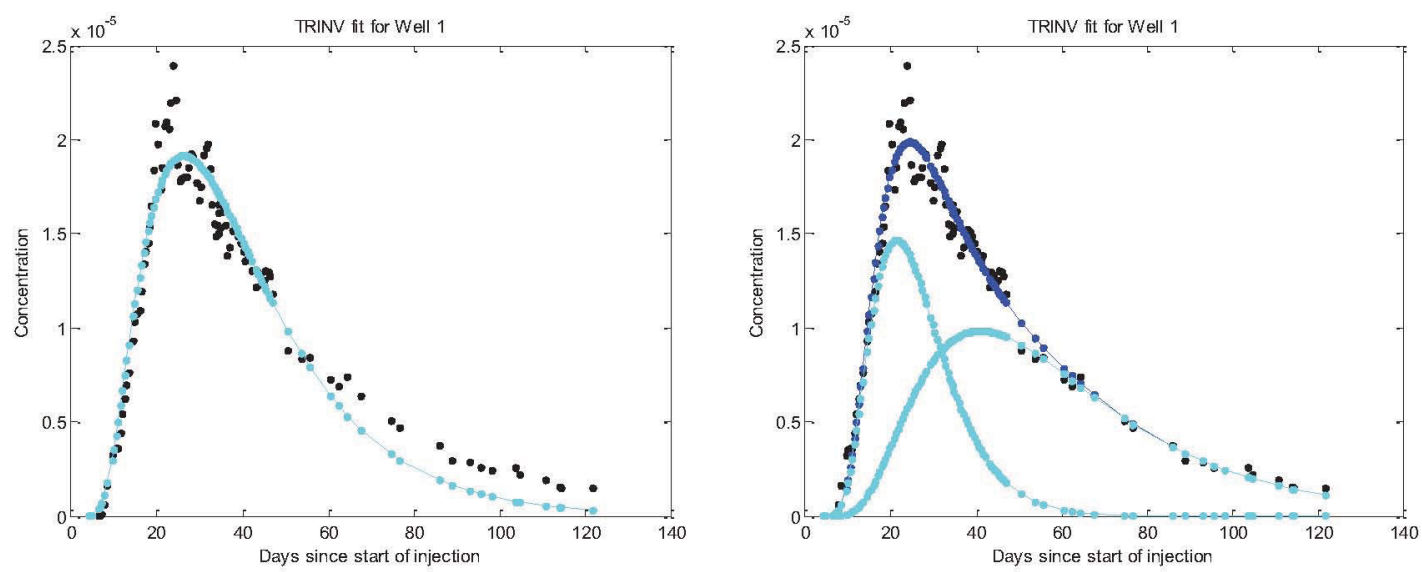

Figure 18. Example graphical output of illustrating aggregate curve fit (dark blue curve) to measured BTC data (symbols) for cases where (A) system is represented with a single fracture set and (B) system is represented as two sets of fractures. Light blue curves illustrate BTCs of the contributing fracture sets.

Table 3. Fitted parameters calculated from fitting equations to BTC data as illustrated in Figure 18.

\begin{tabular}{|l|c|c|c|}
\cline { 2 - 4 } \multicolumn{1}{c|}{} & Single fracture set & \multicolumn{2}{c|}{ Dual fracture set } \\
\hline & Channel 1 & Channel 1 & Channe1 2 \\
\hline Velocity & 40. & 51. & 42. \\
\hline Dispersivity & 203. & 91. & 290. \\
\hline Length & 1239. & 1195. & 2017. \\
\hline Mass fraction & 0.886 & 0.355 & 0.657 \\
\hline
\end{tabular}

\subsubsection{Thermal evolution calculations}

Given estimates of aperture, fracture spacing, path velocity, and path length, thermal evolution of the described fracture sets can be estimated. The ThermalTracer1D uses the Gringarten (1975) solution to describe the temperature evolution of a system of parallel fractures of uniform spacing. The Gringarten solution is described in Laplacian space, which is numerically inverted to provide temperature vs time or space. In practice, Equation A19 of Gringarten 1975 is passed the dimensionless time of eq. A9, $\left(\mathrm{t}_{\mathrm{D}}{ }^{*}\right)$ and $1 / 2$ the dimensionless fracture half spacing, $\mathrm{x}_{\mathrm{ED}}$ (Equation 9). Using typical values for heat-transfer and heat-storage parameters, a velocity of $430 \mathrm{~m} /$ day $^{-1}$ and a fracture aperture of $2 \mathrm{~mm}$, dimensionless outlet temperature, as a function of time for fracture spacings between $15 \mathrm{~m}$ and infinite spacing displays the characteristics shown in Figure 19, demonstrating that even relatively large fractures with high fluxes cool relatively slowly until interfracture spacing becomes quite small. Figure 19 also demonstrates that with large fracture spacing, the Gringarten solution matches the 1D analytical solution for a heat transport to a single isolated fracture, which is the solution used in the cooling calculation of the TRCOOL program (Axelsson 1993) of the ICEBOX software package. 


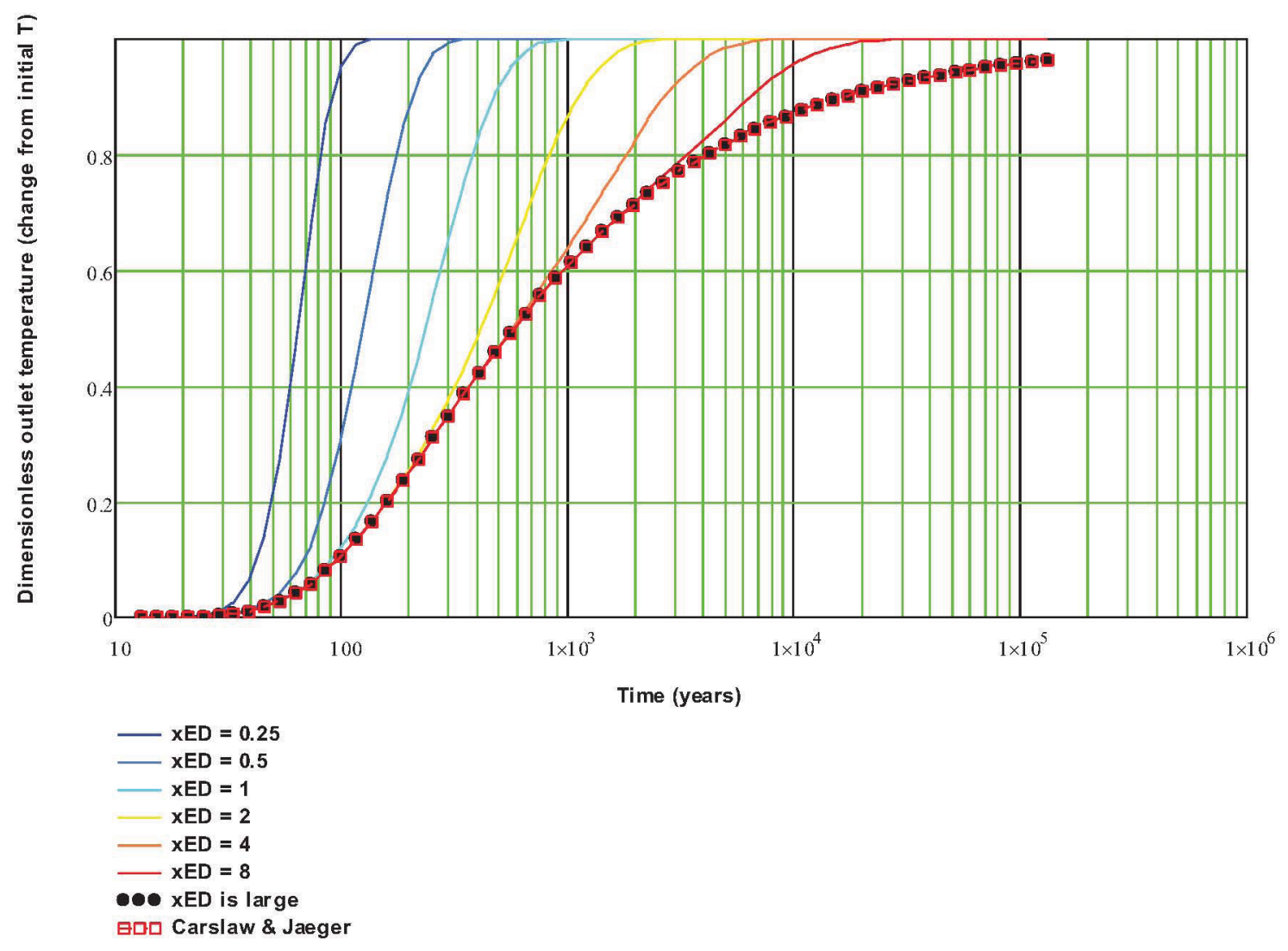

Figure 19. Dimensionless outlet temperature (ordinate axis) vs time for systems of parallel fractures with dimensionless spacing as defined in the legend. In this example, using common heat flow parameters and flow parameters described in the text, the smallest fracture spacing is $15 \mathrm{~m}$. Curve with square symbols illustrates the Carslaw and Jaeger solution for infinite fracture spacing.

\subsubsection{Extension of deterministic approach to temperature-dependent tracer transport}

A conservative tracer test provides a means of estimating average velocity along one or more flow paths, dispersive behavior, and - in some cases - stream tube length. Estimation of thermal behavior, however, requires an estimate of volumetric flow per unit surface area, which is essentially defined by the fracture aperture, $b$. This requires additional information, and the program provides several alternative means of relating tracer characteristics to fracture characteristics.

\subsubsection{Coupling heat transport equation parameters to conservative tracer analysis parameters}

Where equations involving Darcy's law are used, the hydraulic conductivity of a single fracture is assumed to follow the cubic law:

$K=\frac{\rho g}{\mu} \frac{b^{2}}{12}$

with velocity related to pressure drop across the fracture by

$v_{i}=-K \frac{d h}{d x} \stackrel{\text { def }}{=} K \frac{\Delta h}{\mathrm{~L}_{\mathrm{i}}}=\frac{\rho g}{\mu} \frac{b^{2}}{12} \frac{\Delta h}{\mathrm{~L}_{\mathrm{i}}}$ 
The simplest method of estimating aperture from conservative tracer test data is to assume that fracture width (fracture length perpendicular to flow) of the fractures in a particular set $\mathrm{i}$ is constant and known, and that flow is one-dimensional. The aperture can then be determined from the equation

$Q_{i}=v_{i} *$ Area $_{i}=v_{i} * N N f_{i} *\left(b_{i} *\right.$ width $\left._{i}\right)$

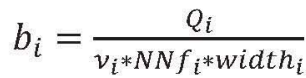

where $\mathrm{NNf}_{\mathrm{i}}$ is the number of fractures in fracture set $\mathrm{i}$.

Alternatively, if the head drop across the system of fractures is known, aperture can be estimated from the equation for velocity in a 1D system. Solving Darcy's law for fracture aperture, assuming the cubic law for fracture hydraulic conductivity gives

$b_{i}=\sqrt{\frac{12 v_{i} \mu}{\rho g} \frac{L_{i}}{\Delta h}}$

With aperture determined from the velocity equation, the number of fractures of specified aperture is again defined by the known volumetric flux associated with a particular set of fractures, and the assumed fracture width. That is, the known volumetric flow through the fracture of calculated aperture $b$ may be through one fracture of width $w$, or through two fractures of width $w / 2$.

If the tracer peak is assumed to travel as in an equivalent dipole flow field (Figure 20) in a single fracture, the necessary characteristics of the dipole flow field can be determined from the inferred velocity and streamtube length, and thus fracture aperture can be calculated from the equation for flow in a dipole:

$Q_{i}=N N f_{i} \frac{\pi K\left(b_{i}\right) b_{i} \Delta h}{\ln \left(\frac{2 r_{f_{i}}}{r_{w}}\right)}=N N f_{i} \frac{\pi \frac{\rho g b_{i}{ }^{3}}{\mu 12} \Delta h}{\ln \left(\frac{2 r_{f_{i}}}{r_{w}}\right)}$

where $r_{f}$ is half the distance between the wells of the dipole.

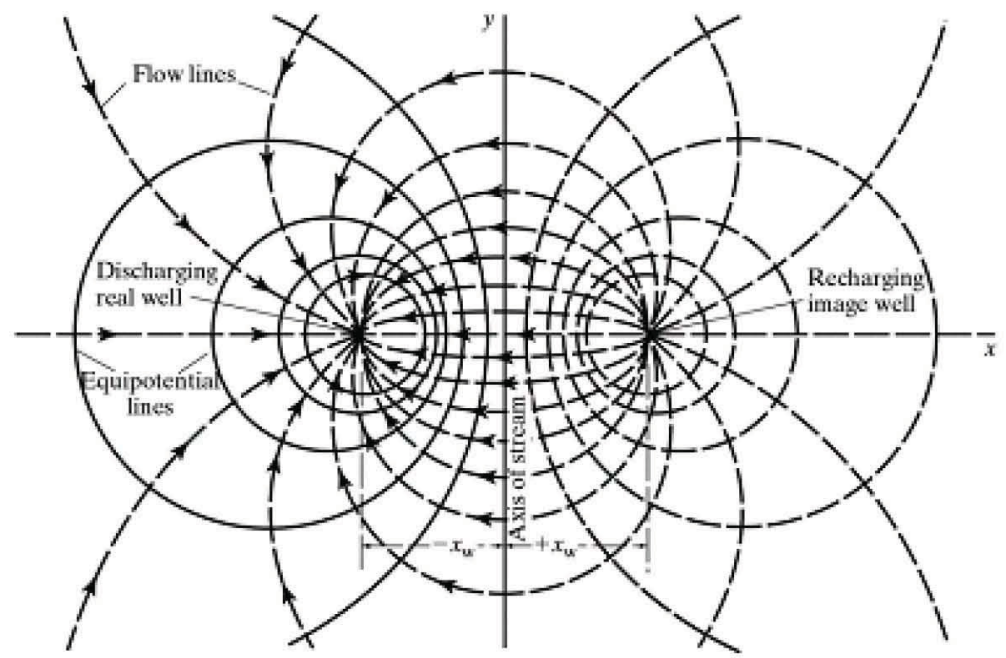

Figure 20. Flow net for a dipole well arrangement, with injection on the right and discharge on the left. 
To calculate the half distance between the wells, $\mathrm{r}_{\mathrm{f}}$, we use the equations for streamtube length and velocity in a dipole presented by Grove and Beetem (1971). For an instantaneous pulse injected into each streamtube of such a system, with dispersion assumed equal to $10 \%$ of streamtube length, the breakthrough curve at the producing well would appear as illustrated in Figure 21A. In this case, the peak of the curve appears at a time equivalent to the travel time through a tube that leaves the injection well at an angle of $43^{\circ}$ from a vector pointing to the production well (Figure 21B).

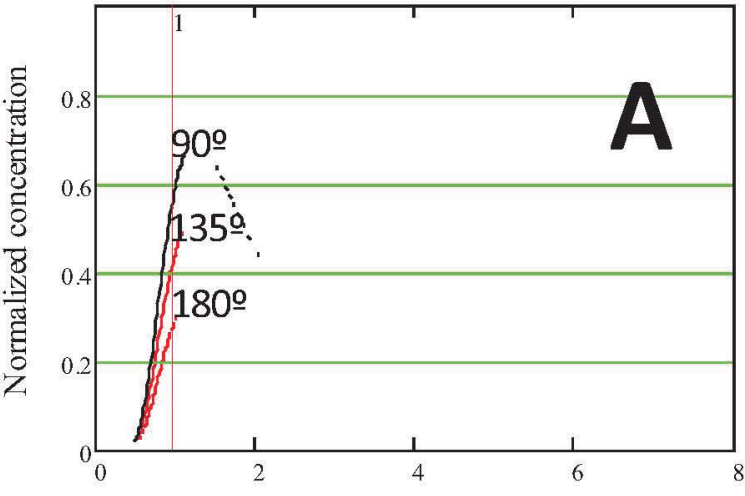

Time relative to shortest travel time

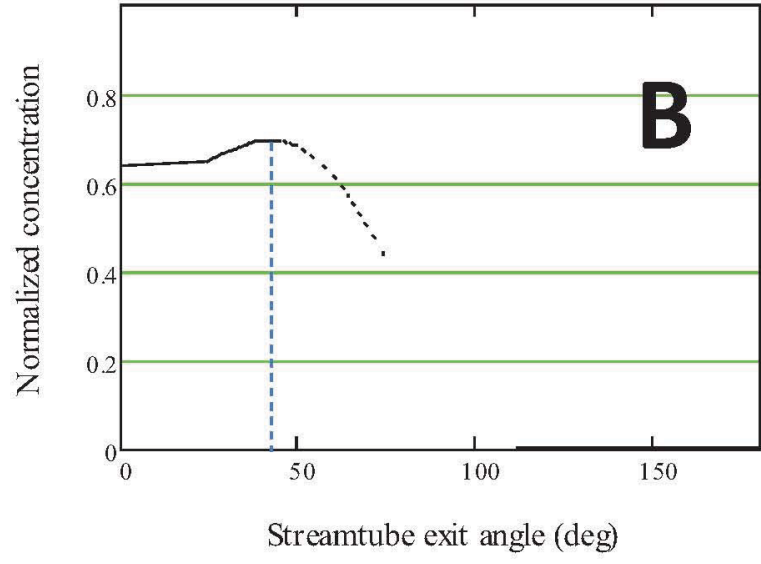

Streamtube exit angle (deg)

Figure 21. Breakthrough curves for a tracer injected into a dipole flow field as a function of (A) time relative to earliest arrival and (B) the exit angle of the streamtube that defines the residence time in the system. Different curves in Panel A reflect ranges of flow paths with specified maximum exit angles, where the exit angle is measured relative to a line connecting the two wells.

Thus the half-distance between the wells, $\mathrm{r}_{\mathrm{f}}$, is related to the length associated with a particular streamtube by (Grove and Beetem 1971, Equation 11)

$L(\alpha)=\frac{2 r_{f} \alpha}{\sin (\alpha)}$

where alpha $=43^{\circ}$ the distance between the wells is $91 \%$ of the calculated streamtube length.

In addition, the Grove and Beetem equation for travel time along a streamtube defined by angle $\alpha$ provides a means of constraining the volumetric flow per unit fracture aperture, $\mathrm{q}_{\mathrm{i}}$. Again assuming that the travel time along the streamtube defined by an angle of $43^{\circ}$ is representative of the travel time associated with the peak concentration of the conservative breakthrough curve, we solve the following equation for $\mathrm{q}_{\mathrm{i}}$.

$t_{\text {trav }}(\alpha)=\left[-\frac{4 \pi * r_{i}{ }^{2}}{q_{i} \sin (\alpha)^{2}} *(\alpha \cot (\alpha)-1)\right]$

With known $\mathrm{r}_{\mathrm{f}}$ and $\mathrm{q}_{\mathrm{i}}$, total volumetric flux through the fracture, $\mathrm{Q}_{\mathrm{i}}$, (from tracer mass balance) fracture aperture can be calculated:

$\frac{Q_{i}}{b_{i}}=q_{i}$

Finally, the number of fractures in set $\mathrm{i}$ can be calculated from the expression for volumetric flow in a dipole system, Equation (31), solved for $\mathrm{NNf}_{\mathrm{i}}$ :

$N N f_{i}=Q_{i} \frac{\ln \left(\frac{2 r_{f_{i}}}{r_{w}}\right)}{\pi\left(\frac{\rho g b_{i}{ }^{3}}{\mu 12}\right) \Delta h}$ 


\subsubsection{Forward and inverse calculation of temperature dependent reactive tracer response}

Calculations of the response of a temperature-dependent reactive tracer test can be performed in forward or inverse mode. The forward mode assumes that BTC data has been entered for a conservative tracer and that necessary parameters defining thermal evolution of a set of fractures have been entered. The required parameters include fracture aperture, interfracture spacing, and time since flow through the fractures was initiated. Temperatures along contributing fracture sets are then combined with the residence time distribution data of the conservative BTC to calculate the corresponding thermal times, where the thermal time is given by Equation (8). In the inverse approach to using reactive tracer data, Tracer Analysis Toolbox attempts to find a set of parameters that satisfy both the conservative and reactive tracer BTC data simultaneously. The primary parameters that are added to the fitted parameter list are fracture aperture and fracture spacing. As discussed in the previous section, fracture aperture can be constrained through hydraulic considerations of varying complexity. Even if fracture aperture is considered independent of the parameters that define the conservative tracer BTC, the addition of the thermal tracer adds only two unknowns. 


\section{FIELD TRACER EXPERIMENT AT RAFT RIVER}

Field testing reactive tracers to monitor thermal drawdown in an actual geothermal reservoir provides a means of identifying potential problems with the method that might not be discovered in laboratory experiments. We therefore established collaboration with U.S. Geothermal, Inc. in 2009 and conducted a field test of the reactive tracer concept in their Raft River reservoir in the summer of 2010 . That site provided several advantages for field testing. It is the closest geothermal reservoir to INL and INL staff is familiar with the history and geology of the site. The reservoir is well characterized and predictions exist for the long-term effect of interference between various sets of wells at the site. For these tests, INL and U.S. Geothermal, Inc. elected to inject tracers at injection well RRG-5 during the annual 2 -month period of injection at that well. Well RRG-5 was originally operated as a full-time injection well but that operation was discontinued after reservoir simulation studies (Holt 2008) indicated that continued injection at that location would lead to relatively rapid thermal drawdown at the primary production wells RRG-1 and RRG-4 after approximately two years (Figure 22). The well is now used for injection only temporarily during the summer months to provide pressure support to the primary production wells and thereby boost power production during the peak demand period.

In practice, reactive tracer injections would take place periodically, in order to attempt to monitor thermal changes in the flow paths connecting injection wells to production wells. To provide a more complete test of the concept, we thus conducted two reactive tracer tests using injection well RRG-5, one at the beginning of the annual injection period and another four weeks later.

Because other changes in the reservoir, such as changes in number and distribution of flow paths connecting the injection well and production well can also affect the recovery of tracer from the system, the second test exposed our field test to a greater range of potential complications than would a single test. Each of our injections paired a reactive tracer with a conservative tracer, with different tracers for each test in order to avoid overlap in recovery.

The interval between the reactive tracer tests that we conducted for this project is much shorter than we envision would be typical in actual application. For a hypothetical EGS, designed to operate on the order of several decades before thermal drawdown reduces production to an uneconomical level, it is reasonable to anticipate that thermal monitoring via reactive tracer tests would be conducted at intervals of no less than one to several years. Holt's reservoir simulations however, suggest that injection at well RRG-5 will lead to rapid thermal drawdown at wells RRG-1 and RRG-4 in less than two years. Thus, while the intent of our second injection was primarily to provide a more complete test of a method that fundamentally requires multiple injections, it appeared possible, though unlikely, that the second test would actually encounter measurably different temperatures along the flow paths connecting the injection well to the production wells. 


\subsection{Raft River Geothermal Field}

The Raft River geothermal reservoir is located in Cassia County Idaho approximately 6 miles north of the Utah/Idaho border near the town of Malta (Figure 23). This site was heavily studied by the U.S. Department of Energy from 1975 to 1982 and was the testing site of the first commercial scale binary (isobutene) cycle geothermal power plant in the world. Presently this site is owned and operated by U.S. Geothermal and is producing power from a 13-MW (nominal) binary isopentane power system.

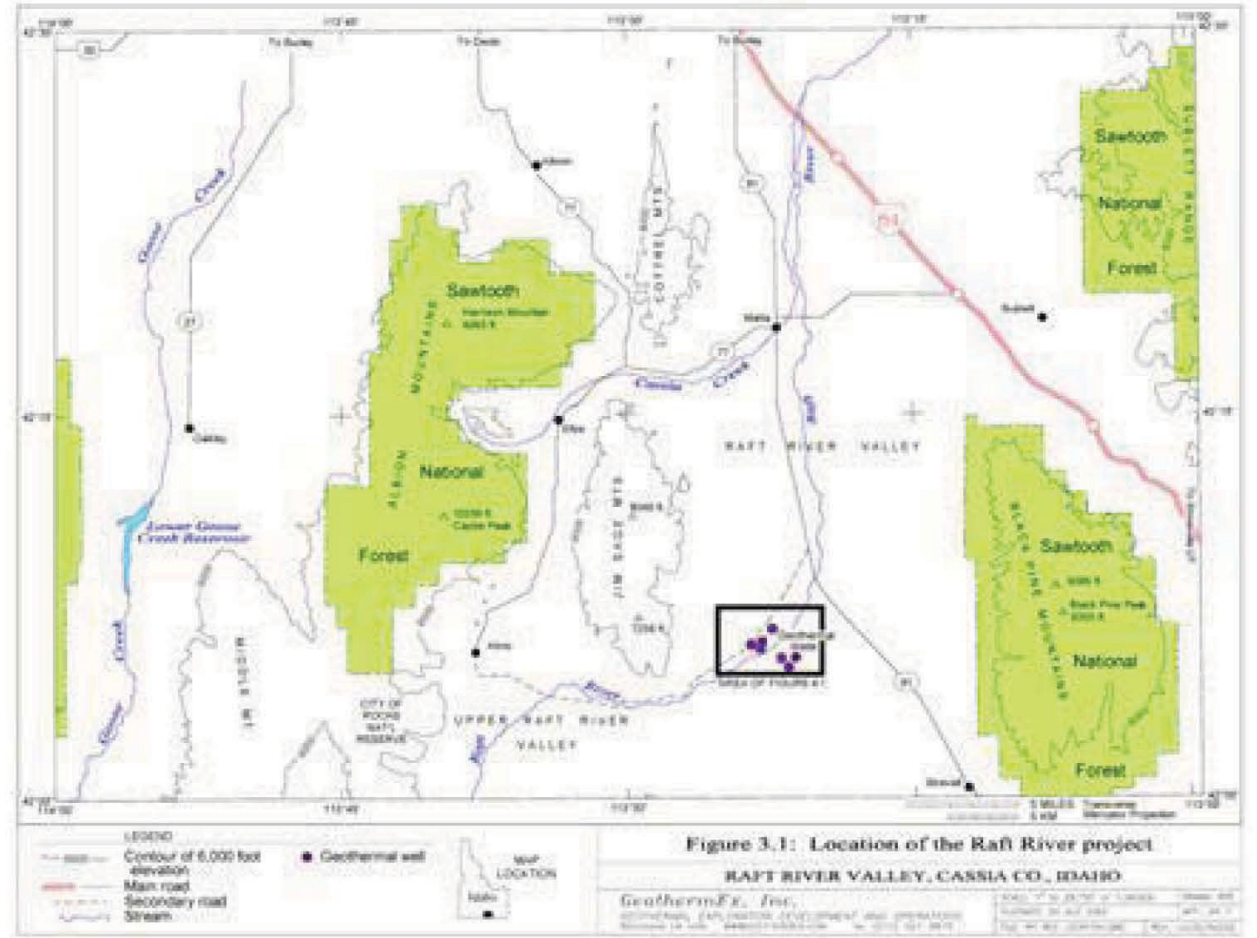

Figure 23. Location of the Raft River geothermal site (from U.S. Geothermal, Inc.).

\subsubsection{Geology}

The geologic structure in the Raft River geothermal area has been extensively studied using geophysical methods, surface mapping, aerial photography and core lithologic descriptions of subsurface core materials. The Raft River geothermal site is located near the southern end of the Raft River northsouth trending valley (Figure 24). This valley is characterized by high-angle normal faulting, low-angle faulting emplacing younger over older rocks, moderate plutonism, and the presence of discontinuous metamorphic terrains (Allman et al., 1982). Beneath the surface alluvium, the Salt Lake Formation is a thick ( 1200 meter) poorly consolidated deposit consisting of siltstone and sandstone. Underlying this formation is a 150 meter metamorphized unit, called the metasediments, consisting of sub-units of schist and quartzite. The base rock is a Precambrian adamellite. The western side of the valley has been down dropped along listric faults in the Bridge and Horse Well Fault zones through the Salt Lake Formation. These faults dip 60 to 80 degrees to the east at the surface and become nearly horizontal in the Tertiary Sediments and may have produced many near vertical open fractures at the base of the sediments. A geophysical anomaly possibly representing a shear zone, called the Narrows zone, exists in the basement Precambrian 


\subsubsection{Hydrology}

The Horse Well and the Bridge Faults are thought to play a significant role in the development of the Raft River geothermal reservoir. Movement along of these faults is believed to have created vertical fractures in the base of the Salt Lake Formation and in the underlying Precambrian metasediments that are responsible for the high well yields. There is some uncertainty in the literature about the role of the Narrows zone plays in recharging the geothermal reservoir. The conceptual model presented by Dolenc et al. (1981) describes recharge through basement fractures, possibly along the southwest extension of the Narrows zone (Figure 25). Allman et al. (1982) describes recharge as lateral transport of water from the Jim Sage Mountains through the faulted metamorphic rocks overlying the adamellite basement. More recently, Holt (2008) successfully modeled the reservoir by applying high permeability zones to the fault and metasediments near the fault intersections. His model included both a lateral recharge component (up to 200 gpm depending on the pressure gradient of cold water) and a constant flux of $175 \mathrm{gpm}\left(380^{\circ} \mathrm{F}\right)$ at the bottom of his model as the best fit through history matching. Tritium analysis of the geothermal reservoir fluids suggests the fluid is at least 60 to 70 years old. Prior to the geothermal development, static water levels were approximately 100 meters above land surface which may of resulted in leakage of the underlying geothermal water along the faults in the Salt Lake Formation creating some level of heating of the upper aquifers. A more recent interpretation chemical analyses from the Raft River wells (Ayling et al., 2011) suggests that the deep geothermal fluids consist of two sets of fluids with little mixing between them. The NW geothermal fluid (fairly equivalent to Dolenc et al., 1981 Type 1 water) effecting wells RRG- 1, 4, and 5 and the SE geothermal fluid located underneath RRG wells 3, 6, 7, and 11 .

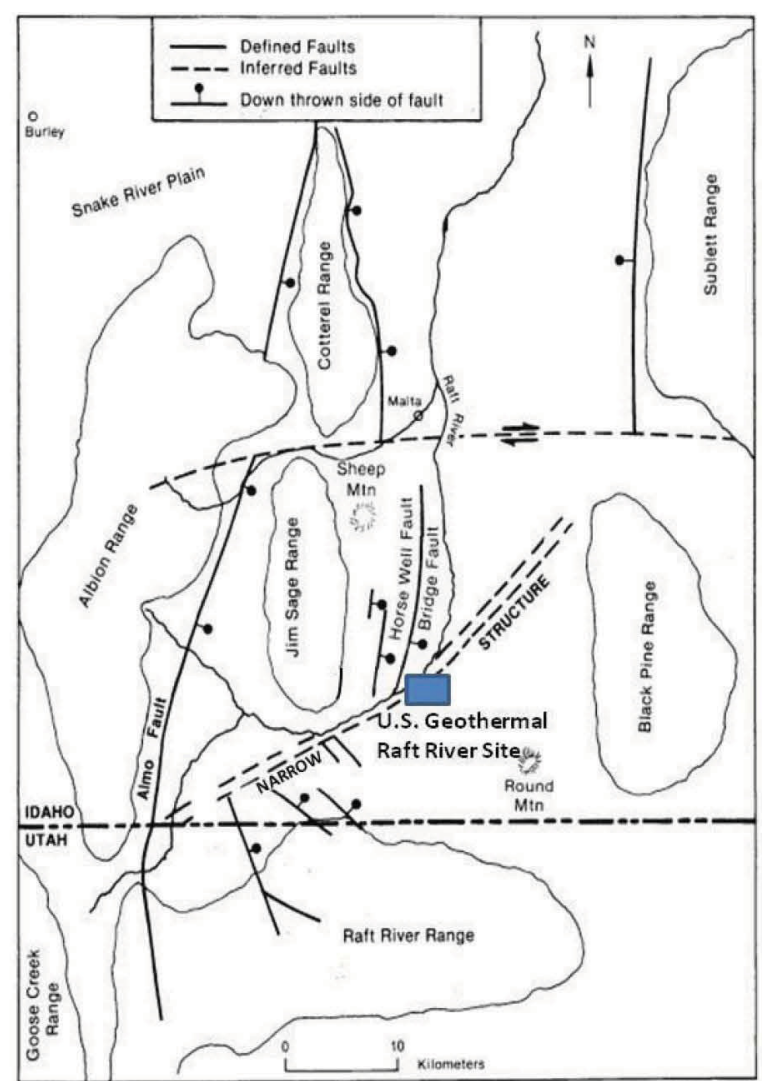

Figure 24. Raft River Valley and major structural features (modified from Dolenc et al., 1981).

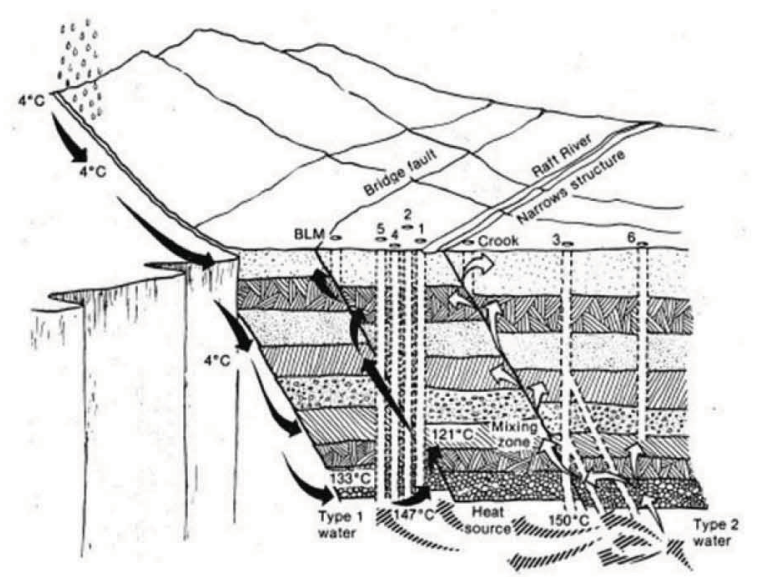

Figure 25. Conceptual model of the hydrology of the Raft River geothermal system (from Dolenc et al., 1981). 


\subsubsection{U.S. Geothermal Interpretation of Reservoir Heat Transport}

Based on the interpreted geology and the geochemistry of previous studies, we can approximate the hydrological flow field for the tracer test as a radially convergent flow field towards the pumping wells in a highly fractured/rubblized semi-confined reservoir. The low confining layer can be considered to be the Precambrian basement and can be considered as semi leaky allowing hot water to enter from the basement layer. The upper confining layer is also leaky with leakage from the reservoir through some of the major faults to the upper aquifers. The listric faulting of the Bridge and Horse Well Faults into the metasediments is believed to have created many fractures in the reservoir. Although the reservoir is composed of fractured rock, Holt successfully modeled the systems as an equivalent porous media with high horizontal permeability. The capture zone created by the pumping of the RRG 1 and 4 production wells extend past the RRG-5 injection well capturing injected fluid at this location as illustrated in the Raft River 2008 tracer test. Estimation of Tracer Response and Tracer Selection

U.S. Geothermal, Inc. conducted a tracer test at Raft River in 2008 to evaluate interwell connectivity and to examine thermal response at the primary reservoir production wells. That test became the model for INL's 2010 field test of the reactive tracer concept because it demonstrated relatively high recovery rates in the primary production wells and provided a priori information for designing a sampling schedule that would capture the tracer breakthrough curve with good resolution.

\subsubsection{U.S. Geothermal, Inc. 2008 Tracer Test Results}

The 2008 tracer test was performed after a several-months-long flow reinjection test at well RRG-5 was initiated on March 3, 2008. Flow rate to the well at that time was $940 \mathrm{gpm}$. One month later, on April 3, $136 \mathrm{kgs}$ (300 lb.s) of fluorescein was added to RRG-5. The tracer was injected as a concentrated solution of fluorescein that was gravity fed into the RRG-5 from two plastic containers in less than 20 minutes. Water samples were collected at various intervals from RRG-1, RRG-2 and RRG-4 for the following 45 days (Figure 26). Holt (2008) simulated this tracer test with his numerical model of the Raft River reservoir. Higher fluorescein concentrations were observed in well RRG-4 than in RRG-1. No fluorescein was seen above background concentrations in well RRG-2. Pumping rates for wells RRG-1 (1080 gpm), RRG-2 (890 gpm), RRG-4 (2130 gpm) and RRG-7 (950 gpm) were fairly constant during the tracer test.

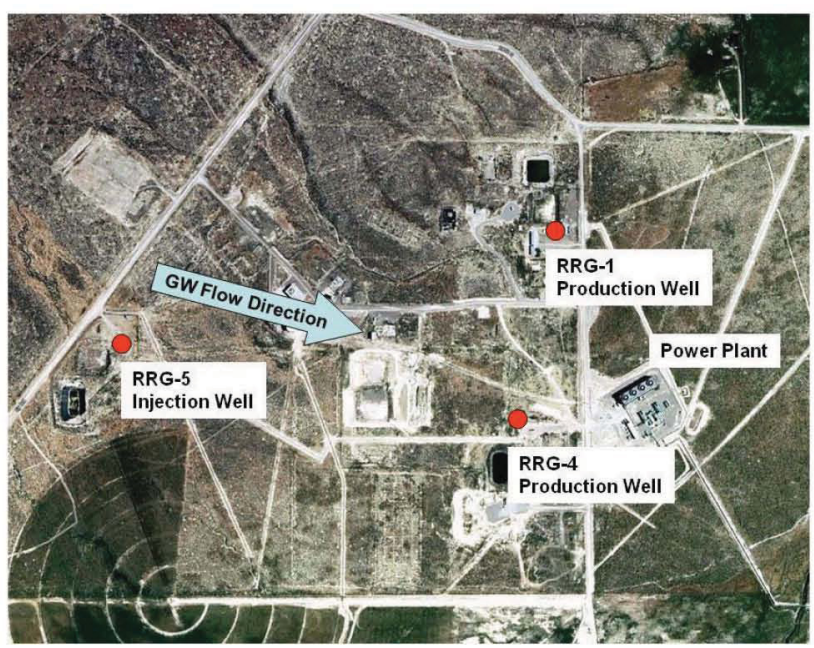

Figure 26. Aerial view of the central portion of the Raft River geothermal site indicating the location of the tracer injection well and the two closest production wells. 
RRG-5 Tracer Injection Test

Tracer Concentrations at RRG-1 and RRG-4

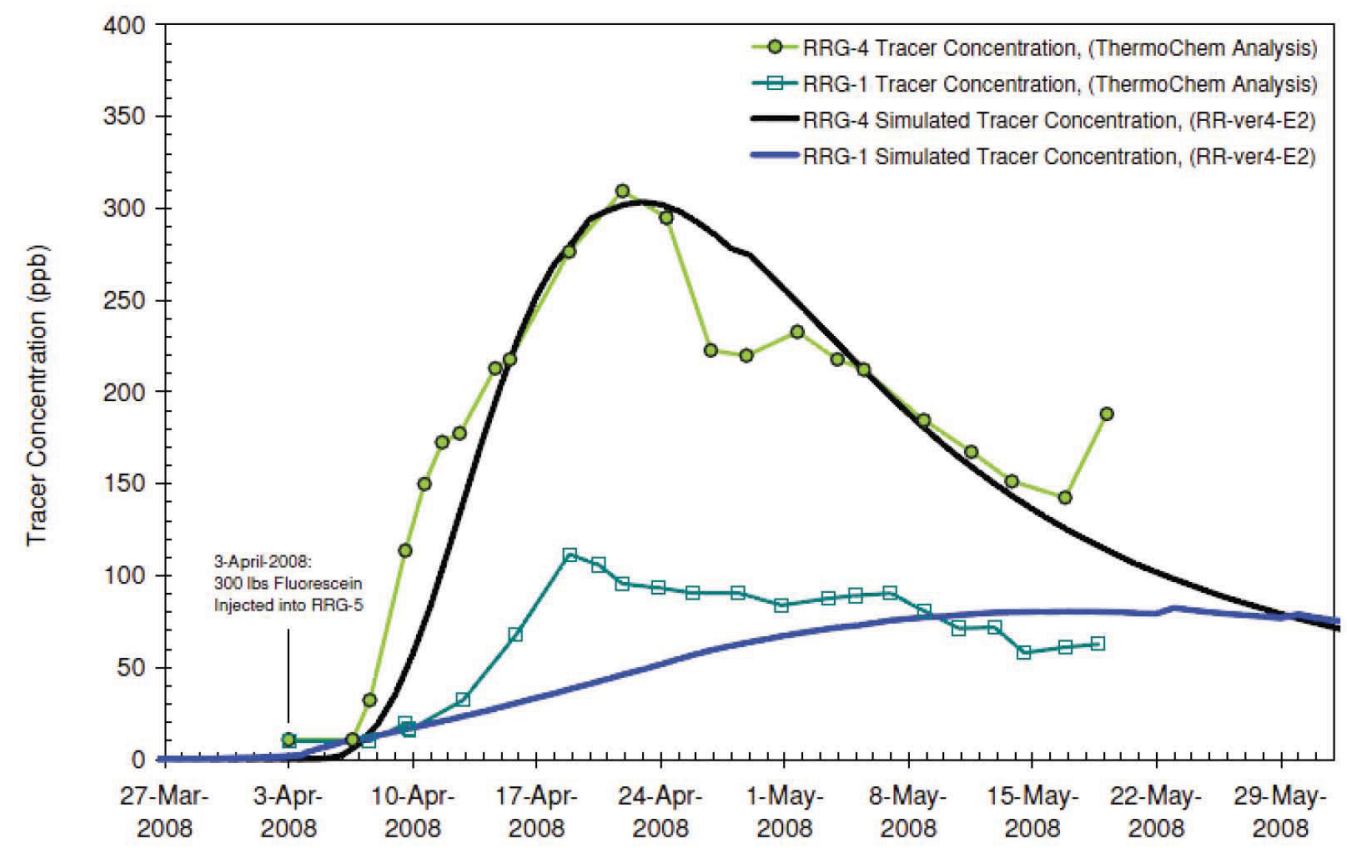

Figure 27. Tracer concentration vs. time following U.S. Geothermal's 2008 tracer test injection.

\subsubsection{Estimated behavior of a reactive tracer in a replication of the 2008 test}

Data from the 2008 fluorescein tracer test was used to estimate response of reactive tracers in the reservoir. Fluorescein concentrations as a function of time were obtained from digitizing the graphical presentation of the tracer test results in the Holt (2008) report (Figure 28). Rather than try to develop a true process-dependent model, we have taken the approach of assuming that the 2008 fluorescein tracer test provides the probability density function of the residence time in the reservoir. Using these residence times, we can then calculate the amount of decay that occurs with the reactive tracers. We therefore fit the tracer test data from RRG-4 with several peak functions using TableCurve 2D (version 5.00). A curve that appeared to represent the data was the gamma function, given by

$C=a \exp \left(-\frac{t-b}{c}\right)\left(\frac{\frac{t-b}{c}+d-1}{d-1}\right)^{d-1}$

where $\mathrm{C}$ is the concentration $(\mu \mathrm{g} / \mathrm{L}), \mathrm{t}$ is the time since the initiation of injection, and $\mathrm{a}, \mathrm{b}, \mathrm{c}$, and $\mathrm{d}$ are fitted parameters. The weights were assumed to be equal to unity. Three points (shown in grey in Figure 28) were not included in the fitting because of their high residuals. Overall, the fit is excellent (Figure 28) with $\mathrm{r}^{2}=0.983$ and a degrees of freedom adjusted $\mathrm{r}^{2}=0.978$, with a fitted standard error of $12.18 \mu \mathrm{g} / \mathrm{L}$. The fitted parameters are provided in Table 4 . All of the parameters are significantly greater than zero as determined by Student's t-test. 


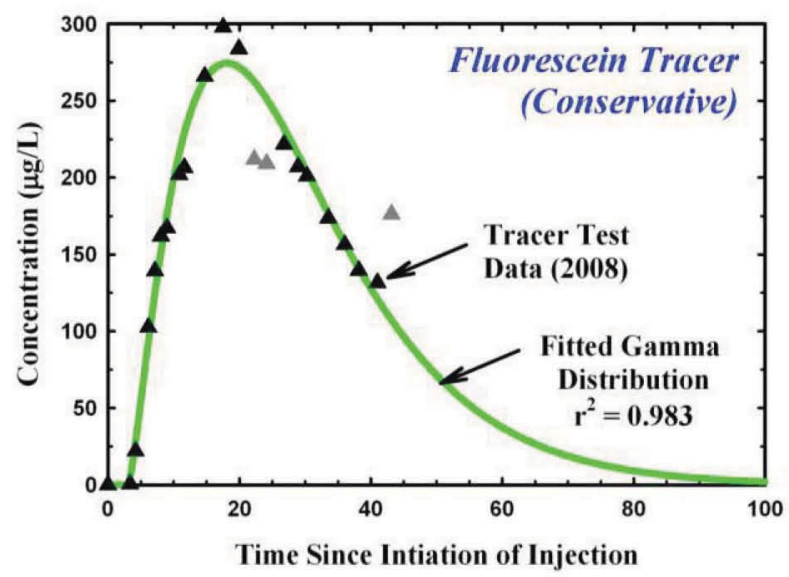

Figure 28. Fitted fluorescein breakthrough curve for RRG-4 from 2008 tracer test (data from Holt 2008).

Table 4. Fitted parameters for fluorescein versus time curve for RRG-4.

\begin{tabular}{|c|r|r|r|c|}
\hline Parameter & \multicolumn{1}{c|}{ Value } & Std Error & t-value & \multicolumn{1}{c|}{$\mathbf{P}>|\mathbf{t}|$} \\
\hline \hline $\mathrm{a}$ & 274.50 & 6.11 & 44.93 & 0.00000 \\
\hline $\mathrm{b}$ & 18.07 & 0.32 & 56.03 & 0.00000 \\
\hline $\mathrm{c}$ & 11.01 & 0.95 & 11.64 & 0.00000 \\
\hline $\mathrm{d}$ & 2.36 & 0.17 & 14.27 & 0.00000 \\
\hline
\end{tabular}

For reactive tracers, we concluded that the amides described by Robinson and Tester (1990) provided the best possibility for success in the temperature ranges expected at Raft River. The rate of decay of the tracer was based on the activation energies and pre-exponential functions provided by Robinson and Tester (1990). The rate of hydrolysis of the esters and amides that they studied are second-order reactions with the rate dependent on both the concentration of the tracer $(\mathrm{C})$ and the $\mathrm{OH}^{-}$concentration:

$\frac{d C}{d t}=-k_{2}\left[O H^{-}\right] C$

where $\mathrm{k}_{2}$ is the $2^{\text {nd }}$-order rate coefficient. The rate coefficient is given by the Arrenhius equation (Equation (6)). The $A$ and $E_{a}$ for the compounds considered in this report are summarized in Table 5. The second-order nature of the hydrolysis reaction (Equation (37)) implies that to determine the rate of tracer degradation requires knowledge of the in-situ $\mathrm{OH}^{-}$concentration.

While some $\mathrm{pH}$ measurements of the groundwater at Raft River have been obtained, they appear to be measurements taken at room temperature or at least at temperatures significantly below the in-situ values. We therefore calculated $\left[\mathrm{OH}^{-}\right]$based on water chemistries reported by Dolenc et al. (1981). The analyses that were used are summarized in Table 6. The speciation was calculated using Phreeqc Interactive (version 2.17.4137, February 25, 2010) (Parkhurst and Apello, 1999). For these calculations we used the LLNL database (llnl.dat 4023 2010-02-09 21:02:42Z dlpark) which is designed to handle calculations up to $300^{\circ} \mathrm{C}$. The calculations were based on the assumption that the measured ion concentrations represent the in-situ concentrations, the water is equilibrated with calcite $\left(\mathrm{CaCO}_{3}\right)$, and the reported temperature is the in-situ temperature. The assumption of equilibrium with calcite is reasonable given the observation of carbonates in the fractures, vugs, and rock matrix at the Raft River site (Dolenc, 1981). The calculated insitu $\mathrm{pH}$ for the 8 wells in Table 6 ranged from 6.211 to 7.197. The median [ $\left.\mathrm{OH}^{-}\right]$for wells RRGE-1, RRGE-4, and RRGE-5 is $13.66 \mu \mathrm{mol} / \mathrm{L}$. Additional calculations were made to determine $\left[\mathrm{OH}^{-}\right]$at $100^{\circ} \mathrm{C}$ by assuming that the initial water chemistry was at the in-situ temperature and at the calculated $\mathrm{pH}$ and 
then re-equilibrating that water with calcite at $100^{\circ} \mathrm{C}$. The calculated $\mathrm{pH}$ at $100^{\circ} \mathrm{C}$ for RRGE-1, RRGE-4, and RRGE-5 ranged from 6.921 to 7.340 and the median $\left[\mathrm{OH}^{-}\right]$is $7.85 \mu \mathrm{mol} / \mathrm{L}$. The effect of temperature on $\mathrm{OH}^{-}$concentration for wells RRG-1, RRG-4, and RRG-5 is shown in Figure 29.

The reactive-tracer breakthrough curves were calculated by assuming the same initial concentrations as used for the conservative tracer, calculating the dilution based on the conservative tracer curve, and then calculating the decay based on the residence time in the reservoir. The simulations are based on two isothermal systems: one at $140^{\circ} \mathrm{C}$ and the other at $100^{\circ} \mathrm{C}$. The results are presented in Figure 30 . Based on the simulated rate of tracer decay and the anticipated length of the injection test, the two reactive tracers selected were butyramide, which was paired with fluorescein in the first injection test, and acetamide, which was paired with napthalene 2,6-disulfonic acid in the second injection test.

Table 5. Pre-exponential factors $(A)$ and activation energies $\left(E_{a}\right)$ for amides (Robinson and Tester, 1990).

\begin{tabular}{|c|c|c|}
\hline Compound & A (liter/mol-sec) & $\mathbf{E}_{\mathbf{a}}(\mathbf{k J} / \mathbf{m o l})$ \\
\hline Acetamide & $4.54 \times 10^{8}$ & $76.0 \pm 10.8$ \\
\hline Butyramide & $2.25 \times 10^{7}$ & $67.6 \times 3.7$ \\
\hline Benzamide & $2.47 \times 10^{5}$ & $49.3 \times 6.9$ \\
\hline
\end{tabular}

Table 6. Water chemistry used to calculate $\left[\mathrm{OH}^{-}\right]$at the Raft River site (Dolenc, et al. 1981).

\begin{tabular}{|c|c|c|c|c|c|c|c|c|c|}
\hline \multirow[b]{2}{*}{ Parameter } & \multirow{2}{*}{$\begin{array}{c}\text { GFW } \\
(\mathrm{mg} / \mathrm{mol})\end{array}$} & \multicolumn{8}{|c|}{ Analyte Concentrations (mg/L) } \\
\hline & & RRGE-1 & RRGE-2 & RRGE-3 & RRGP-4 & RRGP-5 & RRGP-6 & RRGI-7 & MW-4 \\
\hline $\mathrm{Ca}$ & 40.8 & 56 & 42 & 224 & 86 & 41 & 171 & 350 & 160 \\
\hline $\mathrm{Mg}$ & 24.31 & 0.6 & 0.1 & 0.5 & & 0.1 & 1.4 & 1.5 & 0.6 \\
\hline $\mathrm{Sr}$ & 87.62 & 1.4 & 1.2 & 5.2 & 6.4 & 1.2 & 8 & & 1.4 \\
\hline $\mathrm{Na}$ & 22.99 & 455 & 441 & 1194 & 753 & 484 & 2200 & 2200 & 1520 \\
\hline K & 39.1 & 34 & 38 & 105 & & 31 & 32 & & 31 \\
\hline $\mathrm{Li}$ & 6.94 & 1.6 & 1.1 & 3.1 & 3.1 & 1.6 & 5.1 & & 3.7 \\
\hline $\mathrm{HCO}_{3}$ & 61.018 & 41 & 41 & 44 & 42 & 35 & 73 & 32 & 27 \\
\hline $\mathrm{SO}_{4}$ & 96.06 & 36 & 53 & 60 & & 40 & 60 & 64 & 53 \\
\hline $\mathrm{Cl}$ & 35.45 & 776 & 708 & 2260 & 1400 & 800 & 3640 & 4000 & 2610 \\
\hline $\mathrm{F}$ & 19 & 7.9 & 8.7 & 4.9 & 6.3 & 7.2 & 5.7 & 4.9 & 5.6 \\
\hline $\mathrm{SiO}_{2}$ & 60.09 & 121 & 131 & 158 & 104 & 133 & 134 & 83 & 67 \\
\hline Parameter & & RRGE-1 & RRGE-2 & RRGE-3 & RRGP-4 & RRGP-5 & RRGP-6 & RRGI-7 & MW-4 \\
\hline $\mathrm{T}\left({ }^{\circ} \mathrm{C}\right)$ & & 141 & 144 & 149 & 142 & 135 & 71 & 78 & 98 \\
\hline Meas. $\mathrm{pH}$ & & 7.3 & 7.1 & 6.9 & 7.2 & 7.5 & 7.2 & $\mathrm{Nd}$ & 7.7 \\
\hline Calc. pH & & 6.749 & 6.843 & 6.211 & 6.593 & 7.058 & 7.083 & 7.087 & 7.197 \\
\hline Calc. $\left(\mathrm{OH}^{-}\right)$ & $(\mu \mathrm{mol} / \mathrm{L})$ & 13.66 & 18.11 & 5.255 & 10.16 & 23.90 & 2.645 & 3.792 & 11.04 \\
\hline $\mathrm{T}\left({ }^{\circ} \mathrm{C}\right)$ & & 100 & - & - & 100 & 100 & - & - & - \\
\hline Calc. $\mathrm{pH}$ & & 7.077 & - & - & 6.921 & 7.34 & - & - & - \\
\hline Calc. $\left(\mathrm{OH}^{-}\right)$ & $(\mu \mathrm{mol} / \mathrm{L})$ & 8.213 & - & - & 5.933 & 15.02 & - & - & - \\
\hline
\end{tabular}




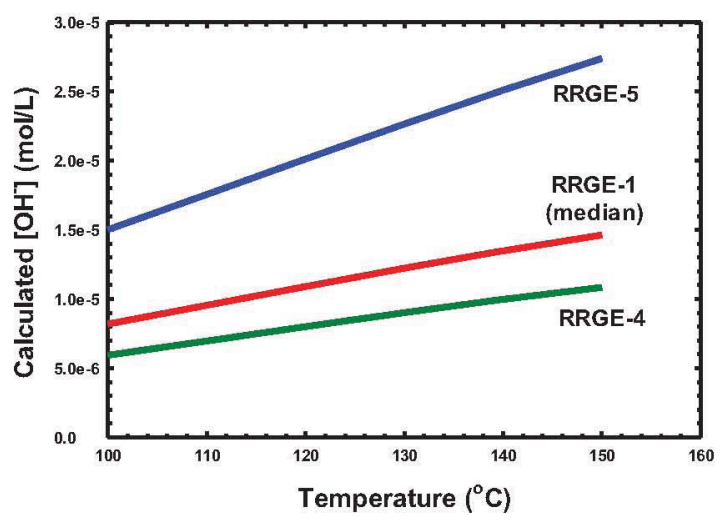

Figure 29. Calculated OH- concentrations for wells used in tracer tests.

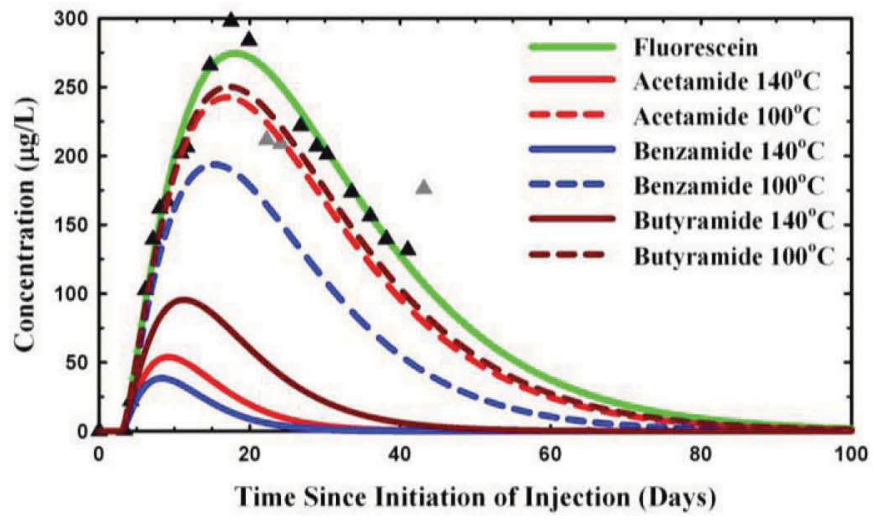

Figure 30. Estimated breakthrough curves for amide reactive tracers based on the 2008 tracer test.

\subsection{Field Activities}

\subsubsection{Tracer Injections}

The well selected for these tests, well RRG-5, has been periodically used as an injection well since 2008 , primarily during the summer months to provide pressure support to RRG-1 and RRG-4. Injection water for RRG-5, as at the other injection wells is a mixture of water produced from wells RRG-1, RRG-2, RRG-4 and RRG-7. Our tracer tests were conducted after onset of this annual injection period had commenced, to ensure that the flow field had reached steady state. Reservoir operations personnel indicated that backpressure does not develop at well RRG-5 during the injection period because of very high permeability in that area. This allowed rapid injection of the large quantity of tracer solutions at the well, as the limiting flow rate for the injection was essentially that of our injection pump.

The two tracer tests were conducted during the summer of 2010. The first injection, consisting of $99 \mathrm{~kg}$ of fluorescein disodium salt and $200 \mathrm{~kg}$ of butyramide (98\%) mixed with 350 gallons of the reservoir reinjection water, was performed on June $21,2010.98 \%$ of the solution was injected ( 7.5 gallons of solution remained in the tank, at a rate of 40 gallons per minute and was completed in approximately nine minutes. The second injection, consisting of $100 \mathrm{~kg}$ of napthalene 2,6-disulfonic acid and $200 \mathrm{~kg}$ of acetamide (99\%) mixed with 300 gallons of the reservoir reinjection water, was performed on July $21,2010.100 \%$ of the solution was injected, at a rate of 30 gallons per minute and the injection was completed in approximately nine minutes. In both tests, the rate of flow of reservoir reinjection water to well RRG-5 was specified as $450 \mathrm{gpm}$. This would represent an injection concentration by about a $0.6 \%$ solution for the conservative tracers and a $1.2 \%$ solution by weight for the reactive tracers. 


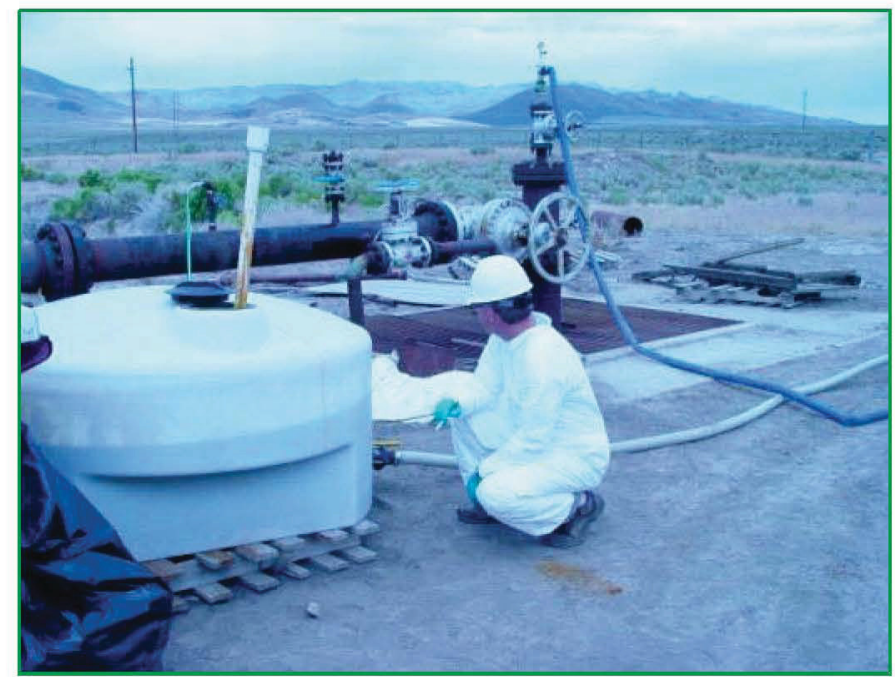

Figure 31. Injection of napthalene 2,6-disulfonic acid sodium salt and acetamide at well RRG-5 on July $21,2010$.

\subsubsection{Sampling}

After tracer injection, water flowing from production wells RRG-1 and RRG-4 was periodically sampled and analyzed for the injected tracers. RRG-1 and RRG-4 are located approximately $790 \mathrm{~m}$ and $740 \mathrm{~m}$, respectively from the injection well, RRG-5 (Figure 26). Sampling at the production wells starting immediately after injection and continued for 170 days. Samples were collected in $250-\mathrm{ml}$ amber glass jars and stored on-site at $4^{\circ} \mathrm{C}$. Pumping rates from the production wells were fairly constant during the tracer sampling (RRG-1 1060 gpm, RRG-2 0 gpm, RRG-4 2190 gpm, and RRG-7 1260 gpm). The pumping rates from the production wells for the 2010 tracer tests, with the exception of RRG-2, were very similar to those during the 2008 tracer test.

\subsubsection{Reservoir conditions during field tracer test period}

\subsubsection{Flow}

The injection into RRG-5 and the extraction from RRG-1 and -4 were fairly constant during the 2010 tracer injection tests. Injection and extraction rates for each of the wells (Figure 32) are plotted as a function of time after the first 2010 tracer test injection at RRG-5.

\subsubsection{Temperature}

Temperatures in the reservoir (Figure 33) change over time. For the two production wells involved in the tracer test (RRG1 and RRG4) there have been small decreases in temperature since late 2007. The temperature in

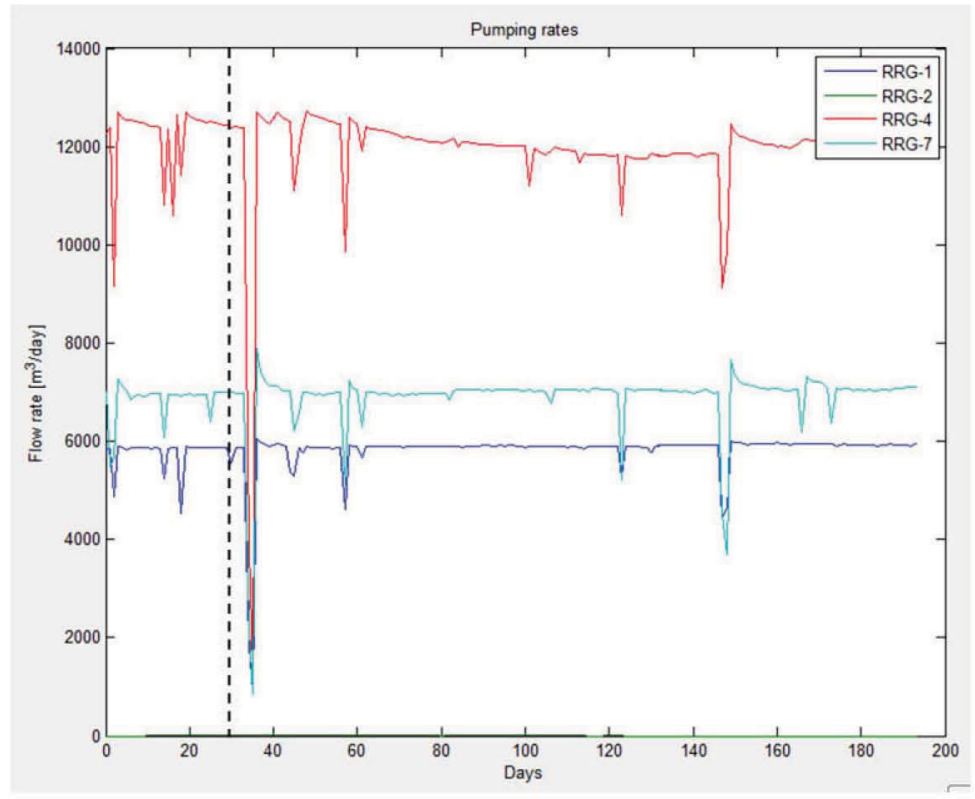

Figure 32. Production rates from Raft River wells over the span of the tracer test. Time (days) axis begins at time of injection of the first (June 21, 2010). Dashed line indicates time of second injection. 
RRG1 was relatively constant at $139.1 \pm 0.2^{\circ} \mathrm{C}$ until July, 2009. After July, 2009, the temperatures were relatively constant at $137.2 \pm 0.6^{\circ} \mathrm{C}$. The differences in the mean values are statistically significant $(\mathrm{t}=$ $66.4, \mathrm{df}=754, \mathrm{p}<0.001)$; however, the difference is relatively small $\left(1.9^{\circ} \mathrm{C}\right)$. The temperature in $\mathrm{RRG} 4$ shows a decline over time with the rate of decline greatest between December 2007 and March 2009. After March, the rate of decline has decreased. The temperatures have decreased from approximately $136.8^{\circ} \mathrm{C}$ to $133.5^{\circ} \mathrm{C}$ in December 2010 .

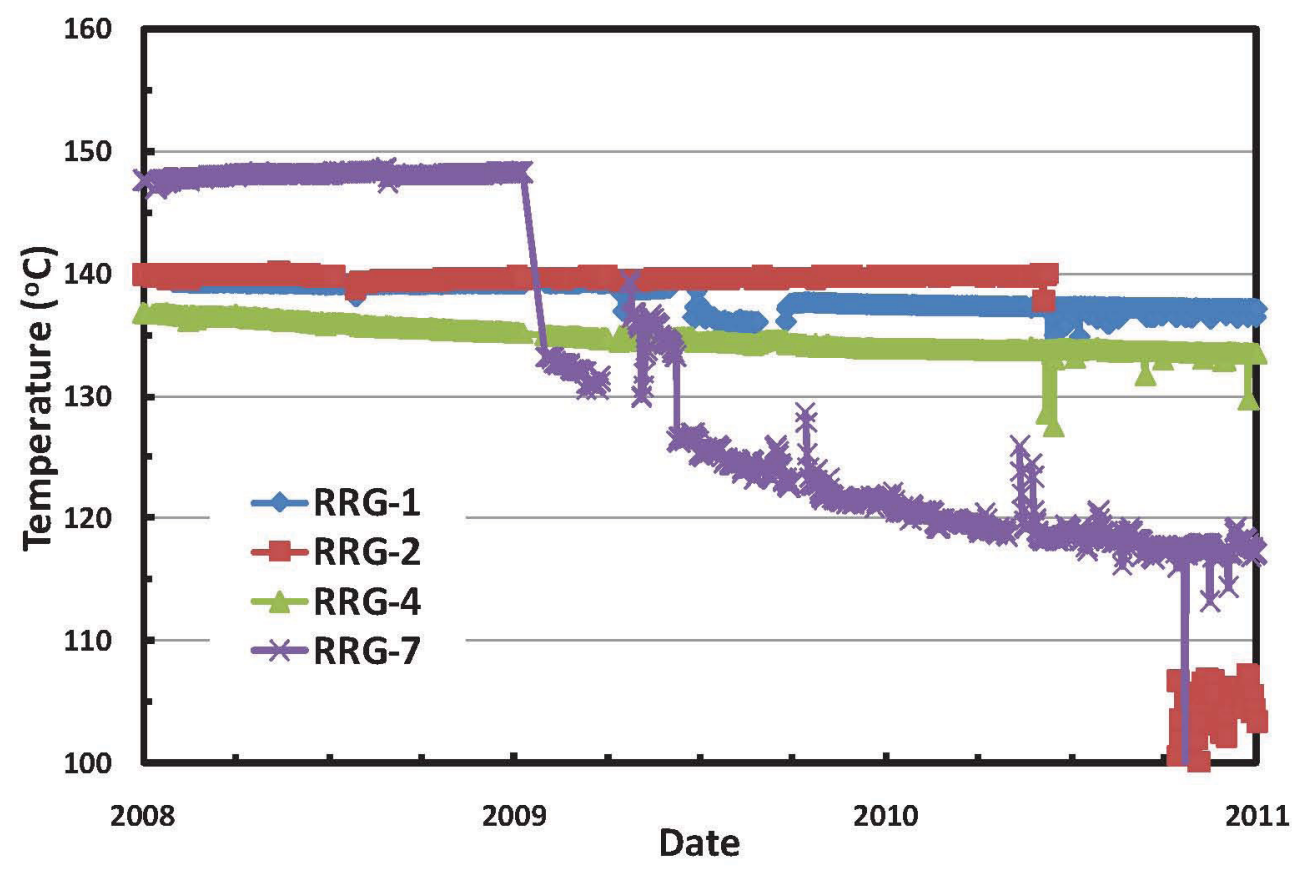

Figure 33. Temperature in production wells RRG1, RRG2, RRG4, and RRG7 over time.

\subsubsection{Field $\mathrm{pH}$}

As discussed in Section 6.1.5, the hydroxide concentration is very important for determining the rate of degradation of the reactive tracers used in our study. In order to determine the hydroxyl concentrations, one has to make some assumptions to determine the $\mathrm{pH}$ of the reservoir fluids. In Section 6.2.2, we estimated the $\mathrm{pH}$ by assuming the reservoir fluids were equilibrated with calcite.

Because of the importance of $\mathrm{pH}$ (or hydroxyl concentration) for the interpretation of reactive tracers in geothermal systems, we initiated a small study of existing technologies for the direct measure of $\mathrm{pH}$. The direct measure of the $\mathrm{pH}$ would be an improvement over making calculations based such assumptions about the geochemistry of the system. Measurement of $\mathrm{pH}$ at elevated temperatures is challenging and common glass electrodes do not function at temperatures greater than $100^{\circ} \mathrm{C}$ and even some specialized electrodes do not function at temperatures above $130^{\circ} \mathrm{C}$. Several metal/metal oxide electrodes are known to work at higher temperatures. $\mathrm{Zr} / \mathrm{ZrO}_{2} \mathrm{pH}$ electrodes are reported to work well (Zhang et al., 2008) and are known to work at temperatures as high as $343^{\circ} \mathrm{C} \mathrm{(e.g.,} \mathrm{Corr} \mathrm{Instruments,} \mathrm{2009).} \mathrm{We} \mathrm{acquired} \mathrm{a} \mathrm{Corr}$ Instruments $\mathrm{Zr} / \mathrm{ZrO}_{2} \mathrm{pH}$ electrode with a high temperature, high pressure $\mathrm{Ag} / \mathrm{AgCl}$ reference electrode to test and to aid in the design procedures by which we can obtain reliable $\mathrm{pH}$ measurements of geothermal fluids. Corr Instruments (2009) suggests that the $\mathrm{Zr} / \mathrm{ZrO}_{2} \mathrm{pH}$ electrode cannot be used below $93^{\circ} \mathrm{C}$ due to the slow response of the electrode below this temperature. The upper temperature limit for this system is about $305^{\circ} \mathrm{C}$ which is determined by the performance of the $\mathrm{Ag} / \mathrm{AgCl}$ reference electrode.

According to Zhang et al. (2008), the overall electrochemical cell for the $\mathrm{Zr} / \mathrm{ZrO}_{2} \mathrm{pH}$ electrode with a $\mathrm{Ag} / \mathrm{AgCl}$ reference electrode is 
$\mathrm{Ag}|\mathrm{AgCl}| \mathrm{Cl}^{-}, \mathrm{H}^{+}, \mathrm{H}_{2} \mathrm{O} \mid \mathrm{ZrO}_{2} \mathrm{Zr}$

The cell potential, $\Delta \mathrm{E}_{\mathrm{T}, \mathrm{P}}$ is

$\Delta E(V)_{T, P}=\Delta E_{\text {cell }}^{o}+\frac{\ln (10) R T}{F}\left[\log a\left(C l^{-}\right)-\frac{1}{2} \log a\left(H_{2} O\right)\right]-\frac{\ln (10) R T}{F} p H_{T, P}$

where $\Delta E_{\text {cell }}^{o}$ is the cell potential at standard state, $\mathrm{R}$ is the gas constant $\left(8.314 \mathrm{~J} \mathrm{~K}^{-1} \mathrm{~mol}^{-1}\right), \mathrm{F}$ is Faraday constant $\left(96487 \mathrm{C} \mathrm{mol}^{-1}\right)$, and $\mathrm{a}\left(\mathrm{Cl}^{-}\right)$and $\mathrm{a}\left(\mathrm{H}_{2} \mathrm{O}\right)$ are the activities of the chloride ion and water, respectively. Zhang et al. (2008) were able to demonstrate that their electrode system at $20^{\circ} \mathrm{C}$ yielded a slope of -0.05822 volts $/(\mathrm{pH}$ unit) which is very close to the theoretical value of $-0.05819 \mathrm{volts} /(\mathrm{pH}$ unit). The intercept of the $\Delta \mathrm{E}_{\mathrm{T}, \mathrm{P}}$ versus $\mathrm{pH}$ curve (at $20^{\circ} \mathrm{C}$ ), $\Delta E_{\text {cell }}^{o}$, is $0.4872 \mathrm{~V}$. The slope they obtained at $200^{\circ} \mathrm{C}$ is $-0.0979 \mathrm{~V} / \mathrm{pH}$ which is slightly less than the theoretical value of $-0.09388 \mathrm{~V} / \mathrm{pH}$. Plots of $\Delta \mathrm{E}_{\mathrm{T}, \mathrm{P}}$ versus $\mathrm{pH}$ for $20^{\circ}$ and $200^{\circ}$ had $\mathrm{r}^{2}$ values of 0.997 , and 0.99 , respectively. These results suggest that we should be able to obtain slopes to within a few percent of the theoretical value.

Calibration of our $\mathrm{Zr} / \mathrm{ZrO}_{2}$ electrode were performed in the laboratory using $\mathrm{NaOH}(0.001 \mathrm{~mol} / \mathrm{kg})$ and $\mathrm{H}_{2} \mathrm{SO}_{4}(0.00005 \mathrm{~mol} / \mathrm{kg})$. Plots of $\mathrm{pH}$ versus temperature for $0.00005 \mathrm{~m} \mathrm{H}_{2} \mathrm{SO}_{4}$ and $0.001 \mathrm{~m} \mathrm{NaOH}$ obtained from Corr Instruments (2009), Table A-3, Appendix B, were fit with arbitrary functions (Figure 34 and Figure 35) for interpolation. The statistics for the regressions are summarized in Table 7.

Electrode potential measurements were obtained in the laboratory using $0.00005 \mathrm{~m} \mathrm{H}_{2} \mathrm{SO}_{4}$ and 0.001 $\mathrm{m} \mathrm{NaOH}$. The electrodes were mounted through ports in the lid of a 1L Parr high temperature/ high pressure reaction vessel. Potential measurements were taken with a high impedance Jenco $\mathrm{pH}$ meter (model number $6173 \mathrm{pH}$ ). The data are summarized in Figure 36 and Figure 37. The associated statistics for the regressions are summarized in Table 8 . At a given temperature, the $\mathrm{pH}$ and electrode potentials for each of the buffers can be obtained from the regression equations provided in Table 7 and Table 8 , respectively. These values can be used to plot $\Delta E_{T, P}$ versus $\mathrm{pH}$ for each temperature of interest (Figure 38). For our case, these curves are somewhat trivial with two data points each, one for the $\mathrm{H}_{2} \mathrm{SO}_{4}$ buffer and one for the $\mathrm{NaOH}$ buffer. The slopes of the $\Delta E_{T, P}$ versus $\mathrm{pH}$ were calculated from

$$
\text { slope }_{\text {meas }}(T, P)=\frac{\Delta E_{T, P}(\mathrm{NaOH})-\Delta E_{T, P}\left(\mathrm{H}_{2} \mathrm{SO}_{4}\right)}{p H_{T, P}(\mathrm{NaOH})-p H_{T, P}\left(\mathrm{H}_{2} \mathrm{SO}_{4}\right)}
$$

A plot of the slopes versus temperature (Figure 39) for the measured data do not compare well with the theoretical Nerst slope given by

$$
\text { slope }_{\text {theor }}(T)=-\frac{\ln (10) R T}{F}
$$

suggesting that $\mathrm{pH}$ measurements obtained with this calibration are likely to be unreliable. There are several possible reasons for this poor behavior:

1. Contamination of the $\mathrm{NaOH}$ buffer by $\mathrm{CO}_{2}$,

2. Lack of equilibrium between the electrode and the solution due to insufficient time at any given temperature,

3. Changes in the concentrations of ions in solution due to the loss of water to the vapor phase or the gain of $\mathrm{CO}_{2}$ from the air phase above the water during heating,

4. Part of the reference electrode may not be at the same temperature as the tip of the electrode,

5. Incorrectly prepared buffers. 
We are currently exploring these possibilities before we recalibrate the electrode system.

According to Equation (38), the $\mathrm{pH}$ should depend on the $\mathrm{Cl}^{-}$activity. If the chloride activity is the same in all samples and buffers, this term can be combined with $\Delta E_{\text {cell }}^{o}$ and the result is just a constant intercept in the $\Delta E_{T, P}$ versus $\mathrm{pH}$ plot and the electrode could be calibrated in the typical manner. However, the chloride concentrations of the buffers as well as the samples are likely to vary substantially.

Therefore, the data should be plotted and analyzed as $\Delta E_{T, P}$ versus $\left(\mathrm{pH}-\log \mathrm{a}\left(\mathrm{Cl}^{-}\right)\right)$and once that value is determined, the $\mathrm{pH}$ can be calculated from the known chloride concentration of the sample. The effect of chloride on the measurement of $\mathrm{pH}$ is not mentioned in the Corr Instruments (2009) instruction manual. The buffers prepared by Zhang et al. (2008) contain 3.5\% NaCl.

In order to obtain reliable $\mathrm{pH}$ measurements, some type of flow through electrode system is needed to ensure that the water remains in the liquid state and to minimize the loss of volatiles such as $\mathrm{CO} 2$, which can alter the $\mathrm{pH}$. We adapted a Parr 1-L high-temperature/high-pressure reaction vessel for this purpose and tested the setup at RRG1 (Figure 40). The vessel appeared to work very well except that the measured temperature in the vessel was close to $131^{\circ} \mathrm{C}$ which is about $10^{\circ} \mathrm{C}$ lower than the temperature reported by Dolenc et al. (1981). In our next trial, we will better insulate the tubing and reaction vessel in order to minimize heat loss.

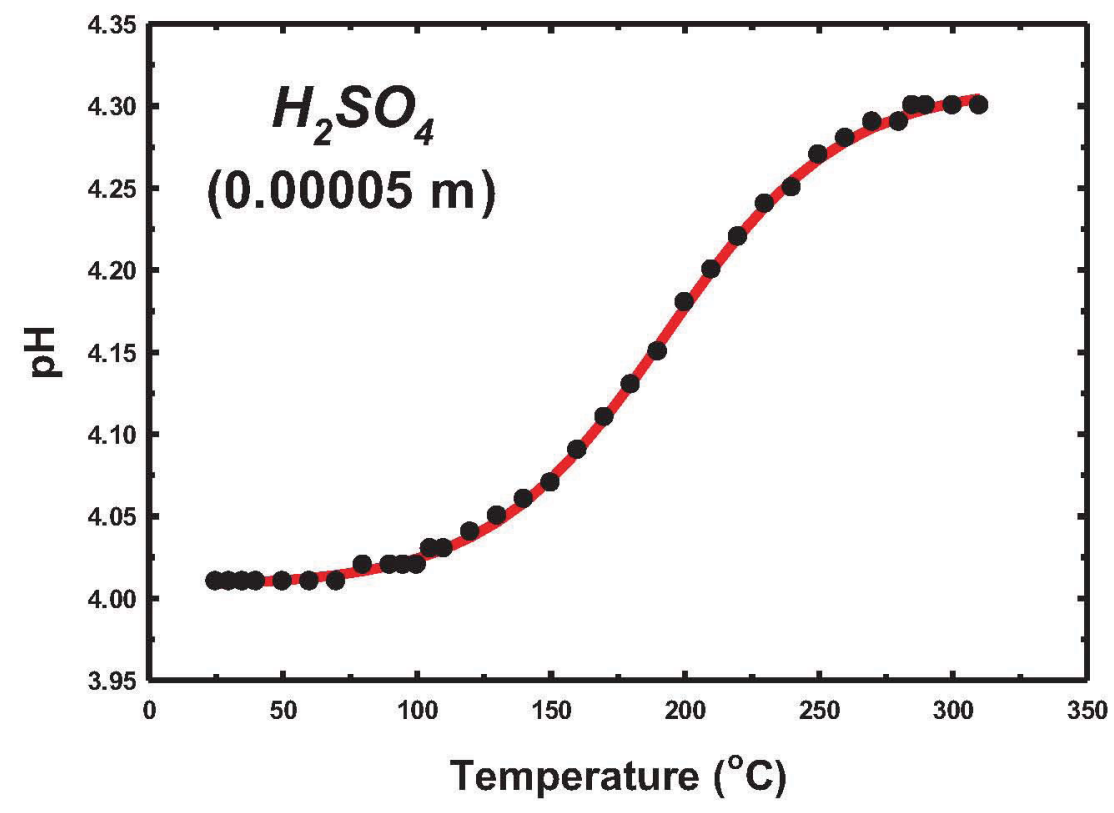

Figure 34. $\mathrm{pH}$ versus temperature for $0.00005 \mathrm{~m} \mathrm{H}_{2} \mathrm{SO}_{4}$. Solid curve is fitted sigmoid function with $\mathrm{r}^{2}=$ 0.9995 and stand error of the fit $=0.00273$. 


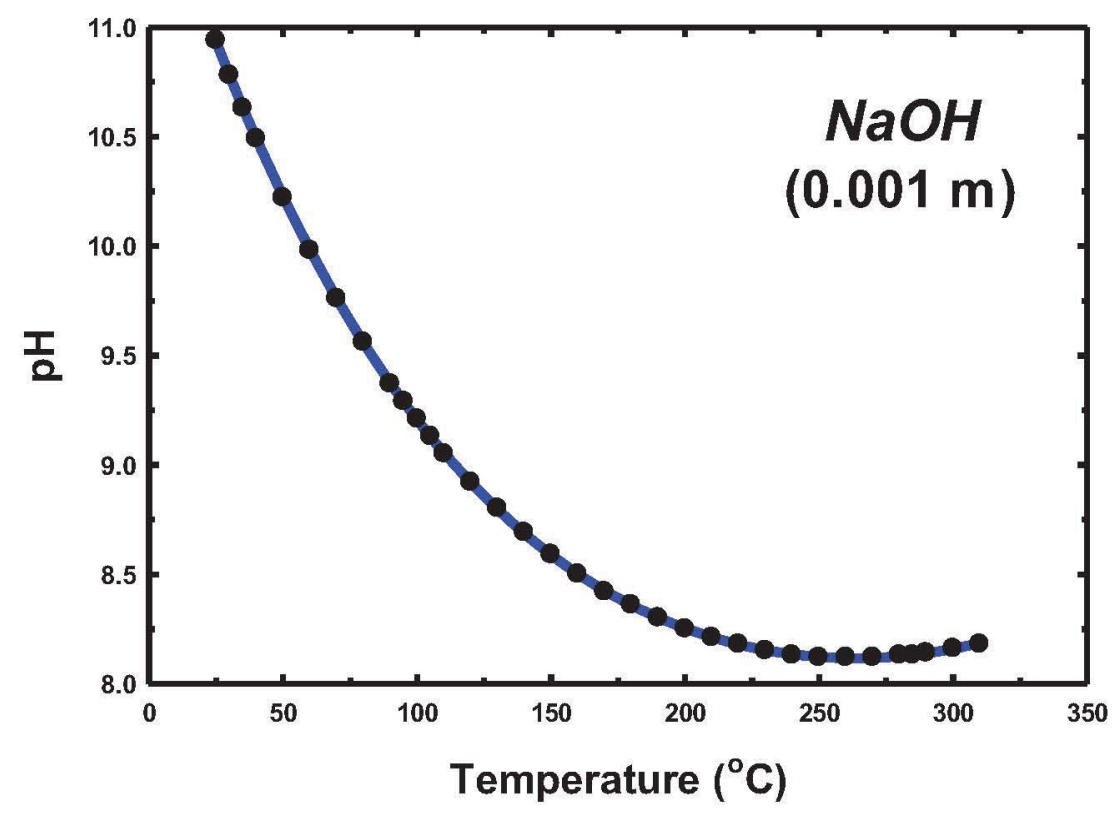

Figure 35. $\mathrm{pH}$ versus temperature for $0.001 \mathrm{NaOH}$. Solid curve is a fitted fourth-order polynomial with $\mathrm{r}^{2}$ $=0.999987$ and standard error of the fit $=0.00345$.

Table 7. Summary statistics for regression lines used in Figure 34 and Figure 35.

\begin{tabular}{|c|c|c|}
\hline Buffer & $\mathbf{H}_{\mathbf{2}} \mathbf{S O}_{\mathbf{4}}$ & $\mathbf{N a O H}$ \\
\hline \hline Concentration (m) & 0.00005 & 0.001 \\
\cline { 2 - 3 } Equation & $p H=a+\frac{b}{1+\exp \left(-\frac{T-c}{d}\right)}$ & $p H=a+b T+c T^{2}+d T^{3}+e T^{4}$ \\
\hline $\mathbf{r}^{2}$ & 0.9995 & 0.999986 \\
$\mathbf{r}_{\text {adi }}^{2}$ & 0.9994 & 0.999984 \\
Std Err Fit & 0.0027 & 0.0035 \\
\hline $\mathbf{a}$ & $4.0070 \pm 0.0011$ & $11.8044 \pm 0.0059$ \\
$\mathbf{b}$ & $0.3060 \pm 0.0025$ & $-0.038419 \pm 0.00022$ \\
$\mathbf{d}$ & $192.55 \pm 0.68$ & $0.0001507 \pm 0.0000026$ \\
$\mathbf{e}$ & $32.81 \pm 0.65$ & $(-2.908 \pm 0.14) \times 10^{-7}$ \\
\cline { 2 - 3 } & --- & $(2.67 \pm 0.17) \times 10^{-10}$ \\
\hline
\end{tabular}




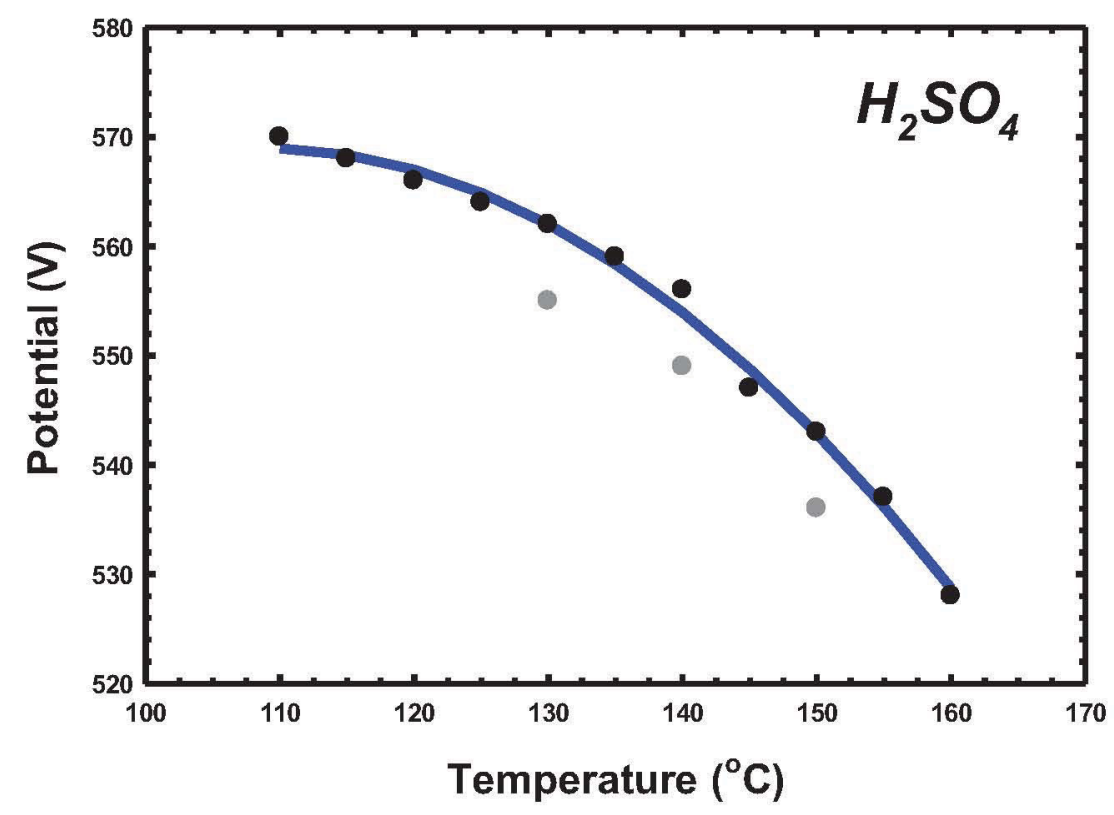

Figure 36. Electrode potential for $0.00005 \mathrm{~m} \mathrm{H}_{2} \mathrm{SO}_{4}$ obtained in the laboratory by Earl Mattson. Solid line is the regression line for the first cooling cycle. Black dots are data from the first cooling cycle used in the regression, gray dots are measurements from the 2nd cooling cycle that were not used in the regression. Statistics for the regression line are summarized in Table 8.

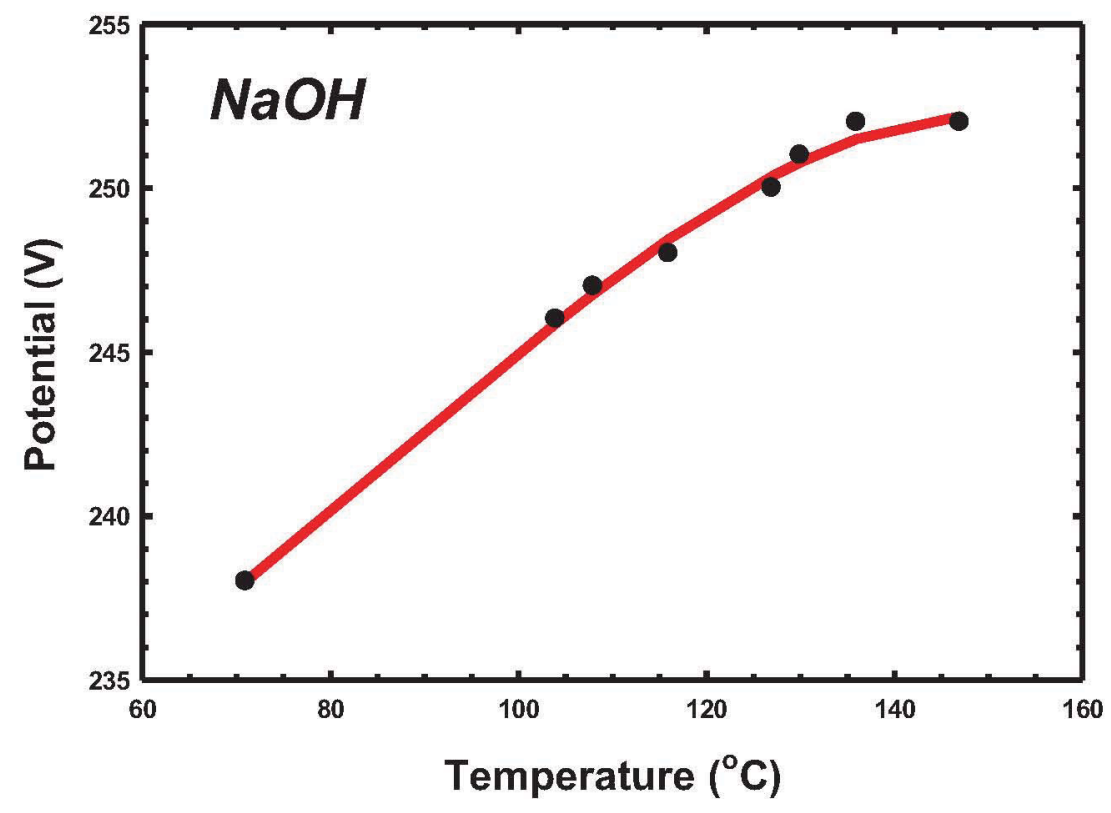

Figure 37. Electrode potential for $0.001 \mathrm{~m} \mathrm{NaOH}$ obtained in the laboratory. Solid line is the regression line for the first cooling cycle. Black dots are data from the first cooling cycle used in the regression. Statistics for the regression line are summarized in Table 8. 
Table 8. Summary statistics for regression of electrode potential versus temperature for $\mathrm{H}_{2} \mathrm{SO}_{4}$ and $\mathrm{NaOH}$ buffers.

\begin{tabular}{|c|c|c|}
\hline Buffer & $\mathbf{H}_{\mathbf{2}} \mathbf{S O}_{\mathbf{4}}$ & $\mathbf{N a O H}$ \\
\hline \hline $\begin{array}{c}\text { Concentration (m) } \\
\text { Equation }\end{array}$ & 0.00005 & 0.001 \\
\cline { 2 - 3 } & $\Delta E_{T, P}=a+b T+c T^{2}$ & $\Delta E_{T, P}=a+b T^{2}+c T^{4}$ \\
\hline $\mathbf{r}^{2}$ & 0.9937 & 0.9952 \\
$\mathbf{r}_{\text {adi }}^{2}$ & 0.9911 & 0.9916 \\
Std Err Fit $^{2}$ & 1.22 & 0.38 \\
\hline $\mathbf{a}$ & $389.3 \pm 30.3$ & $228.55 \pm 0.88$ \\
$\mathbf{b}$ & $3.31 \pm 0.45$ & $0.00211 \pm 0.00014$ \\
$\mathbf{c}$ & $-0.0152 \pm 0.0017$ & $-(4.71 \pm 0.50) \times 10^{-8}$ \\
\hline
\end{tabular}

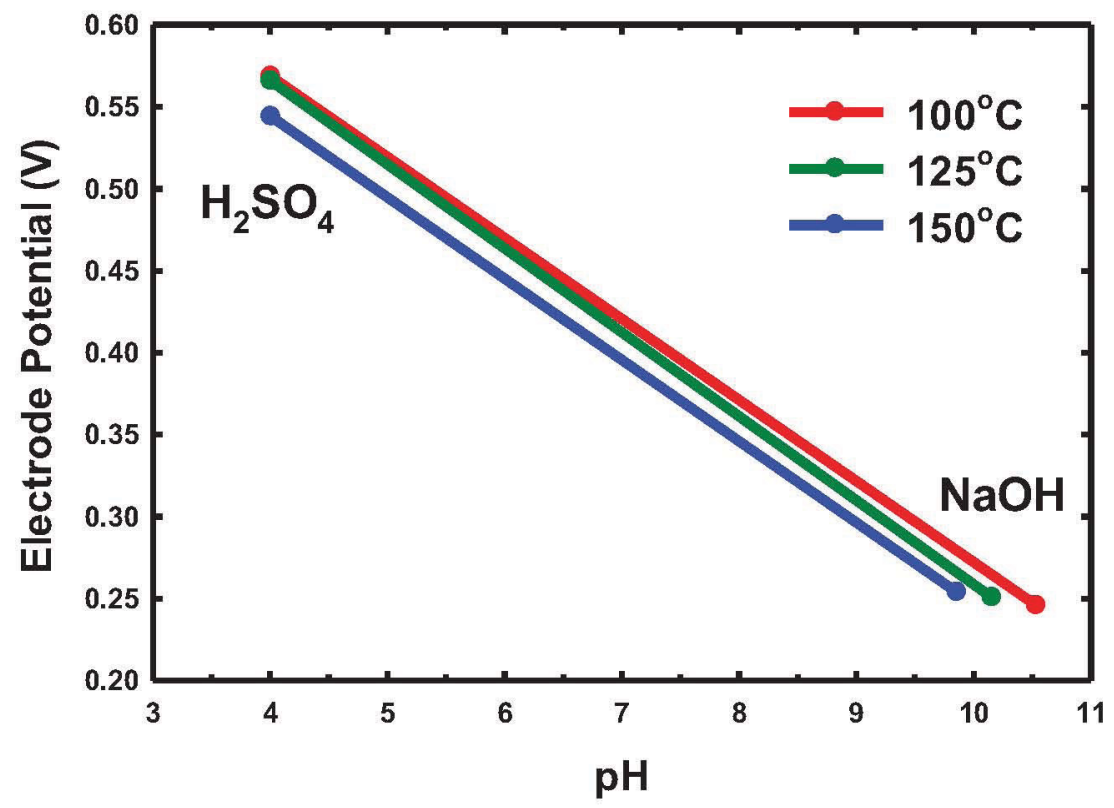

Figure 38. Electrode potential versus $\mathrm{pH}$ for $0.00005 \mathrm{~mol} / \mathrm{kg} \mathrm{H}_{2} \mathrm{SO}_{4}$ and $0.001 \mathrm{~mol} / \mathrm{kg} \mathrm{NaOH}$ at three temperatures based on the regression equations in Tables 1 and 2. 


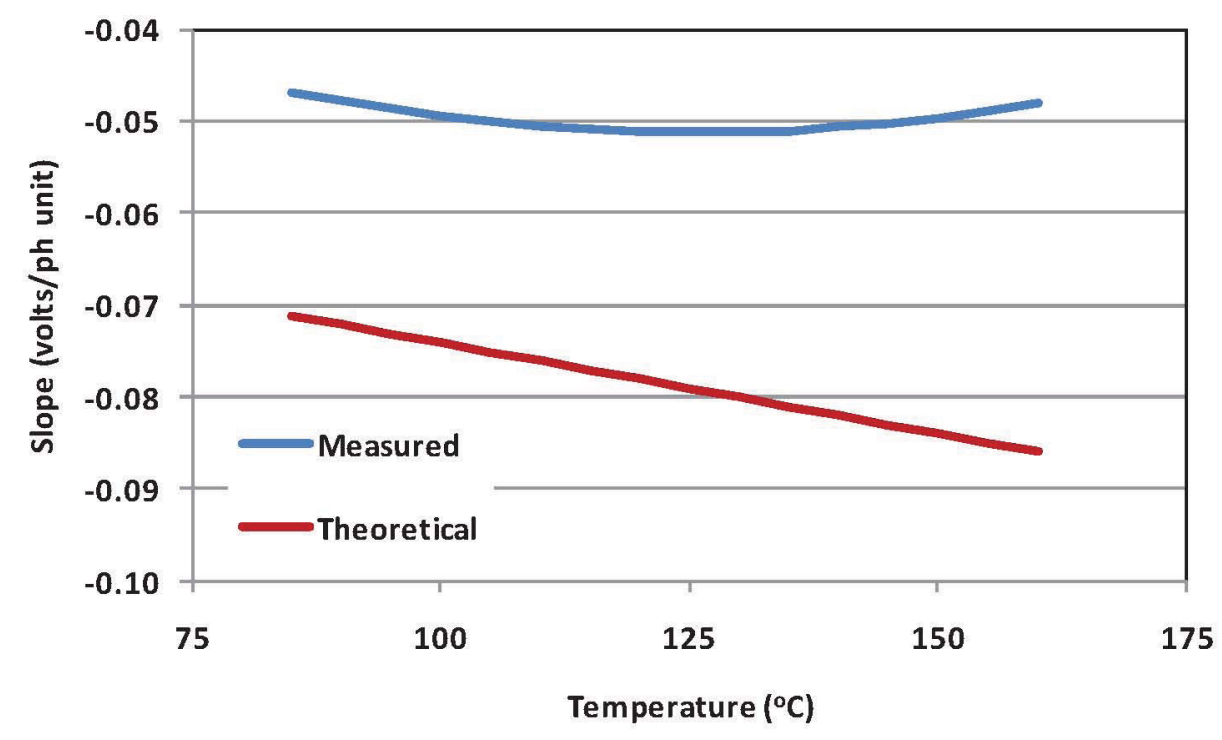

Figure 39. Comparison of measured and theoretical slopes (volts/pH).

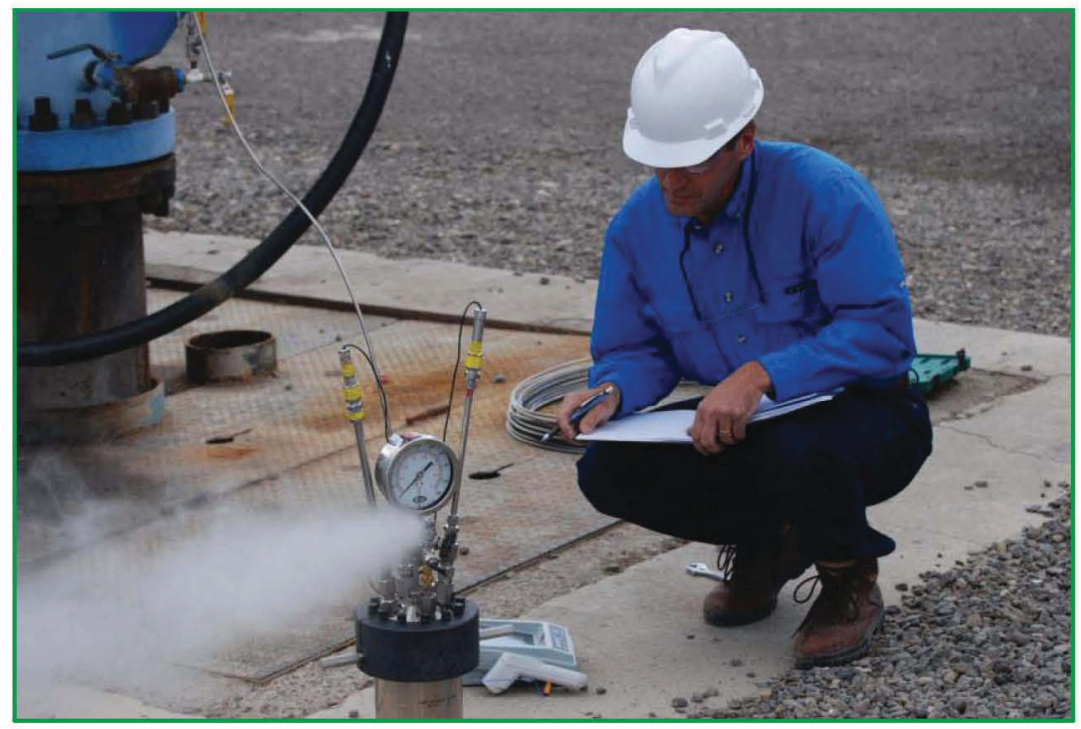

Figure 40. INL staff conducting field measurements of $\mathrm{pH}$ at production well RRG-1.

\subsection{Sample Analysis}

\subsubsection{General Analytical Methods}

Analytical methods for detecting the groundwater tracers (except fluorescein) using HPLC were adapted from Rose et al. (2002). HPLC analyses utilized paired ion chromatography via a JASCO HPLC system with PU-2089S Plus pumps, CO-2065 Plus Intelligent column oven, AS-2057 autosampler, FP2020 Plus fluorescence detector, MD-2018 Plus photo-diode array detector and ChromNAV software. The HPLC system was also equipped with a GL Sciences reversed phase C-18 column, Inertsil ODS-SP, $250 \mathrm{~mm} \times 4.6 \mathrm{~mm}, 5 \mu \mathrm{m}$. The mobile phase for the HPLC column used $5 \mathrm{mM}$ tetrabutylammonium phosphate (TBAP) as the ion pairing agent. The sample injection volume was $200 \mu \mathrm{L}$. Detection was monitored from $200 \mathrm{~nm}$ to $650 \mathrm{~nm}$ as well as selectively at $200 \mathrm{~nm}, 205 \mathrm{~nm}$, and $210 \mathrm{~nm}$. The peaks were manually integrated. 


\subsubsection{Reactive Tracer Sample Preparation}

The polarity of the low carbon chain amides makes the detection of these compounds by HPLC difficult using a nonpolar column. Typical detection limits of actimide and butrymide are approximately $100 \mathrm{ppb}$ in our system. From the measured concentrations during the 2008 fluorescein tracer test, we expected the amides in ground water to be only in the sub ppb levels. Therefore, to obtain detection limits suitable to measure amide concentrations in the Raft River production wells, we developed an evaporation method to concentrate the amides in samples for HPLC analyses. These values were then adjusted by the amount of water evaporated to determine the amide concentrations in the production well samples.

Erlenmeyer flasks $(200 \mathrm{~mL})$ were rinsed with nanopure water to remove contaminants. Fifty $\mathrm{mL}$ of each groundwater sample were measured into the flasks. Two hundred $\mu \mathrm{L}$ of $n$-methylacetamide was injected into some of the samples as an internal standard prior to evaporation, but this was discontinued due to the potential for $n$-methylacetamide to polymerize during heating. Samples were evaporated on hot plates at approximately $80^{\circ} \mathrm{C}$ to evaporate the water without also evaporating tracer compounds. With each set of samples two clean water standards and two groundwater standards that had been injected with an amount $(0.025 \mu \mathrm{L}$ to $1.0 \mu \mathrm{L})$ of $10 \mathrm{ppm}$ acetamide and butyramide solution were also evaporated. Groundwater samples collected from June $16^{\text {th }}$ to June $22^{\text {nd }}, 2010$ from wells RRG-1, RRG-4, and RRG-5 were used as groundwater standards because of the three-day travel time for the tracers between wells RRG-5, and RRG-1 and RRG-4. Samples were evaporated down to at most $10 \mathrm{~mL}$ and allowed to cool to room temperature. Flasks were initially covered with parafilm to prevent further evaporation, but upon considering contamination potential, samples processed afterward were covered tightly with aluminum foil. After cooling, samples were transferred to $15 \mathrm{~mL}$ centrifuge tubes. The Erlenmeyer flasks for each sample were also rinsed again with nanopure water to remove any residual precipitates. Each sample was transferred to a $10 \mathrm{~mL}$ syringe fitted with a $45 \mu \mathrm{m}$ cellulose acetate membrane filter. The samples were filtered into clean $15 \mathrm{~mL}$ centrifuge tubes and then transferred to Erlenmeyer flasks and evaporated to approximately $2 \mathrm{~mL}$. After again allowing samples to cool to room temperature, samples were filtered a second time into clean $15 \mathrm{~mL}$ centrifuge tubes. Approximately $1.2 \mathrm{~mL}$ of each sample was transferred to $1.5 \mathrm{~mL}$ amber vials. The vials were then inserted into the HPLC for analysis.

\subsubsection{Fluorescein disodium salt hydrate}

All samples were analyzed for fluorescein as fluorescein disodium salt hydrate using a FluoroLog Spectrofluorometer and SpectrAcq software. The samples were analyzed using an excitation wavelength of $485.00 \mathrm{~nm}$ and an emission wavelength of $585.00 \mathrm{~nm}$. Calibration standards were prepared from injected sodium fluorescein salt and stored in bottles wrapped in foil to prevent photo-degradation. Standards, adjusted to a $\mathrm{pH}$ of 8 , were run prior to the first sample and at intervals through analytical sessions.

\subsubsection{Naphthalene 2,6-disulfonic acid sodium salt}

The HPLC method used by Rose et al. (2002) was modified to analyze naphthalene 2,6-disulfonate. methanol and water (25:75) with $3.17 \mathrm{mM} \mathrm{Na}_{2} \mathrm{HPO}_{4}, 6.21 \mathrm{mM} \mathrm{KH}_{2} \mathrm{PO}_{4}$, and $5 \mathrm{mM}$ TBAP at a flow rate of $2.5 \mathrm{~mL} \mathrm{~min}{ }^{-1}$ was used isocratically with the fluorescence detector with a run time of approximately 50 minutes. The excitation wavelength $225 \mathrm{~nm}$ and emission wavelength $342 \mathrm{~nm}$ were utilized to program the detector to maximize the sensitivity of the HPLC (Rose et al., 2002). 


\subsubsection{Thermally Reactive Tracers}

Acetamide and butyramide were utilized as thermally reactive tracers. The mobile phase for the HPLC consisted of 5\% methanol and $95 \% 30 \mathrm{mM} \mathrm{pH} 2.8$ phosphate buffer with $5 \mathrm{mM}$ TBAP at a constant flow rate and temperature of $0.30 \mathrm{~mL} \mathrm{~min}^{-1}$ and $35^{\circ} \mathrm{C}$ respectively for a run time of 35 minutes. In some samples, acetamide concentrations were very low or nondetectable. The potential for evaporation of the acetamide with water was considered; however, it was determined that acetamide evaporation levels were approximately $4.9 \times 10^{-7} \mu \mathrm{g} \mathrm{mL}^{-1}$ using the equation:

$\mathrm{C}_{\mathrm{v}}=\mathrm{H}_{\mathrm{i}} * \mathrm{C}_{\mathrm{w}}$

where

$$
\begin{aligned}
& \mathrm{C}_{\mathrm{v}}=\text { Concentration in vapor state } \\
& \mathrm{C}_{\mathrm{w}}=\text { Concentration in water }=8.465 \times 10^{-8} \mathrm{~mol} \mathrm{~L}^{-1} \\
& \mathrm{H}_{\mathrm{i}}=\text { Henry's Law Constant }=9.76844 \times 10^{-4} \text { calculated for acetamide at } 80^{\circ} \mathrm{C}
\end{aligned}
$$

The amount of evaporation would have little effect on the concentration detected by the HPLC.

\subsubsection{Groundwater Matrix}

Direct standards, clean water standards, and groundwater standards were analyzed with each batch of raft river samples. The groundwater standards were used to create a calibration line using the detection levels of acetamide and butyramide. The final concentrations in ppm of acetamide and butyramide in the groundwater samples were plotted against peak areas and a linear regression trendline was fitted to the data (Figure 41). Concentrations of acetamide and butyramide in the Raft River samples were determined from the respective trendline formulas.

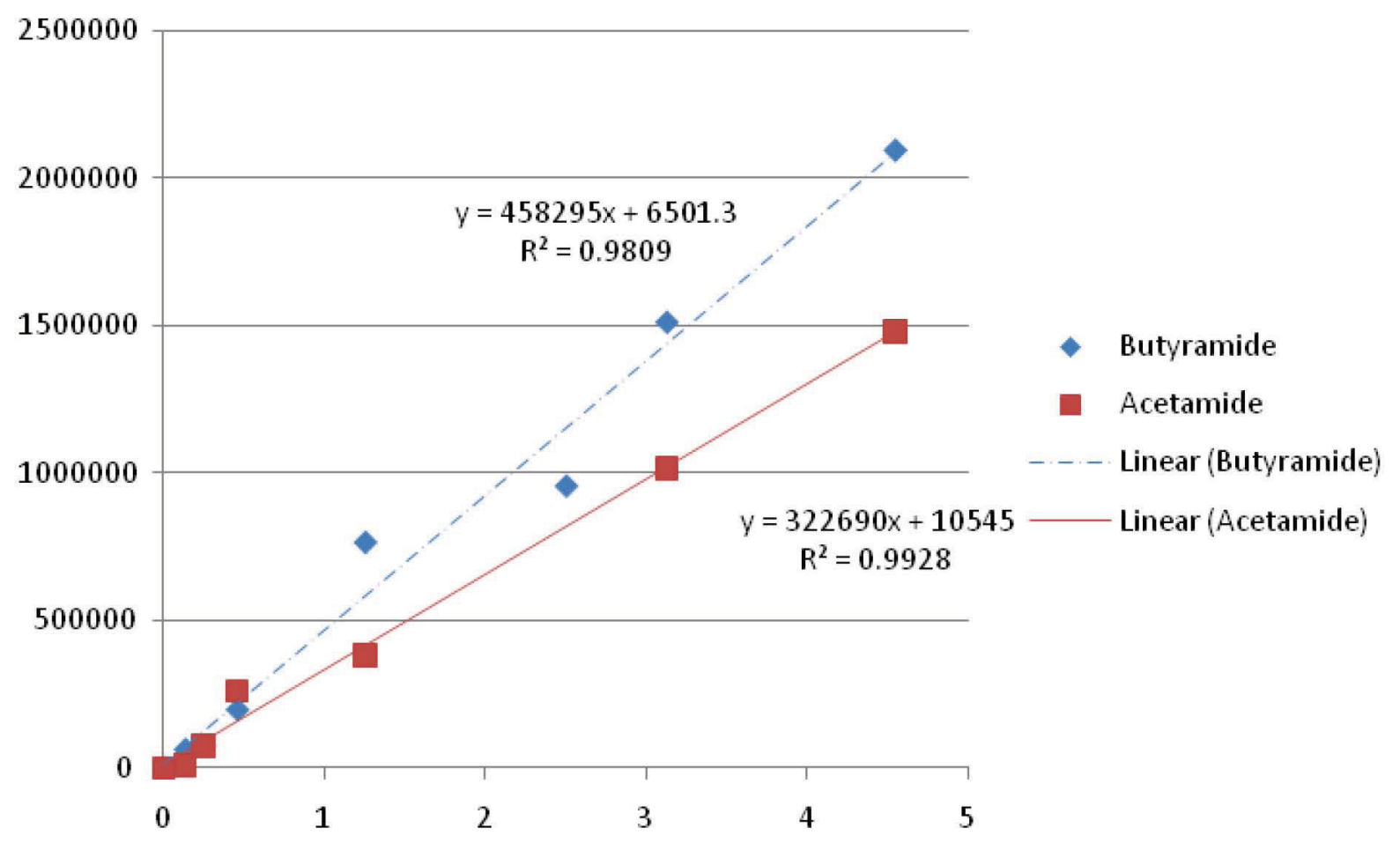

Figure 41. Calibration curves for butryamide and acetamide in the groundwater matrix which were used to determine the reactive tracer concentrations in groundwater samples. 


\subsubsection{Estimate of Analytical Uncertainty}

Uncertainty was determined for the analysis by HPLC methods as well as for the laboratory process. To determine error incurred from the laboratory process, four $50 \mathrm{~mL}$ blank groundwater samples were each injected with $200 \mu \mathrm{L}$ with $10 \mathrm{ppm}$ acetamide and butyramide solution. These samples were evaporated using the same methods as the raft river samples. These samples were then injected with 200 $\mu \mathrm{L}$ of $n$-methylacetamide just before analysis using the HPLC. The percent error was determined by taking the average and standard deviation of the area of the acetamide and butyramide peaks detected from the four samples and inputting them into the formula:

Percent error $=($ standard deviation/average $) \times 100$

The percent error for butyramide was $15.4 \%$ for the laboratory process while the percent error for acetamide was $30.4 \%$. The higher error for acetamide could be attributed to its elution close a signal given from the groundwater itself.

To determine the error by HPLC analysis one of the groundwater samples was analyzed four times consecutively. The area and standard deviation of the acetamide, butyramide, internal standard peaks were each calculated and their percent error was determined. The error for acetamide was $14 \%$, again possibly because of its elution near the groundwater signal, for butyramide was $4.2 \%$, and for the internal standard was $3.4 \%$. 


\section{RESULTS OF TRACER TESTS \\ 7.1 Conservative Tracer Results}

\subsubsection{Recirculation correction}

Water injected at well RRG-5 is a mixture of water from the four production wells; therefore, a portion of the tracer concentrations measured at the production wells RRG-1 and RRG-4 reflect recirculated tracer from the earlier arrival times. To correct for this recirculation, we apply the deconvolution algorithm suggested by Shook (2005), using the Tracer Analysis Toolbox program developed for this project. The program requires flow and concentration data from all wells that contribute to recirculation, automatically calculates the injection concentration from those data and calculates corrected concentration data for each well for which concentration data are provided. Results (Figure 42) demonstrate that although the overall effect of recirculation is relatively small (recirculationcorrected values are only slightly lower than the raw-data values), the correction does slightly alter the shape of the breakthrough curves. These corrected BTCs are used for subsequent interpretation of results.
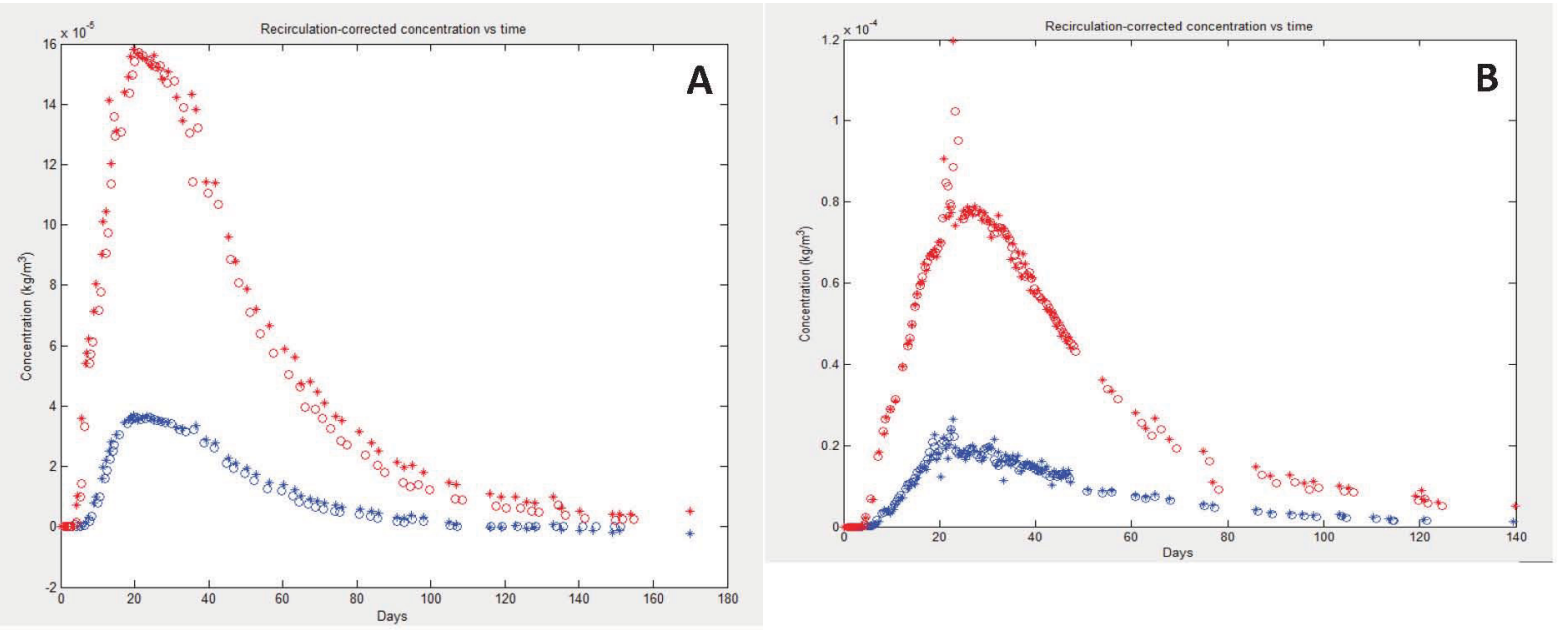

Figure 42. Measured concentration vs. time for first conservative tracer test (Panel A; fluorescein) and for second conservative tracer test (Panel B, naphthalene 2,6-disulfonate) for wells RRG-1 (blue) and RRG-4 (red). The plus $(+)$ symbols are raw data; open symbols show correction for recirculation.

The conservative tracer mass injected in the second tracer test $(100 \mathrm{~kg})$ was essentially identical to the conservative tracer mass injected in the first test. Consequently, concentration plots allow direct comparison of results between both wells and both tests (Figure 43). Results demonstrate excellent capture of the breakthrough curve's shape for both tests at both wells. The curves are also relatively smooth, exhibiting little noise, particularly for the fluorescein data. The noisiest data were those from well RRG-1 during the second tracer test, which used naphthalene 2,6-disulfonate. The irregularities in those data are believed to largely reflect analytical uncertainty in measured tracer concentrations at these lower concentrations.

U.S. Geothermal, Inc., also conducted a fluorescein tracer test in 2008, but conditions and injection method were slightly different for that test. While flow rates at the primary production wells were similar, the cold water injection rate at well RRG-5 was approximately twice that of our 2010 tests. In addition, the injected tracer mass was slightly larger $(136 \mathrm{~kg})$ and injected during a temporary break in the flow to well RRG-5. Results of the 2008 test are also displayed in Figure 43, plotted on a second ordinate axis scaled to compensate for the different injection mass. Those data do not extend past 45 days and, thus, do not capture the full shape of the breakthrough curve, but the available data generally demonstrate that the initial breakthrough and general shape of the breakthrough curves are similar. Primary differences are a 
slightly steeper rising limb in the 2008 breakthrough curve and a suggestion of multiple superimposed peaks in the RRG-1 data from that test. Inferences about such differences are, however, highly uncertain because of differences in the way the test was conducted. We therefore limit most of subsequent discussion to data from our 2010 tests.

Comparison of the measured breakthrough curves from the 2010 test illustrates two primary features that warrant further exploration:

- Concentrations measured at well RRG-4 (squares) are approximately four times greater than those measured in well RRG-1 (circles) for both tests.

- Concentrations measured during the second, naphthalene disulfonate, tracer test (red curves) are approximately half those of the previous, fluorescein, test (green curves).

The first of these observations relates to the characteristics of transport during a single test. The second relates to differences between the two tests and subsequent discussions are organized accordingly.

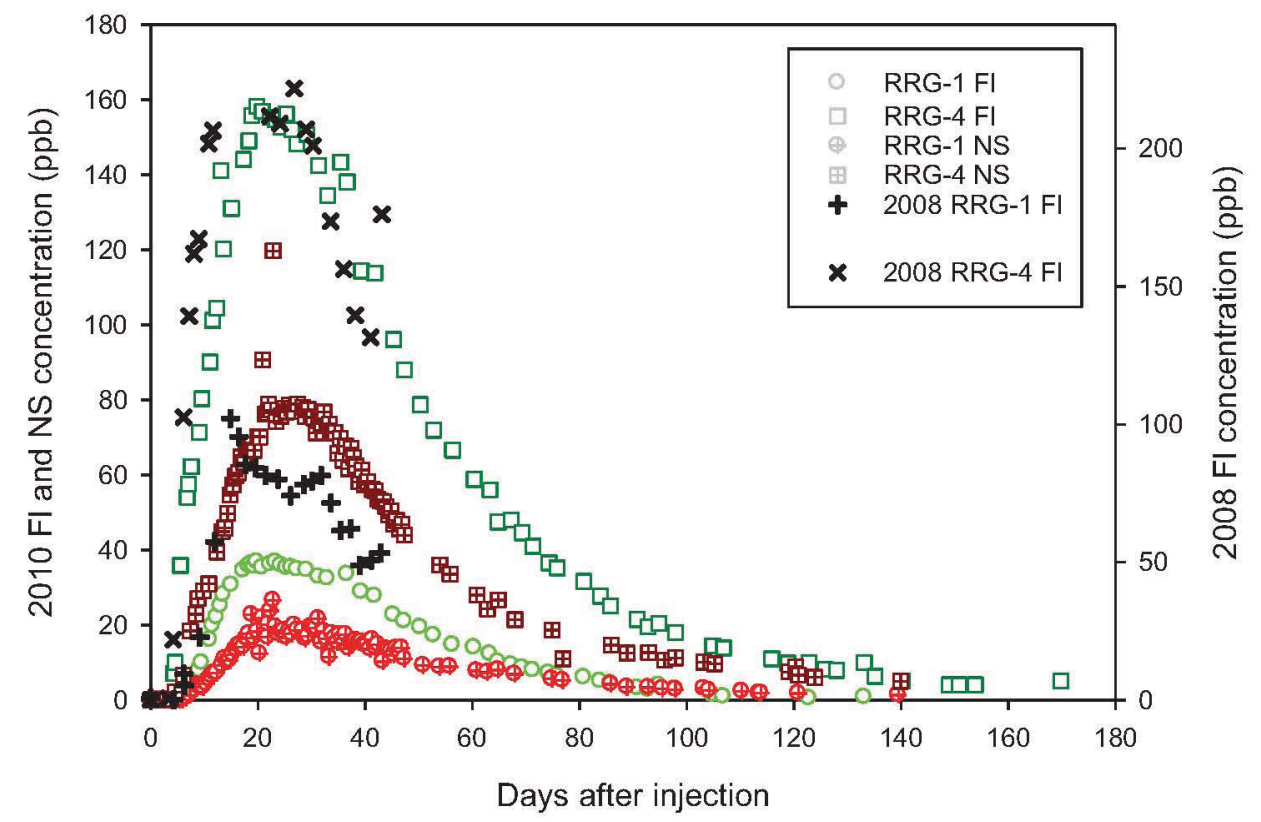

Figure 43. Recirculation corrected data from the two tracer tests conducted by INL and from U.S. Geothermal's 2008 test. Data are shown for both well RRG-1 (circles) and RRG-4 (squares). Green curves show results of fluorescein injection (Test 1). Red lines show results of naphthalene-disulfonate injection (Test 2).

\subsubsection{Interwell comparison of Tracer Test Breakthrough Curves}

The higher concentrations measured at well RRG-4, approximately four times those at well RRG-1, suggest that a larger portion of the tracer mass is conducted to that well; this is consistent with the fact that the pumping rate at RRG-4 is approximately twice at RRG-1. To compare mass recovery at each well, we integrate the time-varying mass flux from the concentration data and flow data using the basic processing options in the Tracer Analysis Toolbox. The mass fraction recovered at each well for each test is displayed in Figure 44. The mass fraction recovered can be interpreted as the fraction of the injected water that is captured by each production well. Comparison of mass fraction recovered at production wells RRG-1 and RRG-4 for the 2010 tests (which were conducted identically) indicates that approximately $90 \%$ of the total tracer mass recovered comes from well RRG- 4 . The 2008 test result is also consistent with these data. Eighty-five percent of the recovered tracer in that test was produced from well RRG-4. 


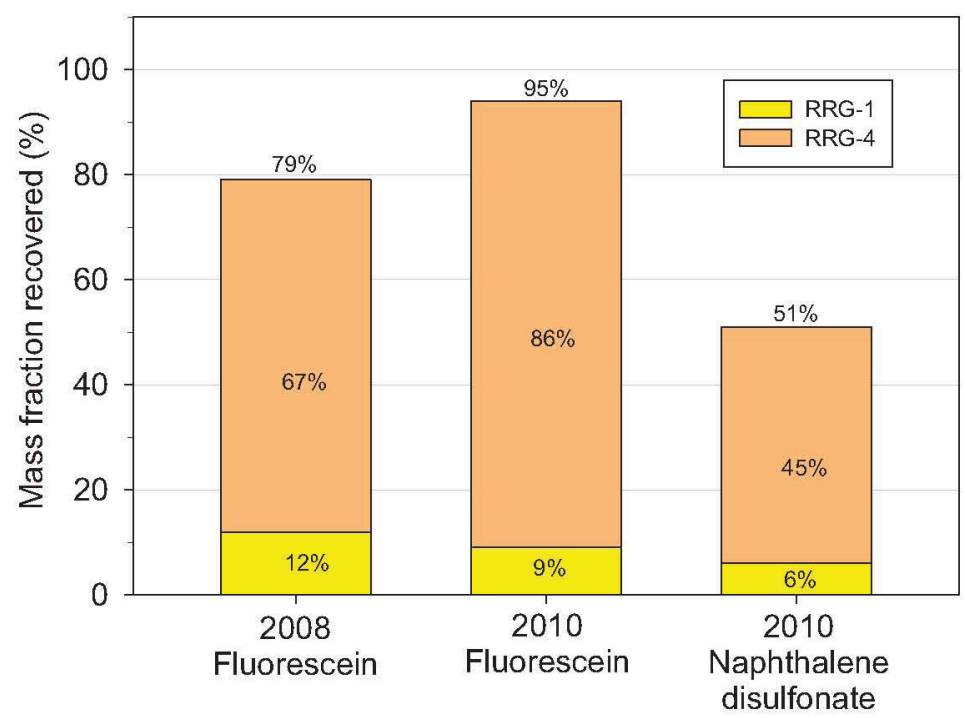

Figure 44. Fraction of injected tracer recovered at each well during INL's 2010 tests and the 2008 U.S. Geothermal test.

To identify differences in the characteristics of flow to the two different wells, we plotted results from the two wells on different axes of the same graph to normalize the curves to their peak concentrations. Results (Figure 45) demonstrate that the shape of the breakthrough curves at the two different wells is remarkably similar in each test, despite differences in the production-well flow rates and locations. The rise of concentration at RRG-1 in both tests was approximately three days later than at RRG-4, but the curves are almost indistinguishable between 15 and 50 days after tracer injection. Differences in well response appear to be significant primarily in the late-time data, after approximately 65 days during Test 1 and 50 days during Test 2 .
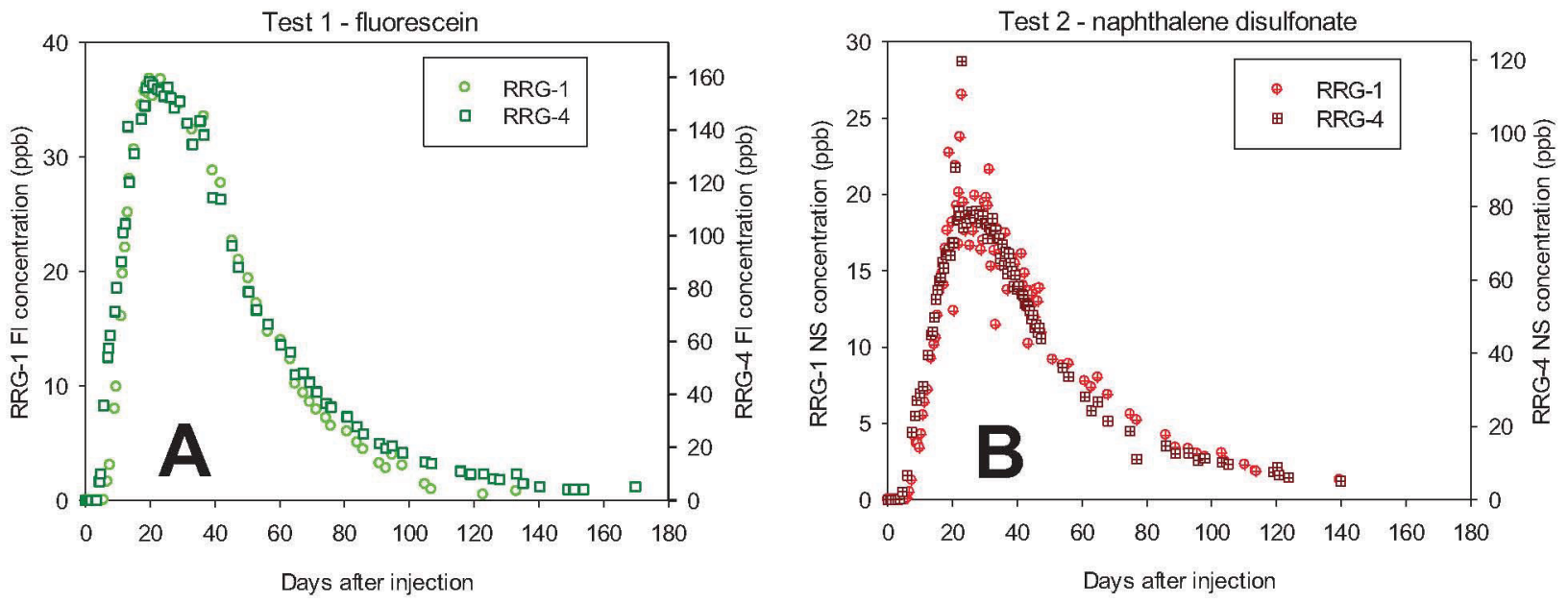

Figure 45. Comparison of conservative tracer breakthrough curve at well RRG-1 with that at RRG-4, for the first (fluorescein) test (A) and second (naphthalene 2,6-disulfonate) test (B).

The correspondence in well response is sufficiently strong that variations in pumping are readily identified by coincident concentration variations. Minor deviations in the shapes of the Test 1 curves (Figure 45A) at 36 and 40 days appear to reflect large deviations in the pumping rates at those times (Figure 32). Although data from Test 2 (Figure 45B) are slightly noisier than the Test 1 results, similar correspondence with variations in pumping are also evident in those curves. 
The similarity between the shape of the breakthrough curves at wells RRG-1 and RRG-4 suggests that characteristics of the flow paths (e.g., roughness, aperture) between the injection and production wells are similar. This is consistent with the conceptual model applied in the groundwater flow and heat-transport modeling analysis completed for U.S. Geothermal, Inc., which treats flow as controlled by an equivalent porous media.

The shapes of the breakthrough curves are similar to those produced in transport through permeable porous media. To illustrate this similarity, we fitted the BTC with the equation describing 1D transport through a system using INL's Tracer Analysis Toolbox. The fitted parameters describe the velocity and spreading of the injected pulse, and included, in this example, velocity, channel length, dispersivity, and fraction of total flow associated with each channel assumed to exist. Panels A and B of Figure 46 illustrate results of curve fitting to Test 1 and Test 2, assuming that the system can be represented as a single channel connecting injection well with production well. Results demonstrate that the equation provides an excellent fit to the data. Parameters derived via this approach are shown in Table 9. Velocity and system length are reasonable, but the dispersivity values $(\sim 250 \mathrm{~m})$ are considerably larger than is commonly calculated for systems in permeable porous media, suggesting that variance in groundwater velocities in the fracture system is much greater than what is encountered in many porous medium systems.
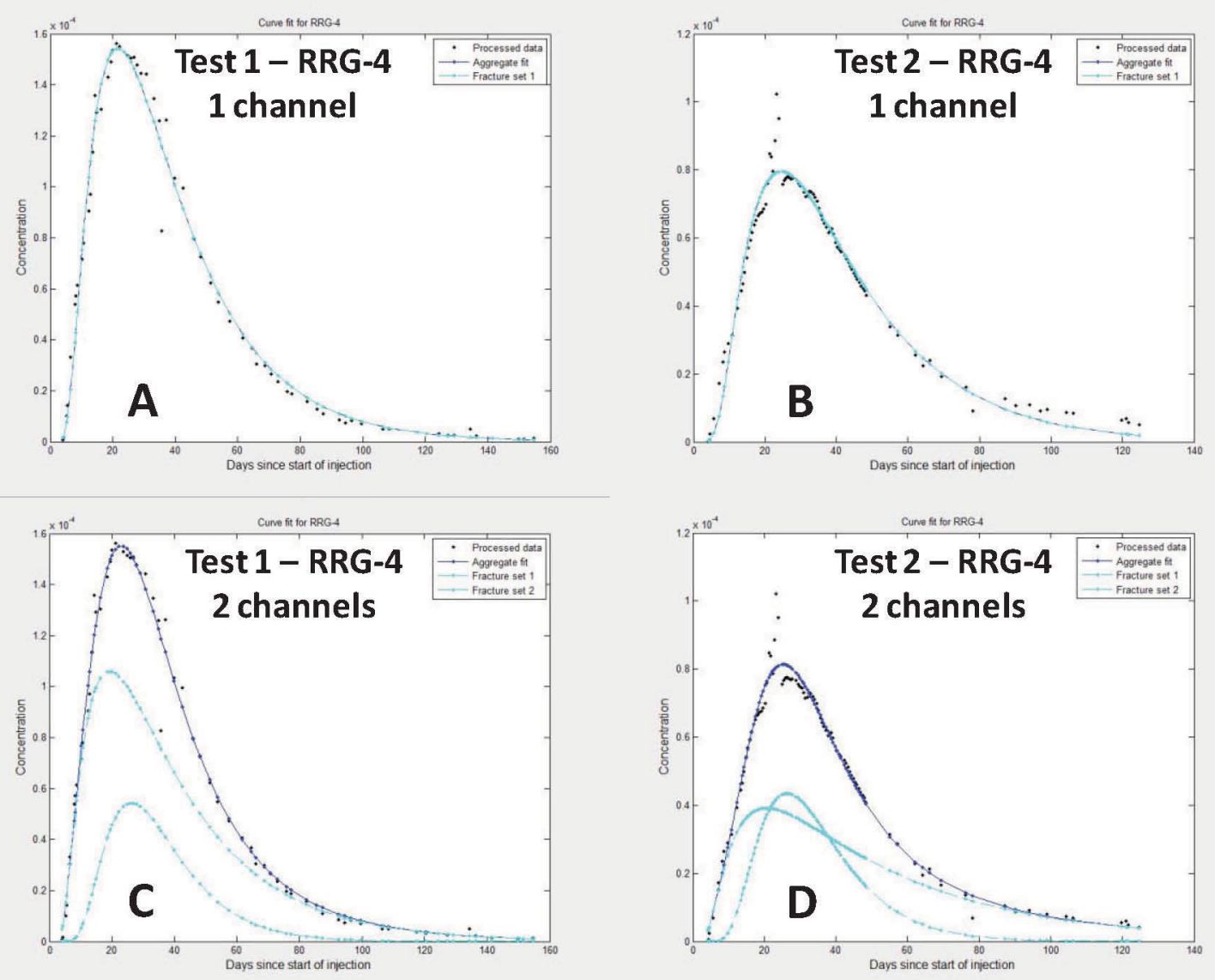

Figure 46. Results of fitting equations to data from well RRG-4 using INL's Tracer Analysis Toolbox. Panels A and B illustrate fit assuming that the system can be represented as a single channel that connects the injection well to the production well. Panels C and D illustrate fit assuming that the system is best represented by two separate channels connecting injection well with each production well. Derived parameters are shown in Table 9. 
To examine whether the system is better represented assuming more than one channel connecting the injection and production well, we repeated the above analysis assuming that the observed BTC at RRG-4 for each test is the aggregate of BTCs from two separate channels (Figure 46, C and D). Although visual inspection evidences a slightly improved fit to the data, the adjusted root sum of squared errors (Table 9) is slightly higher for this case, suggesting that the improvement does not justify the use of the additional parameters involved.

Table 9. Parameters derived from fitting 1D solute transport equation to breakthrough curves from well RRG-4 for Tests 1 and 2.

\begin{tabular}{|c|c|c|c|c|c|c|}
\hline & \multicolumn{2}{|c|}{ Single channel fit } & \multicolumn{4}{|c|}{ Dual channel fit } \\
\hline & RRG-1 & RRG-4 & \multicolumn{2}{|c|}{ RRG-1 } & \multicolumn{2}{|c|}{ RRG-4 } \\
\hline Adjusted root SSQ & 0.76 & 0.33 & \multicolumn{2}{|c|}{0.91} & \multicolumn{2}{|c|}{0.78} \\
\hline & Channel 1 & Channel 1 & Channel 1 & Channel 2 & Channel 1 & Channel 2 \\
\hline Mass fraction & 0.99 & .96 & 0.29 & 0.70 & 0.37 & 0.66 \\
\hline Velocity $\left[\mathrm{m} \mathrm{s}^{-1}\right]$ & $5.0 \mathrm{E}-4$ & $4.6 \mathrm{E}-4$ & $5.3 \mathrm{E}-4$ & $4.9 \mathrm{E}-4$ & $4.9 \mathrm{E}-4$ & $4.1 \mathrm{E}-4$ \\
\hline Mean velocity $\left[\mathrm{m} \mathrm{s}^{-1}\right]$ & $5.0 \mathrm{E}-4$ & $4.6 \mathrm{E}-4$ & \multicolumn{2}{|c|}{$5.0 \mathrm{E}-4$} & \multicolumn{2}{|c|}{$4.5 \mathrm{E}-4$} \\
\hline Length $[\mathrm{m}]$ & 1154 & 1193 & 1353 & 1073 & 1229 & 1083 \\
\hline Velocity/length & 4.3E-07 & $3.9 \mathrm{E}-07$ & $3.9 \mathrm{E}-07$ & 4.6E-07 & $4.0 \mathrm{E}-07$ & $3.8 \mathrm{E}-07$ \\
\hline Dispersivity [m] & 253 & 243 & 149 & 299 & 117 & 423 \\
\hline
\end{tabular}

\subsubsection{Tracer Test Intercomparison}

Comparison of the total mass recovered during each of the 2010 tracer tests (Figure 44) demonstrates that a much lower fraction of the second tracer (naphthalene disulfonate) was recovered relative to the first test. Although fluorescein exhibits some temperature-dependent degradation at higher temperature, that effect should be negligible at the approximately $140^{\circ} \mathrm{C}$ temperatures in the Raft River reservoir. Naphthalene disulfonate is stable to higher temperatures than is fluorescein. The observed difference in mass recovery thus appears to reflect a change in the flow path distribution between the two tests rather than degradation during transport.

Differences in flow path distribution may occur as a result of changes in the flow field, such as may be induced by changes in well-head pressures, or as a result of changes in the fracture geometry, such as fracture contraction associated with reservoir cooling. In this study, the two tests were conducted only 30 days apart, and the pressure distribution imparted by the well field was essentially constant, so changes in the flow field would have to reflect some transient behavior in the system. Changes in the flow paths connecting the wells would not be anticipated to have occurred over the short period between the tests, but such changes might be evident in the shape of the breakthrough curve.

To attempt to identify potential changes in the residence time distribution between the two tracer tests, we plotted results for each test on a single graph, with axis scaling selected to emphasize differences in the shape of the curves. Figure 47 illustrates the breakthrough curve for the fluorescein and the naphthalene disulfonate for the 2010 tracer tests in wells RRG-1 and RRG-4. The normalized tracer curves are very similar in shape, particularly at well RRG-4, where the only significant difference appears to be a slightly later breakthrough during Test 2 . That difference is also apparent at well RRG-1 but larger differences are apparent in the two breakthrough curves at RRG-1 in the late time data, where Test 2 concentrations are significantly lower after 50 days. A significant amount of apparent noise exists in the Test 2 data at well RRG-1, however, so inferred differences in flow path distributions based on comparison with those data are not considered reliable. 

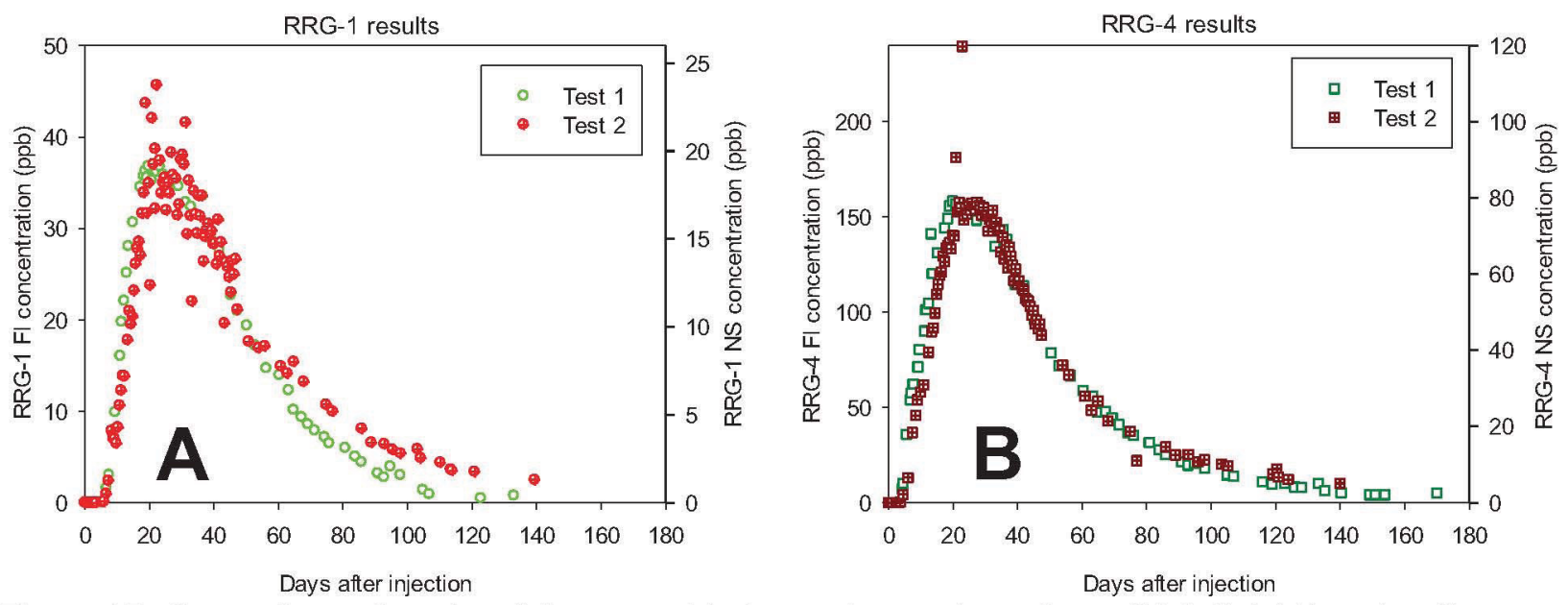

Figure 47. Comparison of results of first test with those of second test for well RRG-1 (A) and well RRG-4 (B).

\subsubsection{Flow Capacity vs. Storage Capacity}

The flow-storage diagram was developed to estimate sweep efficiency of a well intersecting layered media. As described by Shook (2003), these diagrams can be used to describe the fraction of flow originating from a given fraction of the pore volume. Curves that lie closer to the one-to-one line suggest a more homogeneous reservoir, with flow paths of essentially uniform aperture and length. Interpreted in this manner, the curves illustrated in Figure 48 suggest that the distribution of flow paths connecting the injection well with the production wells was essentially unchanged in the 30 days that separated the two tests. The 2008 data suggests that the flow regime during that earlier test was slightly more homogenous than during the 2010 tests; however, inferences based on that comparison are highly uncertain because a higher injection rate was used in the 2008 test, and the data collected did not capture the tail of the breakthrough curve.

\subsection{Reactive Tracers}

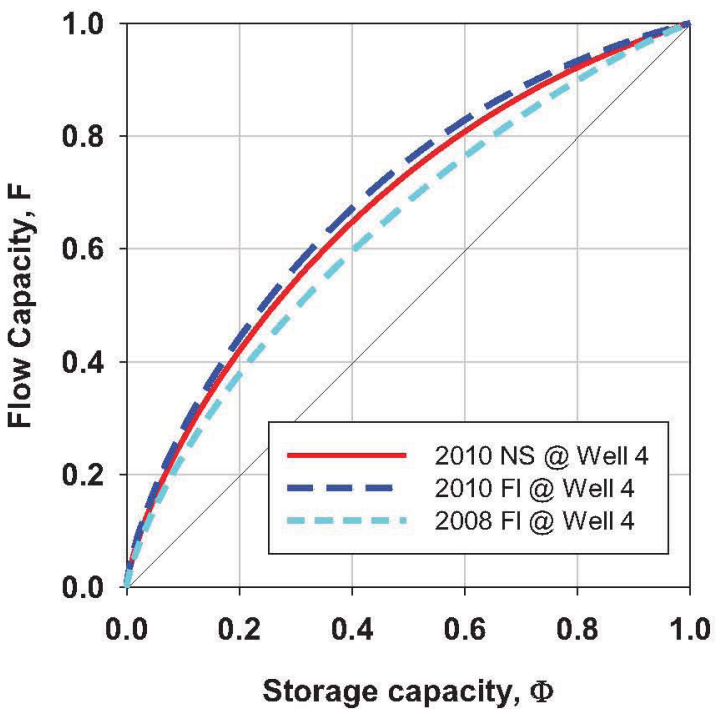

Figure 48. Flow capacity, F, vs. storage capacity, $\Phi$, curves for three conservative tracer tests conducted at Raft River. Note that the 2008 curve is based on extrapolation of the breakthrough curve.

Results of the reactive tracer tests, as measured at well RRG-1 and RRG-4 are shown in Figure 49. The Test 1 data (A) for both RRG-1 and RRG-4 provide a strong indication of a breakthrough curve with shape similar to that of the conservative tracers (an initial detection at $\sim 5$ days, a maximum concentration somewhat earlier that the conservative tracer, and a long tail). The apparent scatter in data from both wells is relatively low relative to the differences between the wells and differences from the conservative tracer data. Results for acetamide in Test 2 (Figure 49B) are considerably noisier, and likely provide only an indication of the timing and concentration of the peak of the breakthrough curve. As discussed in section 6.4.7, the higher analytical uncertainty of the acetamide results may be attributed to the greater background noise at its elution time and the relatively low concentrations of acetamide returned because of its degradation rate. 

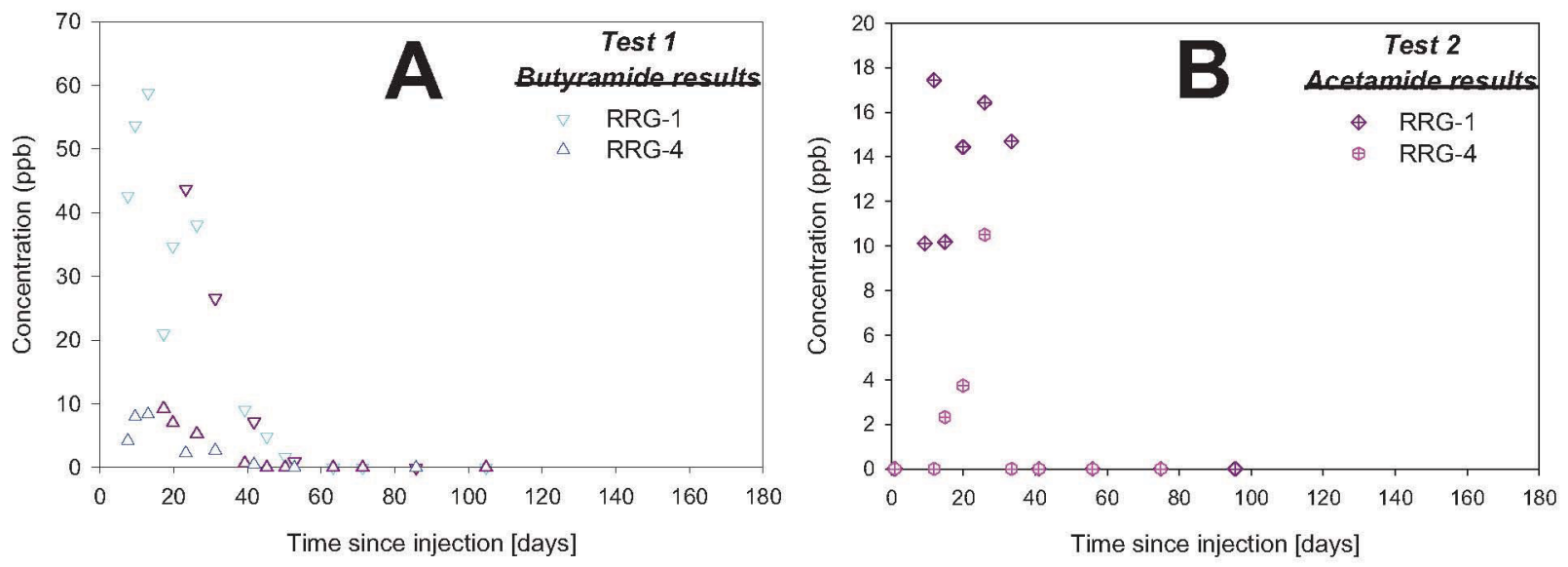

Figure 49. Reactive tracer concentrations measured at wells RRG-1 and RRG-4 coincident with the conservative tracer tests described in the preceding sections. Panel A displays the butyramide concentrations of Test 1. Panel B displays the acetamide data of Test 2.

To use the reactive tracer data to infer something about the reservoir temperature, we assume that those tracers behave identically to their conservative counterparts except for a degradation rate that depends on temperature during transport. A comparison of the reactive tracer return relative to the conservative tracer return, as provided in Figure 50, provides a measure of that degradation, but interpretation of the difference in return requires a calculation of the effect of reactive transport. That is accomplished via a decay correction for each point based on the integral of the temperature-dependent degradation rate over the transport time along the path. The calculation is based on Equations (7) and (8), using parameters summarized in Table 5.

Because cold water injection at well RRG-5 started only several days before our first tracer test injection, it is likely that the flow paths connecting it to the production wells would have experienced little cooling prior to our first tracer injection. Accordingly, the reactive tracer return at Raft River should reflect degradation at the background reservoir temperature, with a reaction time equal to residence time in the reservoir. Based on data from Dolenc et al., we expect that the background reservoir temperature is approximately $139.3^{\circ} \mathrm{C}$.

To examine whether our reactive tracer data appear to reflect the transport behavior of the conservative tracer but with degradation reflecting the expected reservoir temperature, we first fit a smooth curve to the conservative tracer data and use that to calculate a series of hypothetical reservoir conditions where the temperature is constant at between $100^{\circ} \mathrm{C}$ and $150^{\circ} \mathrm{C}$. Those curves are plotted in Figure 50, normalized in the same manner as the conservative tracer data. Note that the relative concentration change, as a function of temperature, is considerably greater for acetamide than for butyramide because the larger activation energy for the former reaction yields slightly stronger dependence on temperature.

Comparison to the measured data for both Test 1 and Test 2 demonstrates that the $139.3^{\circ} \mathrm{C}$ curve is an excellent fit to reactive tracer data. These data provide strong support for the hypothesis that these reactive tracers are transported as ideal thermal tracers, i.e. differing from conservative behavior only via temperature-dependent degradation. Although similar calculations could be performed using spatially varying temperatures, the scatter in the breakthrough curves from both tests, and particularly Test 2 , indicates that the uncertainty in the measurements is currently too large for more refined temperature estimates. 
The application of multiple reactive tracer tests to the same reservoir at different times is intended to identify changes in reservoir temperatures that may have occurred between the two tests. Results of reactive tracer tests conducted at different times in this study suggest that reservoir temperature remained constant between tests. This consistent with the relatively short interval between the two tests ( 30 days), which would not be expected to cause significant cooling.
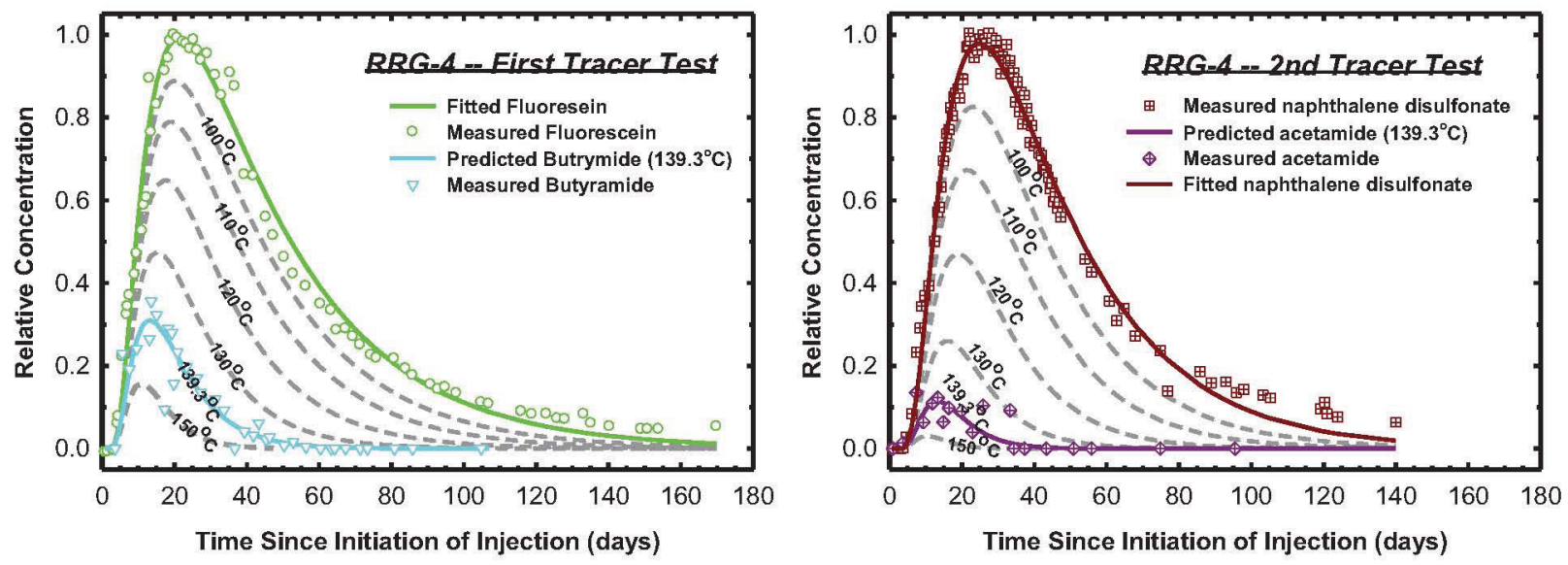

Figure 50. Relative concentrations of conservative and reactive tracers measured at well RRG-4.

\subsection{Summary}

Our field test of the reactive tracer approach strongly supports the potential of this approach as a means of monitoring temperature evolution of a geothermal reservoir, particularly for the tracers applied in this study. Using co-injected conservative tracers as a reference for measuring degradation, the reactive tracer results for both tests return a reservoir temperature estimate consistent with U.S. Geothermal's estimate of the reservoir temperature. The fluorescein, naphthalene disulfonate, and butyramide injections all yielded smooth consistent breakthrough curves. The acetamide tests also provided relatively good results when the concentration was high, however future work aimed at reducing uncertainty of tracer measurements would be valuable.

Interestingly, one of the most remarkable results demonstrated in this study is the dramatically lower tracer recovery during the second test. Conservative tracer recovery during the first test was relatively high (95\%), indicating that virtually all of the water injected at well RRG-5 flowed to the two primary production wells. Recovery during the second test $(51 \%)$, however, was approximately half that of the first test. Recovery of reactive tracers was also significantly lower during the second test, but when the effects of temperature-dependent degradation are calculated from the conservative tracer data, the results are remarkably consistent with the Test 1 results. Thus, although it is possible that analytical errors affected one of the conservative tracer results, the combined data do not support that possibility. If the naphthalene tracer results are erroneously low, the reservoir temperature calculated from the Test 2 results would be on the order of $120^{\circ} \mathrm{C}$, much lower than is reasonable. If, on the other hand, the fluorescein results are erroneously high, the reservoir temperature calculated from the Test 1 results would be tens of degrees higher than is reasonable based on other data.

Taken together, the conservative and reactive tracer data demonstrate that tracer recovery was significantly lower during the second test, which was initiated only 30 days after the first test. At the same time, when the two test results are normalized to their maximum concentration, the shapes of the breakthrough curves are nearly identical. This preservation of the shape of the curve, with significantly lower recovery, strongly suggests that a second set of flow pathways were being utilized at the injection well RRG-5 and these pathways are not being captured by either of production wells RRG-1 and RRG-4. 
Changes in the flow regime could occur for a number of reasons. Because the cold water injection at RRG-5 began only slightly before the first tracer test, it is possible that the introduction of cold water at that point caused relatively rapid cooling of the flow paths carrying water from RRG-5. If so, the cooling could have been sufficient to cause contraction in the surrounding rock and, therefore, expansion of fractures. This hypothesis seems unlikely, however, as we would expect alterations of the paths connecting RRG-5 with RRG-4 and RRG-1 to be evidenced as changes in the breakthrough curves. The normalized breakthrough curves between the two tests demonstrate little, if any, difference. We therefore conclude that the reduced recovery in the second test reflects alteration of the flow regime in a manner that directs flow to previously unused flow paths that do not flow to the primary production wells. This change occurred during the time separating the two tests, and after cold water injection at well RRG-5 had already been operating for approximately a week. This finding is significant as it indicates that injection of coldwater at well RRG-5 produces changes in the reservoir over a timescale of weeks and that those changes benefit reservoir operations by altering flow so that an increasing portion of injected cold water bypasses the production wells. Further study of this phenomenon could yield a method of reducing costs associated with reinjection while providing pressure support at the primary production wells. 


\section{CONCLUSIONS}

Reactive tracer tests may be a viable method for detecting reservoir temperature changes along paths between cold-water injection wells and production wells in engineered geothermal systems and conventional geothermal reservoirs. This report summarizes work that was completed to advance the use of reactive tracers for measuring thermal evolution in geothermal reservoirs. It reviews the theoretical basis for the interpretation of reactive tracers, identifies and assesses the applicability of various tracers, and describes methods that were developed to design and interpret tracer tests. These concepts and tools are tested via application of two reactive tracer tests conducted at Raft River Geothermal as part of this project. We summarize our conclusions in the following sections.

\subsection{Theoretical and Numerical Development}

- A Tracer Analysis Toolbox that offers several analytical tools for consideration of reactive tracers which depend on flow-path temperature and transport time was developed. The toolbox incorporates common approaches to tracer analysis in geothermal systems including residence time distribution analysis, which focuses on examining sweep efficiency in the reservoir, and curve fitting methods that calculate parameters of solute transport equations for simplified flow models.

- The Tracer Analysis Toolbox allows access to an array of useful analytical routines via userfriendly interface, including:

- correction of concentration vs. time data for effects of recirculation,

- construction of flow-storage diagrams to examine reservoir sweep efficiency,

- calculation of temperature as a function of distance along flowpaths, described by userspecified aperture, flow rate, length and interfracture spacing,

- calculation of temperature as a function of time at a production well as a function of userspecified aperture, flow rate, length and interfracture spacing, and

- inverse estimation of parameters for equations describing simplified models of conservative and reactive tracer transport.

- Implementation of algorithms as separate MATLAB functions allows user extension via inclusion of routines with common input/output format.

- Implementation via compiled MATLAB executable allows distribution independent of MATLAB availability.

- Thermal profiles between cold-water injection wells and production wells can take on two characteristic shapes, depending on the reservoir characteristics. For systems dominated by a single fracture or by widely spaced fractures, the profiles are hinged at the injection well and have an inverted "J" shape. For systems composed of porous media or closely spaced fractures, the thermal front moves through the reservoir as a classic "S"-shaped breakthrough curve. The general shape of these thermal profiles will impact the ability of reactive tracers to monitor thermal evolution of the reservoir.

- Reactive tracers with a single thermal degradation pathway can be sensitive enough to detect thermal evolution of the reservoir. In general, the greater the activation energy for the reaction, with a concomitant increase in the pre-exponential factor, the greater the sensitivity of the tracers ability to distinguish thermal evolution along a flow pathway.

- A method that uses instantaneous quenching of the thermal-degradation reaction mathematically shows promise as a means of increasing the sensitivity of reactive tracers for measuring thermal drawdown. However, significant work is needed to indentify applicable tracers or approaches that demonstrate this property. 
- Alternative reaction schemes involving either simultaneous or sequential pathways do not increase the sensitivity of reactive tracers.

\subsection{Laboratory Studies}

- Several single-pathway tracers have been identified from the literature, and their kinetic parameters summarized. For low-temperature hydrothermal systems $\left(<160^{\circ} \mathrm{C}\right)$, acetamide and butyramide may be useful. For higher temperature systems $\left(>250^{\circ} \mathrm{C}\right)$, some carboxylated benzoic acids, fluorinated benzoic acids, fluorinated phenylacetic acids, and fluorescein may be appropriate.

- Temperature-time sensitive colloid tracers may be an alternative type of tracers that can be employed. Two approaches can be taken: a) racemization reactions and b) thermoluminescence. Thermoluminescence will provide information about the maximum temperature encountered by the particle along its flow path through the reservoir. Each of these methods may require some form of encapsulation.

- Laboratory results indicate that highly soluble, thermally sensitive salts can remain stable in their encapsulated form. Encapsulation methods were tested in the laboratory using test coatings of polystyrene (PS), polymetheylmethacrylate (PMMA) and a polyimide (PI) over sodium chloride, copper sulfate, and copper acetate. This ability to encapsulate thermally reactive tracers will enable further testing of this general approach.

- A tracer test using both conservative and reactive tracers was planned to examine the behavior of reactive tracers in a geothermal reservoir. The test was designed for application at the Raft River Geothermal site in south-central Idaho, in collaboration with U.S. Geothermal, Inc. Design of the test was largely based on analysis of a 2008 tracer test conducted by U.S. Geothermal. Calculations of reactive concentrations versus time indicated that acetamide and butyramide would function well as thermally reactive tracers in the Raft River reservoir.

- A method to measure low concentrations of butyramide and acetamide by HLPC was developed. The method involves pre-concentration of the sample by evaporation at $80^{\circ} \mathrm{C}$. The method allowed the measurement of thermally reactive tracer breakthrough curve under condition of severe reservoir dilution.

- The feasibility of using a $\mathrm{Zr} / \mathrm{ZrO}_{2}$ electrode to directly measure $\mathrm{pH}$ at reservoir temperatures was investigated. The flow-through system designed to measure the $\mathrm{pH}$ worked very well. Future modification to the system should include a better insulation method to minimize heat loss during measurement and inclusion of the chloride concentration in the electrode calibration system.

\subsection{Field Studies}

- Two tracer tests were conducted to test the ability of reactive tracers to accurately determine reservoir temperatures and to detect changes in those temperatures that may be affected by the injection of cold water at well RRG-5. In the first tracer test, fluorescein was used as a conservative tracer while butyramide was used as a reactive tracer. In the second tracer test, naphthalene 2,6-disulfonate was used as a conservative tracer and acetamide was used as a reactive tracer. Results demonstrated several notable results:

- Paired with a conservative tracer, the reactive tracers appeared to provide an excellent measure of reservoir temperature.

- A relatively large degree of scatter in the second reactive tracer test data did not permit the detailed comparison of breakthrough curve shapes that might have provided evidence of cooling between the two tests. Such cooling, however, is not anticipated to have occurred during the relatively brief interval ( 30 days) between those tests. 
- Recovery during the second tracer tests was approximately half that of the first test, demonstrating increasing flow of water from well RRG-5 away from the primary production wells. The combined use of a conservative and a reactive tracer provided a high degree of confidence in this result, which may have important implications to operation of the reservoir.

\subsection{Summary}

The work conducted during this study addresses the effectiveness of using thermally reactive tracers as a method to investigate the thermal evolution of a geotheramal reservoir undergoing utilization for energy development. We have developed numerical tools, laboratory and field techniques to assess the viability of the thermal tracer technique. We tested the numerical tool on a set of thermal tracer tests conducted at an existing hydrogeothermal system. The thermal tracer's breakthrough concentrations measured in the field agreed with numerical predictions. Our ability to conduct thermal degradation tracer tests, interpret the data, and predict reservoir temperatures in the field suggests that the thermal tracer technique shows promise as an analysis/management tool at fractured engineered geothermal systems. 


\section{REFERENCES}

Adams, M. C., J. N. Moore, L. G. Fabry and J.-H.Ahn (1992), “Thermal stabilities of aromatic acids as geothermal tracers." Geothermics 21(3): 323-339.

Allman, D.W., Tullis, J.A, Dolenc, M.R., Thurow, T.L. and Skiba P.A. (1982), "Raft River Monitor Well Potentiometric Head Responses and Water Quality as Related to the Conceptual Ground-Water Flow System", EG\&G Idaho Inc. Technical Report (EGG-2215), Vol. II, prepared for the US Department of Energy, Idaho Operations Office.

Alonso, U., T. Missana, A. Patelli, V. Rigato and J. Ravagnan (2002), "Size effects on colloids diffusion in granite micro fractures." Geochimica Et Cosmochimica Acta 66(15A): A15-A15.

Arimoto, M., H. Ichikawa and Y. Fukumori (2004), "Microencapsulation of water-soluble macromolecules with acrylic terpolymers by the Wurster coating process for colonspecific drug delivery." Powder Technology 141(3): 177-186.

Axelsson, G., O.G. Fldvenz, H. Kristmannsddttir and G. Svemsddttir (1993), "Injection experiment at Laugaland in Eyjafjoraur, Central North Iceland" (in Icelandic). Report 08-93052, National Energy Authority, Reykjavik, 69 pp.

Ayling, B., P. Molling, R. Nye, and J. Moore (2011), Fluid Geochemistry at the Raft River Geothermal Field, Idaho: New Data and Hydrogeological Implications, Thirty-sixth Workshop on Geothermal Reservoir Engineering. Stanford University, Stanford, CA., Jan 31-Feb 2, 2011

Bada, J. L., J. B. Maynard and B. P. Luyendyk (1970), "Marine Sediments -Dating By Racemization Of Amino Acids." Science 170 (959):730-732.

Bear, J. (1972), Dynamics of Fluids in Porous Media. Dover Publications. ISBN $\underline{\text { 0-486-65675-6. }}$

Becker, M. W. (2003), "Effect of tracer buoyancy on tracer experiments conducted in fractured crystalline bedrock." Geophysical Research Letters 30(3), 1116, doi:10.1029/2002GL016480

Becker, M. W., and A. M. Shapiro (2000), "Tracer transport in fractured crystalline rock: Evidence of nondiffusive breakthrough tailing." Water Resources Research 36(7): 1677-1686.

Becker, M. W., and R. J. Charbeneau (2000), First passage time mathematical models for groundwater tracer tests conducted in uniform and radially convergent flow, J. Contam. Hydrol., 40(4), 299-310.

Becker, M. W., P. W. Reimus and P. Vilks (1999), “Transport and attenuation of carboxylatemodified latex microspheres in fractured rock laboratory and field tracer tests." Ground Water 37(3): 387-395.

Behrens, H., I. Ghergut, M. Sauter and T. Licha (2009), "Tracer properties and spiking results (from geothermal reservoirs)," Proceeding of the Thirty Fourth Workshop of Geothermal Reservoir Engineering, February 9-11, SGPTR-187. Stanford, University, Stanford, CA.

Carlslaw, H.S., and J.C. Jaeger (1959), Conduction of Heat in Solids. Oxford University Press, Oxford, U.K., $510 \mathrm{p}$.

Chrysikopoulos C. V. (1993) "Artificial tracers for geothermal reservoir studies." Environmental Geology, 22, 60-70.

Chrysikopoulos, C. V., and A. AbdelSalam (1997), "Modeling colloid transport and deposition in saturated fractures." Colloids and Surfaces a-Physicochemical and Engineering Aspects 121(2-3): 189-202.

Clarke, S. J. and C. V. Murray-Wallace (2006), "Mathematical expressions used in amino acid racemisation geochronology - A review." Quaternary Geochronology 1(4): 261-278. 
Corr Instruments (2009), "High-Temperature High-Pressure pH and Reference Probes, Instruction Manual. Corr Instruments, LLC, Sanantonio Texas, USA, www.CorrInstruments.com, September, 2009.

de Hoog, F.R., J.H. Knight, and A.N. Stokes, (1982) "An improved method for numerical inversion of Laplace transforms," S.I.A.M. J. Sci. and Stat. Comp., 3: 357-366.

Dolenc, M.R., Hull, L.C., Mizell, S.A., Russell, B.F., Skiba, P.A., Strawn, J.A., and Tullis J.A. (1981), "River River Geoscience Case Study", EG\&G Idaho Inc. Technical Report (EGG-2125), Vol. I, prepared for the US Department of Energy, Idaho Operations Office.

Grindrod, P. and A. J. Lee (1997), "Colloid migrationin symmetrical non-uniform fractures: Particle tracking in three dimensions." Journal of Contaminant Hydrology 27(3-4): 157-175.

Grindrod, P., M. S. Edwards, J. J. W. Higgo and G.M. Williams (1996), "Analysis of colloid and tracer breakthrough curves.” Journal of Contaminant Hydrology 21(1-4): 243-253.

Gringarten, A.C., P.A. Witherspoon, and Y. Ohnishi (1975), "Theory of heat extraction from fractured hot dry rock." Journal of Geophysical Research. 80(8): 1120-1124.

Grove, D.B., and W.A. Beetem, (1971), "Porosity and dispersion constant calculations for a fractured carbonate aquifer using the two well tracer method," Water Resour. Res., 7: 128-134.

Harvey, R. W., L. H. George, R. L. Smith and D. R. LeBlanc (1989), "Transport of Microspheres and Indigenous Bacteria through a Sandy Aquifier: Results of Natural and Forced-Gradient Tracer Experiments." Environmental Science and Technology 23(1): 51-56.

Heuze, F.E. (1983), "High-temperature mechanical, physical and thermal properties of granitic rocks-- A review." International Journal of Rock Mechanics and Mining Sciences \& Geomechanics Abstracts, . 20(1): 3-10.

Hollenbeck, K.J. (1998), INVLAP.m: A MATLAB function for numerical inversion of Laplace transforms by the de Hoog algorithm, http://www.isva.dtu.dk/staff/karl/invlap.html.

Holt, R.J., (2008), "Numerical model development and results: Raft River Geothermal Field, Cassia County, Idaho." Report submitted to U.S. Geothermal, Inc. by Geothermal Science, Inc., November 5, 2008, 48p.

Horai, K.-i. and J.-i. Susaki (1989), "The effect of pressure on the thermal conductivity of silicate rocks up to 12 kbar." Physics of the Earth and Planetary Interiors, 55(3-4): 292-305.

Horne, R.J., and Rodriguez, F., (1981), "Dispersion in Tracer Flow in Fractured Geothermal Systems", in Proceedings Seventh Workshop Geothermal Reservoir Engineering, Stanford University, Stanford, CA, December

James, S. C. and C. V. Chrysikopoulos (1999), "Transport of polydisperse colloid suspensions in a single fracture." Water Resources Research 35(3): 707-718.

James, S. C. and C. V. Chrysikopoulos (2000), "Transport of polydisperse colloids in a saturated fracture with spatially variable aperture." Water Resources Research 36(6): 1457-1465.

Kaufman, D. S. (2006), "Temperature sensitivity of aspartic and glutamic acid racernization in the foraminifera Pulleniatina." Quaternary Geochronology 1(3): 188-207.

Knapp, R. B., M. L. Chiarappa and W. B. Durham (2000), "An experimental exploration of the transport and capture of abiotic colloids in a single fracture." Water Resources Research 36(11): 3139-3149.

Lasaga, A.C. (1998), Kinetic Theory in the Earth Sciences. Princeton University Press, 811 p. 
Levenspiel, O., 1972, Chemical Reaction Engineering, 2nd Edition, John Wiley and Sons, New York, NY, Ch. 9.

Liu, L., and Q.-X. Guo (2001), "Isokinetic realationship, isoequilbrium relationship, and enthalpy-entropy compensation." Chem. Rev., 101: 673-695.

Mahesh, K., P. S. Weng and C. Furetta (1989), Thermoluminescence in Solids and Its Applications. Ashford, Kent TN 25 4NW, England, Nuclear Technology Publishing.

Maloszewski, P., Zuber, A., 1984. Interpretation of artificial and environmental tracers in fissured rocks with a porous matrix. Isotope Hydrology. International Atomic Energy Agency (IAEA), Vienna, Austria, pp. 635-651.

Maloszewski, P., Zuber, A., 1985. On the theory of tracer experiments in fissured rocks with a porous matrix. J. Hydrol. 79, 333-358.

Mattson, E., M. Plummer, C. Palmer, L. Hull, S. Miller, and R. Nye (2011), Comparison of Three Tracer Tests at the Raft River Geothermal Site, 2011 Stanford Geothermal Workshop, Palo Alto, CA.

McKay, L. D., R. W. Gillham and J. A. Cherry (1993), "Field Experiments in a Fractured Clay Till .2. Solute and Colloid Transport." Water Resources Research 29(12): 3879-3890.

Mercier, N. (2008), "Dating Of Quaternary Sediments by Optically Stimulated Luminescence: A Review." Quaternaire 19(3): 195-204.

Missana, T., M. G. Gutierre, U. Alonso and J. Quinones (2002), "Migration of bentonite colloids in a granite fracture." Geochimica et Cosmochimica Acta 66(15A): A515-A515.

Moench, A.F., 1989. Convergent radial dispersion: a Laplace transform solution for aquifer tracer testing. Water Resour. Res. 25 (3), 439- 447.

Moller, N., C. Christov and J. Weare (2006), "Thermodynamic Models of Aluminum Silicate Mineral Solubility for Application to Enhanced Geothermal Systems." Thirty-first Workshop on Geothermal Reservoir Engineering. Stanford University, Stanford, California.

Nellis, G and S. Klein, (2008), Heat Transfer, Extended Sections, Numerical Inverse Laplace Transform. E29: Section 3.4.7. Cambridge University Press. http://www.cambridge.org/us/engineering/author/nellisandklein/downloads/extended/Section\%203.4.7.pdf, Accessed 5/56/2011.

Niehren, S. and W. Kinzelbach (1998), "Artificial colloid tracer tests: development of a compact on- line microsphere counter and application to soil column experiments." Journal of Contaminant Hydrology 35(1-3):

Nottebohm, M., T. Licha and H. Behrens (2009), "Thermal Decay of Selected Organic Substances for Using Them as 'Smart Tracers' in Geothermal Reservoirs." Stanford Geothermal Workshop. Stanford, CA.

Parkhurst, D.L. and Appelo, C.A.J. (1999), "User's guide to PHREEQC (Version 2)-A computer program for speciation, batch-reaction, one-dimensional transport, and inverse geochemical calculations.” U.S. Geological Survey Water-Resources Investigations Report 99-4259, 310 p.

Plummer, M. A., C. D. Palmer, L. C. Hull and E. D.Mattson (2009), "Sensitivity of a Reactive-Tracer Based Estimate of Thermal Breakthrough in an EGS to Properties of the Reservoir and Tracer." Thirty-Fifth Workshop on Geothermal Reservoir Engineering. Stanford University, Stanford, CA.

Plummer, M., C. Palmer, E. Mattson, and L. Hull (2011), "A Reactive Tracer Analysis Method for Monitoring Thermal Drawdown in Geothermal Reservoirs," 2011 Stanford Geothermal Workshop, Palo Alto, CA. 
Plummer, M., C. Palmer, E. Mattson, G. Redden, and L. Hull (2010a) Advancing Reactive Tracer Methods for Monitoring Thermal Drawdown in EGS, 2010 Geothermal Resources Council Annual Meeting, Sacramento, CA.

Plummer, M.A, C.D. Palmer, L.C. Hull, E.D. Mattson (2010b), "Sensitivity of a Reactive-Tracer Based Estimate of Thermal Breakthrough in an EGS to Properties of the Reservoir and Tracer", Proceedings, Thirty-Fifth Workshop on Geothermal Reservoir Engineering, Stanford University, Stanford, California, February 1-3, 2010, SGP-TR-188.

Redden, G., M. Stone, K. Wright, E. Mattson, C. Palmer, H. Rollins, M. Harrup, and L. Hull (2010), "Tracers for Characterizing Enhanced Geothermal Systems," 2010 Stanford Geothermal Workshop, Palo Alto, CA.

Reno, M. D., S. C. James and S. J. Altman (2006), "Colloid dispersion in a uniform-aperture fracture." Journal of Colloid and Interface Science 300(1): 383.

Robinson, B. A., J. W. Tester and L. F. Brown (1984), "Using chemically reactive tracers to determine temperature characteristics of geothermal reservoirs." Geothermal Resources Council Ann. Meeting, Reno, Nev., 26-29 Aug. 1984. Reno, Nev.

Robinson, B.A. and J.W. Tester (1984), "Dispersed Fluid Flow in Fractured Reservoirs: An Analysis of Tracer-Determined Residence Time Distributions," J. Geophysical Res. 89 (B12): 10374-10384.

Robinson, B.A. and J.W. Tester, 1990. Kinetics of alkaline hydrolysis of organic esters and amides in neutrally-buffered solution. International Journal of Chemical Kinetics, 22: 431-448.

Robinson, B.A. (1985), Non-reactive and chemically reactive tracers: theory and applications. Ph.D. thesis, Massachusetts Institute of Technology, Cambridge, MA.

Rose, P. E., Johnson, S. D., Kilbourn, P., and Kasteler C., (2002), "Tracer Testing at Dixie Valley, Nevada Using 1-Naphthalene Sulfonate and 2,6-Naphthalene Disulfonate", Proceedings, TwentySeventh Workshop on Geothermal Reservoir Engineering, Stanford University, Stanford, CA, January 28-30

Rose, P. E., S. D. Johnson and P. Kilbourn (2001b), "Tracer Testing At Dixie Valley, Nevada, Using 2Naphthalene Sulfonate And 2,7-Naphthalene Disulfonate." Twenty-Sixth Workshop on Geothermal Reservoir Engineering.Stanford University, Stanford, California.

Rose, P.E., W.R. Benoit, and P.M. Kilbourn, (2001a), "The Application of the polyaromatic sulfonates as tracers in geothermal reservoirs." Geothermics 30: 617-640.

Sauty, J. P., (1978), "Identification des parametres du transport hydrodispersif dans les aquiferes par interpretation des tracages en ecoulement cylindrique convergent ou divergent," Jour of Hydrology, 39: 69-103.

Shan, C. and K. Pruess (2005), "Sorbing Tracers - A Potential Tool For Determining Effective Heat Transfer Area In Hot Fractured Rock Systems." Thirtieth Workshop on Geothermal Reservoir Engineering. Stanford University, Stanford, California.

Shook, G. M. (2003), "A Simple, Fast Method of Estimating Fractured Reservoir Geometry from Tracer Tests", Geothermal Shook, G. M. (2005), "A systematic method for tracer test analysis: an example using Beowawe tracer data," Proceedings, 15th Workshop on Geothermal Reservoir Engineering, Stanford, SGP-TR-176.

Shook, G.M.. and J.H. Forsmann (2005), "Tracer Interpretation Using Temporal Moments on a Spreadsheet,” INL/EXT-05-00400, pp. 20.

StrongGunderson, J. M. and A. V. Palumbo (1997), "Laboratory studies identify a colloidal groundwater tracer: Implications for bioremediation." Fems Microbiology Letters 148(2): 131-135. 
Tester, J. W. et al. (2006), "The Future of Geothermal Energy: Impact of enhanced geothermal systems (EGS) on the United States in the 21st century," Massachusetts Institute of Technology and Department of Energy Report, Idaho National Laboratory, INL/EXT-06-11746.

Tester, J.W., B.A. Robinson, and J. Ferguson, (1987), " "The theory and selection of chemically reactive tracers for reservoir thermal capacity production." Proceeding of the Twelfth Workshop of Geothermal Reservoir Engineering, Stanford University, Stanford, CA, January 20-22, SGP-TR-109.

The United Nations University, Geothermal Training Programme, Orkustofnun, Grensasvegur 9, IS-108 Reykjavik, Iceland, Report 1984

Toran, L. and A. V. Palumbo (1992), "Colloid Transport through Fractured and Unfractured Laboratory Sand Columns.” Journal of Contaminant Hydrology 9(3): 289-303.

Tsukegi, T., T. Motoyama, Y. Shirai, H. Nishida and T. Endo (2007), "Racemization behavior of 1,1lactide during heating." Polymer Degradation and Stability 92(4): 552-559.

Vilks, P. and D. B. Bachinski (1996), "Colloid and suspended particle migration experiments in a granite fracture." Journal of Contaminant Hydrology 21(1-4): 269-279.

Vilks, P. and M. H. Baik (2001), "Laboratory migration experiments with radionuclides and natural colloids in a granite fracture." Journal of Contaminant Hydrology 47(2-4): 197-210.

Vilks, P., L. H. Frost and D. B. Bachinski (1997), "Field-scale colloid migration experiments in a granite fracture." Journal of Contaminant Hydrology 26(1-4): 203-214.

Vilks, P., N. H. Miller and A. Vorauer (2008), "Laboratory bentonite colloid migration experiments to support the Aspo Colloid Project." Physics and Chemistry of the Earth 33(14-16): 1035-1041.

Zhang, Zhang and $\mathrm{Hu}$ (2008), " $\mathrm{Zr} / \mathrm{ZrO}_{2}$ Sensors for in Situ Measurement of $\mathrm{pH}$ in High-Temperature and -Pressure Aqueous Solutions." Analytical Chemistry 80(8): 2982-2987.

Zvikelsky, O. and N. Weisbrod (2006), "Impact of particle size on colloid transport in discrete fractures." Water Resour. Res. 42:. W12S08, doi:10:1029/2006WR004873.

Zvikelsky, O., N. Weisbrod and A. Dody (2008), "A comparison of clay colloid and artificial microsphere transport in natural discrete fractures." Journal of Colloid and Interface Science 323(2): 286-292. 
Appendix A

Reservoir Cooling Time versus Tracer Transport Time 


\section{Appendix A}

\section{Reservoir Cooling Time versus Tracer Transport Time}

For a single fracture, the relative temperature in the reservoir at a point $\mathrm{x}$ at time $\mathrm{t}_{1}$ is given by the

$$
T_{R 1}=\frac{T(\infty, 0)-T\left(X, t_{1}\right)}{T(\infty, 0)-T_{i n j}}=\operatorname{erf}\left(\frac{L \lambda_{r} X}{\rho_{f} c_{p_{-} f} b v \sqrt{\alpha_{r}\left(t_{1}-x / v\right)}}\right)
$$

(Carslaw and Jaeger 1959, Section 15.3, Case III), where

$$
\begin{aligned}
& \lambda_{r}=\text { rock thermal conductivity } \\
& X=\text { the fractional distance traveled along the flow path }(\mathrm{x} / \mathrm{L}) \\
& b=\text { fracture aperture } \\
& \rho_{f}=\text { carrier fluid density } \\
& c_{p f}=\text { fluid specific heat } \\
& v=\text { velocity in the fracture } \\
& \alpha_{r}=\text { rock thermal diffusivity } \\
& t=\text { time since the initiation of fluid injection } \\
& T_{i n j}=\text { injection temperature. }
\end{aligned}
$$

Solving Equation (A-1) for $\mathrm{t}_{1}$, we obtain

$$
t_{1}=\frac{L}{v}+\frac{1}{\alpha_{r}}\left(\frac{L}{v}\right)^{2}\left(\frac{\lambda_{r} X}{b \rho_{f} c_{p_{-} f} \cdot e r f^{-1}\left(T_{R 1}\right)}\right)^{2}
$$

An analogous equation can be obtained for the time $t_{2}$ at which the relative reservoir temperature reaches $T_{R 2}$. The time difference, $t_{2}-t_{1}$, the time that it takes to decrease the temperature from $T_{R 1}$ to $T_{R 2}$, is

$$
t_{2}-t_{1}=\left[\left(\frac{L}{v}\right) \frac{1}{\alpha_{r}}\left[\frac{\lambda X}{\rho_{f} c_{p_{-} f} b}\right]^{2}\left\{\left[\frac{1}{e r f^{-1}\left(T_{R 2}\right)}\right]^{2}-\left[\frac{1}{e r f^{-1}\left(T_{R 1}\right)}\right]^{2}\right\}\right]\left(\frac{L}{v}\right)
$$

Thus, the time to change the temperature in the reservoir at some point $\mathrm{X}$, is some factor, $\xi$, times the time scale for the tracer to travel from the injection point to the production well $(\mathrm{L} / \mathrm{v})$, where

$$
\xi=\left[\left(\frac{L}{v}\right) \frac{1}{\alpha_{r}}\left[\frac{\lambda X}{\rho_{f} c_{p_{-} f} b}\right]^{2}\left\{\left[\frac{1}{e r f^{-1}\left(T_{R 2}\right)}\right]^{2}-\left[\frac{1}{e r f^{-1}\left(T_{R 1}\right)}\right]^{2}\right\}\right]
$$

Ideally, $\xi$ should be at least 10 to insure that there is no significant change in the temperature over the time scale of the tracer test. In calculations used in this report, we have used 0.50 and 0.49 , respectively, for the values of $T_{R 1}$ and $T_{R 2}$. 


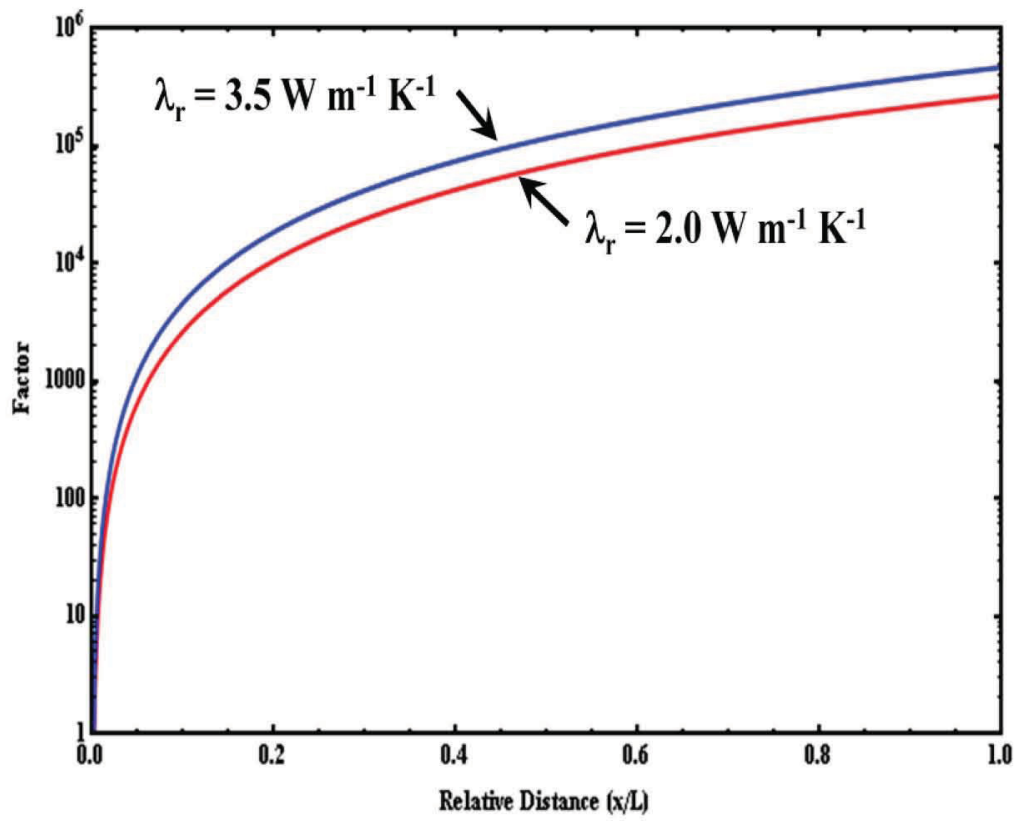

Figure A-1. Factor times the tracer travel time from the injection point to the production well to cool the reservoir at $\mathrm{X}$ from 0.50 to 0.49 relative temperature. 